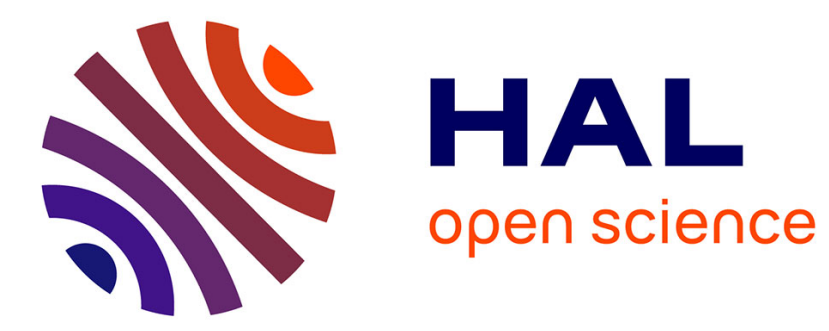

\title{
Nanostructured materials for photocatalysis
}

Chunping Xu, Prasaanth Ravi Anusuyadevi, Cyril Aymonier, Rafael Luque, Samuel Marre

\section{To cite this version:}

Chunping Xu, Prasaanth Ravi Anusuyadevi, Cyril Aymonier, Rafael Luque, Samuel Marre. Nanostructured materials for photocatalysis. Chemical Society Reviews, 2019, 48 (14), pp.3868-3902. 10.1039/C9CS00102F . hal-02185643

\section{HAL Id: hal-02185643 \\ https://hal.science/hal-02185643}

Submitted on 18 Jul 2019

HAL is a multi-disciplinary open access archive for the deposit and dissemination of scientific research documents, whether they are published or not. The documents may come from teaching and research institutions in France or abroad, or from public or private research centers.
L'archive ouverte pluridisciplinaire HAL, est destinée au dépôt et à la diffusion de documents scientifiques de niveau recherche, publiés ou non, émanant des établissements d'enseignement et de recherche français ou étrangers, des laboratoires publics ou privés. 


\title{
Nanostructured materials for photocatalysis
}

Chunping Xu, ${ }^{a}$ Prasaanth Ravi Anusuyadevi, ${ }^{* b}$ Cyril Aymonier, ${ }^{b}$ Rafael Luque ${ }^{\text {cd }}$ and Samuel Marre*b

\author{
* Corresponding authors \\ a School of Food and Biological Engineering, Zhengzhou University of Light Industry, Dongfeng Road 5, Zhengzhou, P. R. China \\ ${ }^{\mathrm{b}}$ CNRS, Univ. Bordeaux, Bordeaux INP, ICMCB, UMR5026, 33600 Pessac, France \\ E-mail: $\underline{\text { ranu.prasaanth@gmail.com, samuel.marre@icmcb.cnrs.fr }}$
}

c Departamento de Quimica Organica, Universidad de Cordoba, Campus de Rabanales, Edificio Marie Curie (C-3), Ctra Nnal IV-A, Km 396, Cordoba, Spain E-mail: rafael.luque@uco.es

a Peoples Friendship University of Russia (RUDN University), 6 Miklukho Maklaya str., Moscow, Russia

\section{Abstract}

Photocatalysis is a green technology which converts abundantly available photonic energy into useful chemical energy. With a rapid rise of flow photoreactors in the last decade, the design and development of novel semiconductor photocatalysts is happening at a blistering rate. Currently, developed synthetic approaches have allowed the design of diverse modified/unmodified semiconductor materials exhibiting enhanced performances in heterogeneous photocatalysis. In this review, we have classified the so far reported highly efficient modified/unmodified semiconductor photocatalysts into four different categories based on the elemental composition, band gap engineering and charge carrier migration mechanism in composite photocatalysts. The recent synthetic developments are reported for each novel semiconductor photocatalyst within the four different categories, namely: pure semiconductors, solid solutions, type-II heterojunction nanocomposites and Z-scheme. The motivation behind the synthetic upgrading of modified/unmodified (pure) semiconductor photocatalysts along with their particular photochemical applications and photoreactor systems have been thoroughly reviewed.

\section{Introduction}

Photocatalysis is a multidisciplinary field combining physics, chemistry, materials science and chemical engineering pushing the boundaries for many decades for more effective light utilisation and harvesting to promote chemical reactions. The amalgamation of various research fields within photocatalysis spurred exponentially due to the synthesis of multitudinous products, environmental reforming and production of clean hydrogen $\left(\mathrm{H}_{2}\right)$ fuel and $\mathrm{CO}_{2}$ conversion among others. ${ }^{1-4}$ Photocatalysis exhibits several key advantages over conventional catalytic processes involving tedious steps, high temperatures and pressures and using transition metal catalysts. ${ }^{5,6}$

The implementation of process engineering strategies into photocatalysis pointed out that heterogeneous photocatalysis is preferable to homogeneous in most cases, due to the facile separation of products, higher stability and easier recyclability of photocatalysts. Heterogeneous photocatalysis typically involves photoinduced chemical reaction on the surface of semiconductor materials (photocatalyst) upon exposure to photons.

Titanium dioxide $\left(\mathrm{TiO}_{2}\right)$ stood as the main facet of heterogeneous photocatalysis during the past decades, among all semiconductor photocatalysts available. ${ }^{7,8}$ This was mainly due to its high photocatalytic efficiency and several advantages: stability under extreme conditions, appropriate band edge potentials, etc. The pivotal motive of our work is to provide an overview of various alternative semiconductor heterogeneous photocatalysts, considered so far and to categorize them into groups depending on their composition and methodology of application. The different classes of photocatalysts - along with their applications in photochemical reactions - mentioned in this review start with binary and ternary semiconductors (SCS) and end up in detailing more prominent aspects of nanocomposite photocatalysts, generated by the conjunction of binary, ternary and other semiconductor materials. This contribution aims to consolidate the different semiconductor systems, the rationale behind their design or 
indicate the particular photochemical reactions for which their performances were higher compared to other SCs, along with the type of photoreactor systems in which the photocatalysts were implemented. Obviously, we did not aim to address all the semiconductors here, but a rather intensive focus is made on the most efficient systems. Alternatively, this review addresses the current updated synthetic routes for obtaining such requisite SCs and furnish the description of the polyphasic photocatalytic reactors in which they have been studied. In the past decades manifold of synthetic strategies were reported in modifying the photocatalysts for performing different photochemistries or rendering them active in visible region/any part of the electromagnetic spectrum. These novel attempts emanated into wide range of photocatalytic systems. The progressive motif in the development of semiconductor materials in the regime of sensitized photoreactions has led us to classify them into four different families or categories (see Fig. 1).

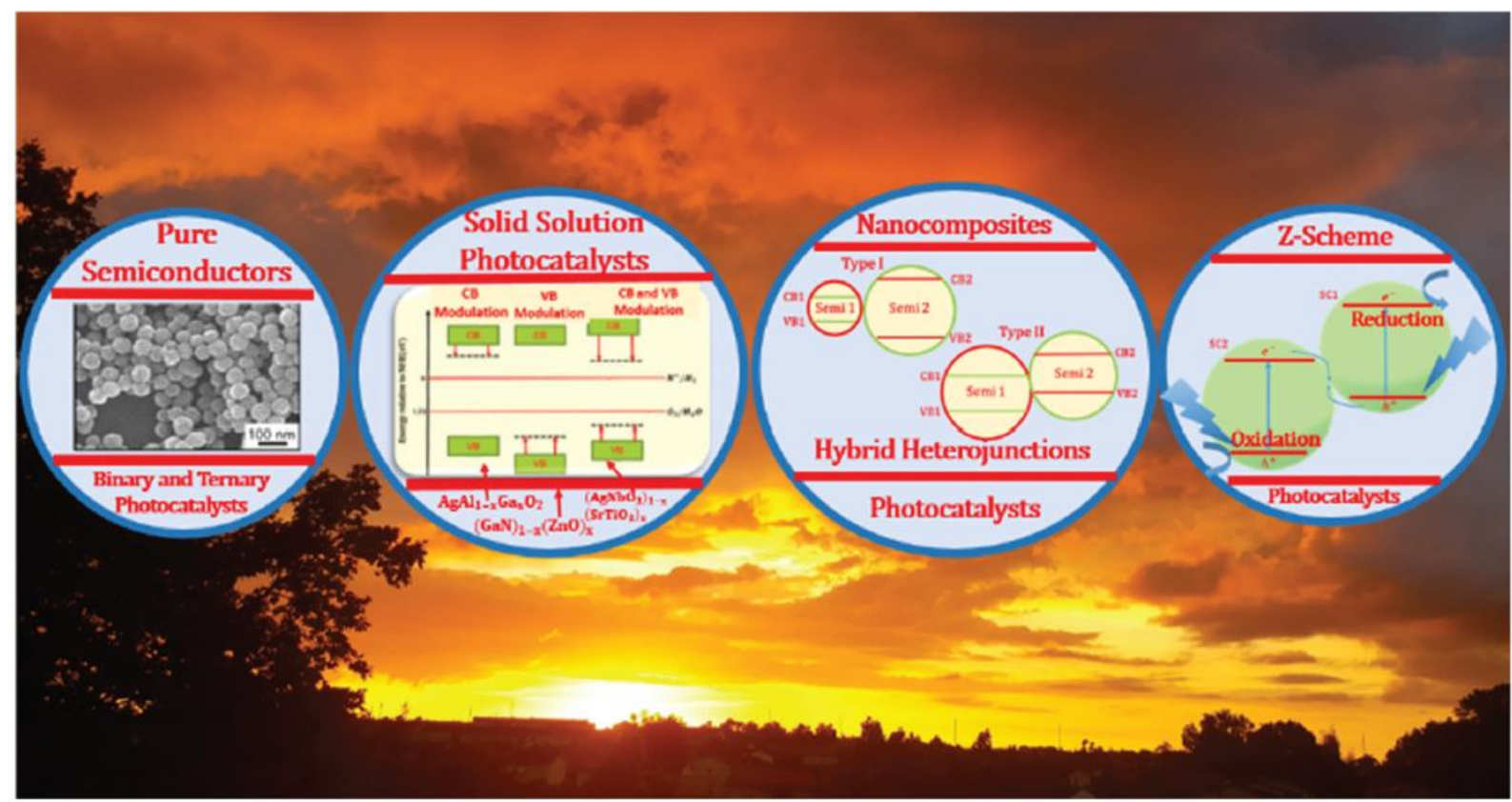

Fig. 1 Classification of semiconductor photocatalysts into four different families.

\section{Binary semiconductor photocatalysts}

Synthetic methods of binary SCs have enhanced their photocatalytic performances by achieving monodispersity and unique morphologies with high specific surface area. Diverse nanomaterials with well-defined surface properties are present in different binary SCs, as described in Fig. 2. The intrinsic parameters of the synthesis, nature of the nanomaterials synthesized as result of such reactive domains along with their corresponding photocatalytic applications have been summarized in Table 1.

\section{Oxides-based binary photocatalysts}

Teoh et al. synthesized $\mathrm{TiO}_{2}$ nanoparticles by Flame Spray Pyrolysis (FSP) method (Fig. 3a and b), which displayed higher activity for sucrose photo-mineralization than the commercially available Degussa P25. ${ }^{9}$ 


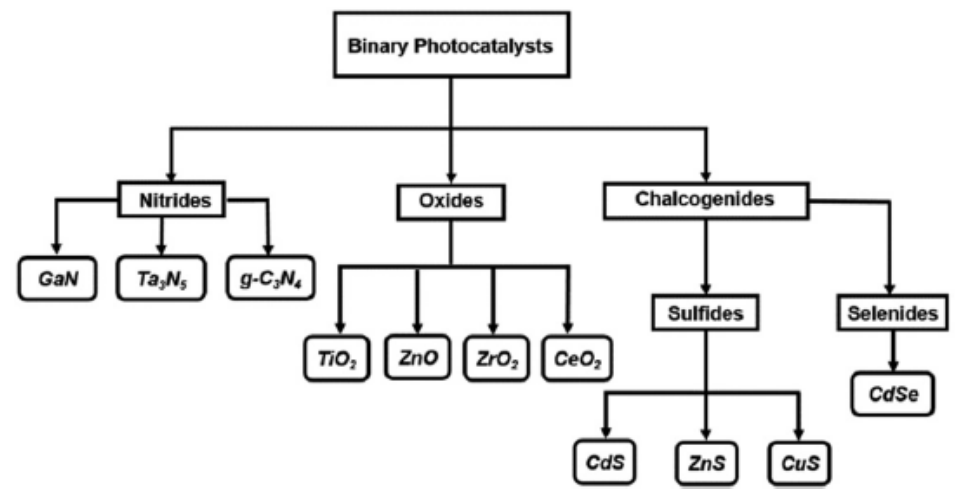

Fig. 2 Flowchart summarizing the various binary semiconductor nano photocatalysts reported in this review.

Direct FSP technique yielded nanomaterials with well-regulated specific surface area and morphology; high purity of crystallite phases without the requirement of post treatment processes (precipitations and centrifugations, etc.). Different particle sizes were obtained by varying the flow rate of precursors to the flame spray reactor, portrayed in Fig. 3a. Subsequently, Teoh et al. published a detailed review on the successful attempt of FSP for synthesizing diverse binary nanophotocatalysts $\left(\mathrm{ZnO}, \mathrm{WO}_{3}\right.$, etc.), doped binary $\mathrm{SCs}$, noble metal loaded systems and mixed complex metal oxide nanocomposites (NCS). ${ }^{10}$

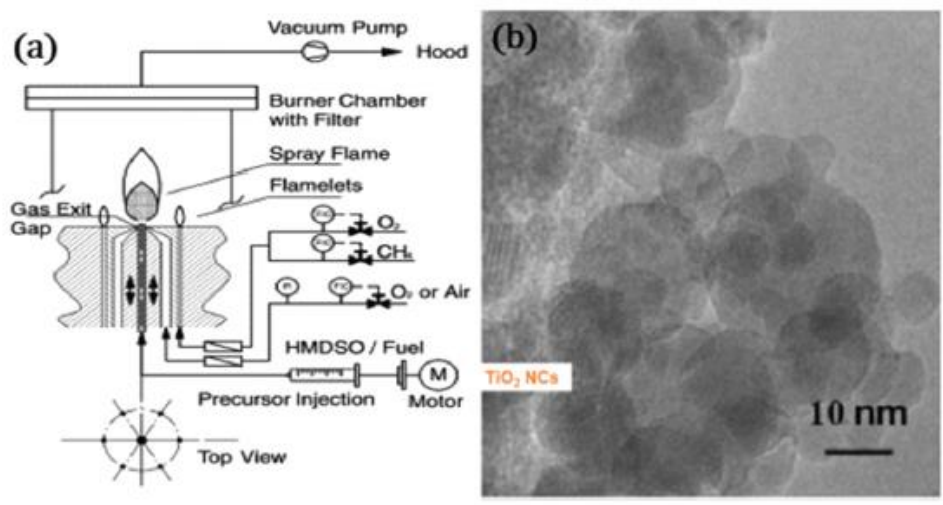

Fig. 3 (a) FSP reactor utilized for the continuous synthesis of $\mathrm{TiO}_{2}$ photocatalyst, ${ }^{11}$ more active than the commercial Degussa P25 synthesized by flame aerosol technique. (b) HR-TEM image of $\mathrm{TiO}_{2}$ Nanocrystals (NCs) synthesized using the FSP reactor. ${ }^{9}$ ((a) Reprint with permission from L. Mädler, H. K. Kammler, R. Mueller, and S. E. Pratsinis, Controlled synthesis of nanostructured particles by flame spray pyrolysis, J. Aerosol Sci., 2002, 33, 369-389 Copyright 2018 Royal Society of Chemistry. (b) Reprint with permission from W. Y. Teoh, L. Mädler, D. Beydoun, S. E. Pratsinis and R. Amal, Direct (one-step) synthesis of $\mathrm{TiO}_{2}$ and $\mathrm{Pt} / \mathrm{TiO} \mathrm{O}_{2}$ nanoparticles for photocatalytic mineralisation of sucrose, Chem. Eng. Sci., $2005,60,5852-5861$, Copyright 2018 Royal Society of Chemistry).

Zhanxia et al. synthesized peculiar nano-flower (stratified 3D-flower like nanostructures with 2D building block) shaped zirconia $\left(\mathrm{ZrO}_{2}\right)$. Their precursor selection ( $\mathrm{ZOS}$ - zirconium oxide sulphate \& sodium acetate) and their synthetic strategy (hydrothermal + calcination) furnished the required 3D-nanoflowers. This peculiar $\mathrm{ZrO}_{2}$ nanoflower (with a lower specific surface area than the $\mathrm{ZrO}_{2}$ nanoparticles) discloses enhanced photocatalytic performance for dye degradation than the tetragonal $\mathrm{ZrO}_{2}$ nanoparticles (NPs) with higher surface area. The higher 
activity observed was due to their superior absorbance of photons, as depicted in the absorption spectrum of Fig. 4b.
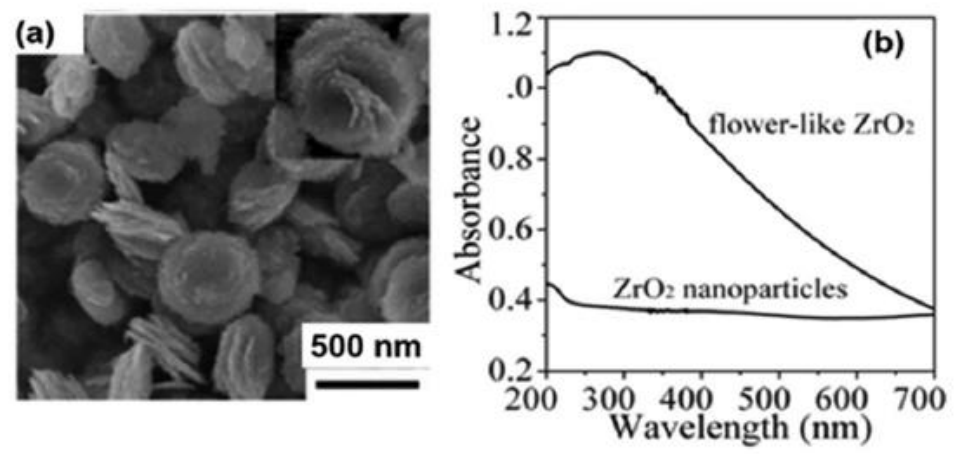

Fig. 4 (a) FE-SEM image of nanoflower shaped $\mathrm{ZrO}_{2}$. (b) UV-vis absorption spectrum depicting the enhanced absorption behaviour of the flower shaped nanostructures of $\mathrm{ZrO}_{2}$ compared to the tetragonal $\mathrm{ZrO}_{2} \mathrm{NPs}^{12}$ ( $(a$ and b) Reprint with permission from Z. Shu, X. Jiao and D. Chen, Synthesis and photocatalytic properties of flower-like zirconia nanostructures, CrystEngComm., 2012, 14, 1122-1127, Copyright 2018 Royal Society of Chemistry).

The enhanced absorption behaviour stems from the specially exposed facets (100) of the petals present in the graded nanoflower structures. ${ }^{12} \mathrm{Nano}_{\mathrm{ZrO}}$ outperforms several binary nanophotocatalysts (zinc oxide (ZnO) and cerium oxide $\left(\mathrm{CeO}_{2}\right)$ ) for disparate chemical reactions due to its high negative conduction band (CB) edge potential and wider optical band gaps for different crystalline phases, cubic ( $3.8 \mathrm{eV})$, tetragonal (4.11 eV) and monoclinic (4.51 eV). ${ }^{13-15}$ The photochemistry explored so far on both $\mathrm{ZnO}$ and $\mathrm{CeO}_{2}$ were carried out on nanomaterials synthesized in batch mode by hydrothermal process or by simple precipitation techniques. ${ }^{16-18}$ However, due to the rapid development of supercritical fluid flow processes, the synthesis yielded $\mathrm{ZnO}$ and $\mathrm{CeO}_{2}$ nanomaterials with welldefined properties for photocatalysis. ${ }^{19,20}$

\section{Chalcogenides-based binary photocatalysts}

Across the realm of heterogeneous photocatalysts, binary chalcogenides were assessed on equal intensity as binary oxide SCs. Zinc sulfide (ZnS) and cadmium sulfide (CdS) nanophotocatalysts were tremendously researched in the last four decades for their successful applications, not only in environmental purification reactions but also for the reduction of carbon dioxide $\left(\mathrm{CO}_{2}\right)$, aldehydes, water splitting and reductive dehalogenation of benzene derivatives. Especially, ZnS was focused a lot, due to their wider energy band gap of about 3.2-4.4 eV ${ }^{21}$ (largest among the binary chalcogenides of group $I I-\mathrm{VI}^{22}$ ) and its facile phase control of $\mathrm{ZnS}$ nanocrystals. ${ }^{23} \mathrm{~A}$ simple, robust production of $\mathrm{ZnS}$ nanoporous nanoparticles (NPNPs) via the solution phase thermal decomposition technique in the presence of $\mathrm{N}$ vinylpyrrolidinone (PVP) was reported by Hu et al. These ZnS NPNPs photocatalysts outperformed commercial $\mathrm{TiO}_{2}$ in degrading eosin $\mathrm{B}$ dye. ${ }^{24}$ They do not require any post treatment process as required by ZnS photocatalyst (synthesized by continuous process) for improving their activity. ${ }^{25}$ The higher photocatalytic activity of ZnS NPNPs, stems from their high monodispersity and spherically uniform shape. Each sphere of $\mathrm{ZnS}$ is an aggregate of hexagonal ZnS nanocrystals (NCs) of 3-5 nm formed as a result of self-assembly process as depicted in Fig. 5 . 

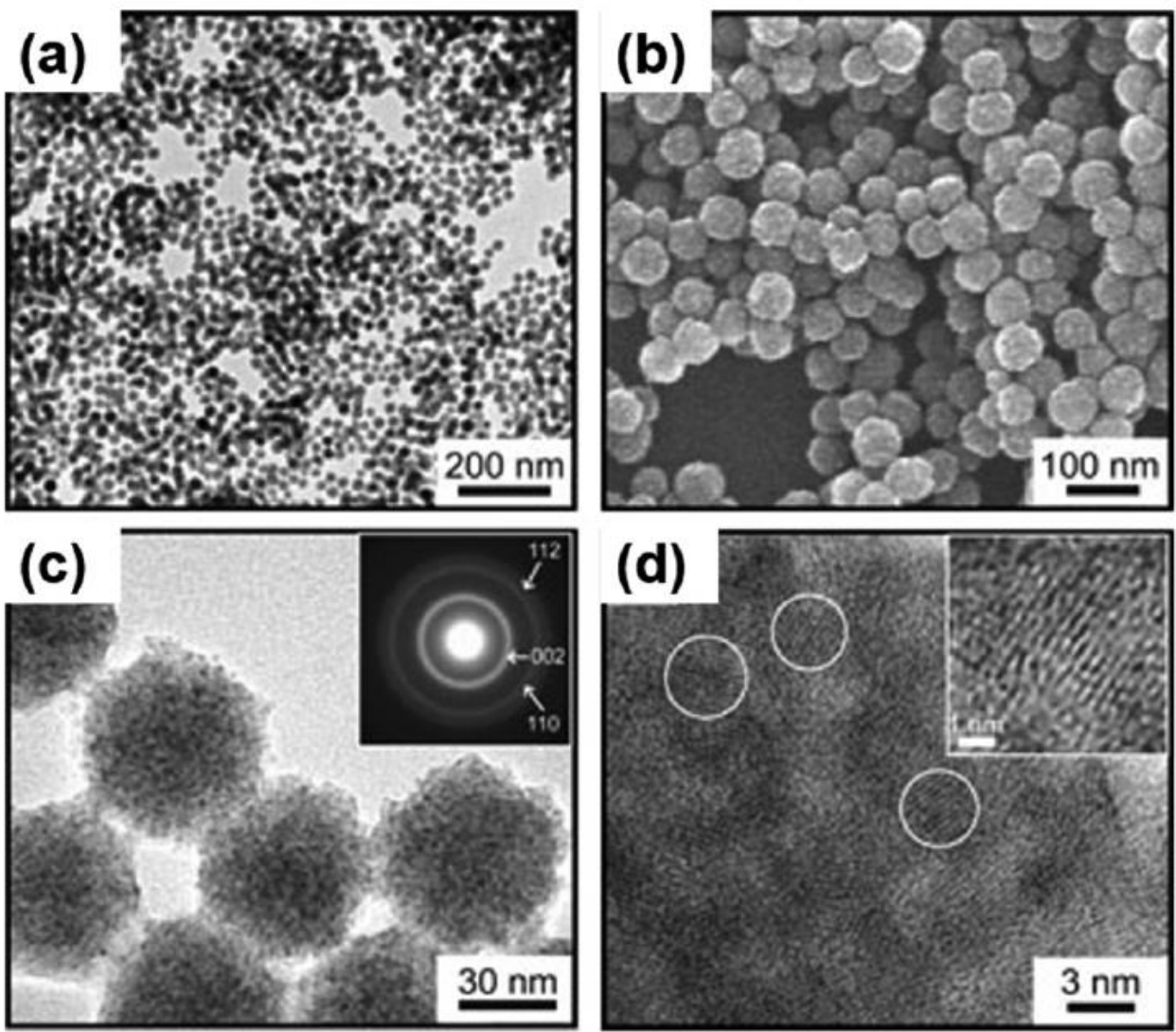

Fig. 5 (a) TEM image of ZnS NPNPs. (b) SEM image of spherical nanoporous ZnS. (c) HR-TEM of ZnS NPNPs with electron diffraction of nanostructures in the inset of the figure. (d) HR-TEM depicting the lattice fringes of ZnS NCs, which undergoes self-assembly process to form the nanoporous ZnS spheres. ${ }^{24}$ ( $(a, b, c$ and d) Reprint with permission from J.-S. $\mathrm{Hu}$, et al., Mass Production and High Photocatalytic Activity of ZnS Nanoporous Nanoparticles, Angew. Chem., Int. Ed., 2005, 44, 12691273, Copyright 2018 John Wiley and Son).

Identically, the synthesis of hollow spherical CdS and hollow nanoporous copper sulfide (CuS) were reported by Luo et al. ${ }^{26}$ and Xu et al., ${ }^{27}$ respectively. Jing et al. introduced the thermal sulfidation technique replacing the traditional synthetic methodology of precipitation and subsequent heat treatment for obtaining nanosized CdS photocatalysts. The thermal sulfidation technique lowers the phase transformation and crystallization temperature of CdS compared to the other synthetic routes. ${ }^{28} \mathrm{CdS}$ from this technique possesses nano-step arrangement on its surface, exhibited enhanced stability against both air oxidation and photocorrosion during the photocatalytic process. It manifested larger activity for $\mathrm{H} 2$ generation than the conventionally synthesized $\mathrm{CdS}$ nanomaterial. CdS-based photocatalytic systems profoundly displayed exalted performances for the production of solar-fuel and environmental remediation processes because of its narrow band gap $(2.38 \mathrm{eV})$ and higher negative conduction potential than the reduction potential of $\mathrm{H} 2 \mathrm{O} / \mathrm{H} 2 .{ }^{26,28,29}$ Likewise, cadmium selenide ( $\mathrm{CdSe}$ ) based nanophotocatalytic system was also acutely implemented in water splitting for hydrogen $(\mathrm{H} 2)$ production, inspite of its narrow bulk band gap (1.74 eV). Enhanced photocatalysis of nano $\mathrm{CdSe}$ for $\mathrm{H} 2$ generation stems from its high magnitude of surface electron charge density and strong quantum confinement behaviour. Wherein precise variation of size of CdSe NCs tunes the energy band gaps providing the appropriate band edge (redox) potentials for photocatalysis. ${ }^{30} \mathrm{~A}$ strong relationship 
between the photocatalytic $\mathrm{H}_{2}$ production and various size of CdSe NCs (1.75-4.81 nm) synthesized by solvothermal method was reported by Holmes et al. ${ }^{31}$

\section{Nitrides-based binary photocatalysts}

Compared to binary oxides/chalcogenides, the exploration of binary nitrides as photocatalysts emerged only in the last two decades. Gallium nitride $(\mathrm{GaN})$ inspection as a photocatalyst started after its immense success in sensing fields due to high mechanical strength and chemical stability (at various $\mathrm{pH}$ ) compared to other binary SCs. ${ }^{32}$ The first case of GaN photocatalysis for water splitting reaction implementing powdered GaN was reported by Kida et al. ${ }^{33}$ Following which, the synthesis of GaN SC in the form of nanowires exhibiting higher activity for photodegradation of organic dyes compared to the submicron GaN dot arrays and thin films was reported by Jung et al. ${ }^{34}$ Tantalum nitride $\left(\mathrm{Ta}_{3} \mathrm{~N}_{5}\right)$ is an interesting, auspicious, transition metal binary nitride SC used for solar water splitting, due to its narrow direct band gap $(2.1 \mathrm{eV})$ and suitable band edge potentials. ${ }^{35-38}$ For the degradation of dye (methylene blue) under visible light, $\mathrm{Ta}_{3} \mathrm{~N}_{5}$ exhibits higher photocatalytic activity than visible light active nitrogen doped titania nanomaterials. ${ }^{39} \mathrm{Ma}$ et al. developed a synthetic strategy where they coupled alkali metal treated tantalum oxide precursor with ammonolysis process yielding highly crystallized $\mathrm{Ta}_{3} \mathrm{~N}_{5}$ nanomaterials, which evinces six times higher photocatalytic activity for water oxidation reaction than $\mathrm{Ta}_{3} \mathrm{~N}_{5}$ nanomaterials synthesized by other techniques. ${ }^{40}$

Graphite-like carbon nitride $\left(\mathrm{g}-\mathrm{C}_{3} \mathrm{~N}_{4}\right)$ is also a direct visible light active $\mathrm{SC}(2.7 \mathrm{eV}) .{ }^{41}$ Unlike other $\mathrm{SCs}, \mathrm{g}-\mathrm{C}_{3} \mathrm{~N}_{4}$ is a nonmetallic conjugated stable polymer, $\mathrm{n}$-type organic SC composed of earth abundant compounds (carbon and nitrogen). It possesses distinctive optical, structural and electronic properties optimum for photocatalytic processes. ${ }^{42} \mathrm{~g}-\mathrm{C}_{3} \mathrm{~N}_{4}$ implementation in photocatalysis was first demonstrated by Wang et al. for water splitting under visible light irradiation. ${ }^{43} \mathrm{~A}$ number of additional studies were subsequently carried out on the synthesis and development of $\mathrm{g}-\mathrm{C}_{3} \mathrm{~N}_{4}$-based photocatalysts for applications in solar fuel generation, bacterial disinfection, pollutants degradation and organic transformations. ${ }^{44-53}$ Dong et al. recently reported the synthesis of novel g- $C_{3} \mathrm{~N}_{4}$ via thermal polymerization using sodium nitrate as oxidizing agent. As-synthesized g- $\mathrm{C}_{3} \mathrm{~N}_{4}$ were able to degrade tylosin (TYL) (antibiotics) within 30 min under simulated sunlight irradiation. The activity was several times higher as compared to conventional g- $\mathrm{C}_{3} \mathrm{~N}_{4}$ photocatalysts. The increase in activity was attributed to the alteration of the g$\mathrm{C}_{3} \mathrm{~N}_{4}$ crystal structure (induced by sodium nitrate) and a red shift in the visible light absorption range. ${ }^{54}$ To conclude, we have briefly exposed in this section some notable binary photocatalysts and their recent synthetic improvements. For traditional photocatalysts, the synthetic methodologies have been developed rapidly and now continuous synthetic techniques are available to synthesize photocatalysts at very high yield, as seen in the cases of $\mathrm{TiO}_{2}$ or $\mathrm{ZnO}$. Concerning the unconventional binary photocatalysts like GaN or CuS, the synthetic methodologies ${ }^{55}$ are specially studied to tune their photocatalytic activities not as deeply investigated to date as compared to conventionally synthesized systems.

\section{Ternary photocatalysts}

Ternary oxide/chalcogenide SCs comprise two different metallic cations and a single anion. These have been significantly studied in the heterogeneous photocatalytic field because of their stable nature and ability to promote various chemistries as compared to binary SCs. The photocatalysts reviewed in this section can be grouped into different categories according to their composition and crystalline structure as depicted in Fig. 6 . Table 2 summarizes the synthesis and details of photocatalytic process of ternary SCs which are reported here. 


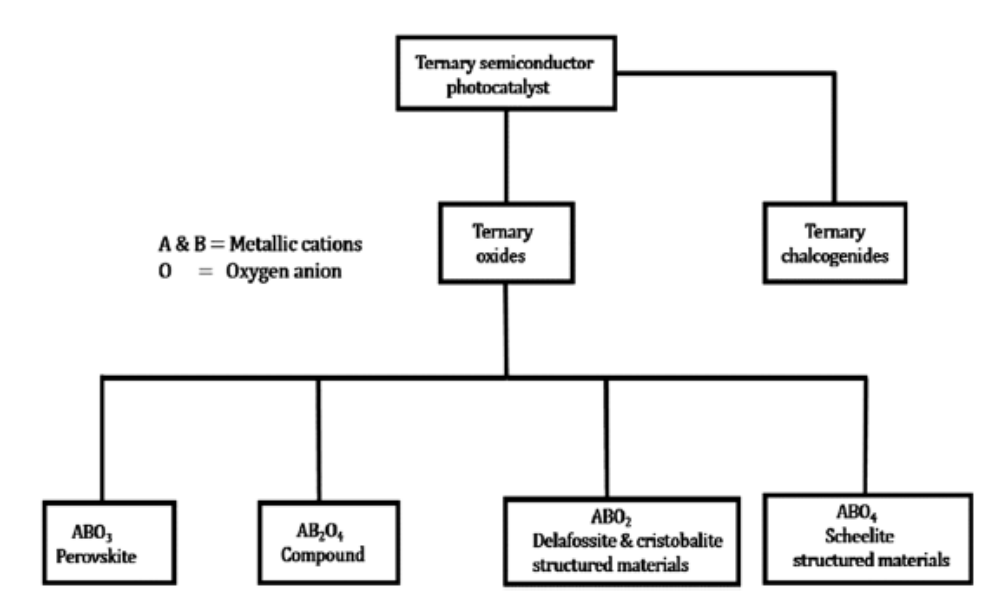

Fig. 6 Flow chart of the diverse ternary semiconductor photocatalysts reviewed in this article.

\section{Ternary oxide photocatalysts}

Perovskite photocatalysts ( $\mathrm{ABO}_{3}$ types). Perovskite oxide (cubic crystal structure) $\mathrm{SCs}$, with the general formula $\mathrm{ABO}_{3}$ are most propitious photocatalysts studied in the field. Here the terms A \& B refer to different metallic cations. Predominantly, the ' $A$ ' cation is either alkali or alkaline or rare earth metal element whereas the ' $B$ ' cation is regularly a transition metal element, whose size is smaller than the $A$ cation. Strontium titanate $\left(\mathrm{SrTiO}_{3}\right)$ finds immense application in heterogeneous photocatalysis \& thermoelectric fields due to their thermal stability, high photocorrosion resistance and facile capacity to precisely tune its physical \& chemical properties depending on its composition. ${ }^{56}$ Such tunability makes $\mathrm{SrTiO}_{3}$ a nice n-type semiconductor at room temperature via simple electrodonation or doping strategies. $\mathrm{SrTiO}_{3}(3.2 \mathrm{eV})^{57}$ photocatalyst works effectively for absolute mineralization or degradation of organic pollutants under UV irradiation, ${ }^{58-61}$ enhanced water splitting reaction with a metal cocatalyst loaded on its surface ${ }^{57,62}$ and ammonia production/decomposition reactions. ${ }^{63}$ The standard solid state synthetic method of nano $\mathrm{SrTiO}_{3}$ photocatalysts requires elevated temperature but it suffers from polydispersed size distribution and reduced specific surface area. In the last decade, this synthetic process was replaced by hydrothermal, ${ }^{59}$ sol-gel ${ }^{64}$ and solvothermal method. ${ }^{65}$ Mariko et al. reported that $\mathrm{SrTiO}_{3} \mathrm{NPs}^{2}$ synthesized by the lower temperature hydrothermal technique exhibited enhanced degradation of nitric oxide (NO) gas (58.70\% in 22 $\mathrm{min}$ ) compared to the $\mathrm{SrTiO}_{3}$ photocatalysts synthesized by conventional solid state method ( $56 \%$ in 22 minutes) due to the high specific area of $\left(33.1 \mathrm{~m}^{2} \mathrm{~g}^{-1}\right)$ in the former and lower value $\left(2.88 \mathrm{~m}^{2} \mathrm{~g}^{-1}\right)$ in the latter case under UV irradiation. ${ }^{66}$

Unlike titanates, tantalates exhibit photocatalytic water splitting activity without the addition of reduction (NiO or $\mathrm{Pt}$ ) or oxidation $\left(\mathrm{IrO}_{2}\right.$ or $\left.\mathrm{MnO}_{x}\right)$ co-catalysts due to the higher $\mathrm{CB}$ and $\mathrm{VB}$ edge of tantalates as compared to the redox potential of water ( $C B$ consists of Ta $5 d$ orbital and VB consists of $O 2 p$ orbital). $C B$ and VB edge potentials are more negative and positive with respect to reductive and oxidative band edge potentials of the co-catalysts, respectively. The high delocalization of excitons energy is due to corner sharing crystal arrangement. ${ }^{67}$ Lithium tantalate $\left(\mathrm{LiTaO}_{3}\right)$ exhibits the highest activity for water splitting under UV light without co-catalyst due to its wide band gap of 4.6-4.7 $\mathrm{eV} . \underline{68}$ The common synthetic methods of $\mathrm{LiTaO}_{3}$ (solid state synthesis, spray drying methods and polymerizable complex route) yielding large particles with small surface area were replaced by solvothermal and hydrothermal routes. Takasugi et al. synthesized $\mathrm{LiTaO}_{3}$ by both solvothermal and hydrothermal routes. $\mathrm{LiTaO}_{3}$ obtained by their solvothermal route shows highly enhanced $\mathrm{H}_{2}$ production rate $\left(600 \mu \mathrm{mol} \mathrm{h}^{-1}\right)$ compared to their activity of $\mathrm{LiTaO}_{3}$ obtained from the hydrothermal route which gave very low $\mathrm{H}_{2}$ production rate $\left(8 \mu \mathrm{mol} \mathrm{h}{ }^{-1}\right)$. Significant specific surface area $\left(23.7 \mathrm{~m}^{2} \mathrm{~g}^{-1}\right)$ and very small particle size $(10-30 \mathrm{~nm})$ were the reasons for better performance of $\mathrm{LiTaO}_{3}$ obtained from the solvothermal route. ${ }^{69}$ 
Sodium tantalate $\left(\mathrm{NaTaO}_{3}\right)$, contrary to $\mathrm{LiTaO}_{3}$, exhibits low activity for water splitting without co-catalyst loading. $\frac{70}{}$ The study of co-catalyst loaded $\mathrm{NaTaO}_{3}$ system led to the development of lanthanide (La) doped $\mathrm{NiO} / \mathrm{NaTaO}_{3}$ highly active photocatalytic system which yielded tremendous $\mathrm{H}_{2}$ evolution at a rate of $5.9 \mathrm{mmol} \mathrm{h}^{-1}$ under UV irradiation without any sacrificial agent(s). ${ }^{71}$ Currently, La-doped $\mathrm{NaTaO}_{3}$ photocatalysts has been successfully employed for the decomposition of refractory organic compounds, ${ }^{72,73}$ reduction of $\mathrm{CO}_{2},{ }^{74}$ photocatalytic steam reforming of methane ${ }^{74}$ and ammonia synthesis. ${ }^{75}$ Regarding the synthetic prospective of $\mathrm{NaTaO}_{3}$ photocatalysts, direct band gap $\mathrm{NaTaO}_{3}(4.1 \mathrm{eV})$ with orthorhombic structure are obtained from the traditional solid state route displaying low activity for water splitting. Replacing the typical solid state by sol-gel technique, $\mathrm{NaTaO}_{3}$ with a monoclinic structure possessing an indirect band gap $(3.9 \mathrm{eV})$ with high density of states near the band edges are produced, evincing a higher activity compared to solid state synthesized $\mathrm{NaTaO}_{3}{ }^{76} \mathrm{He}$ et al. synthesized $\mathrm{NaTaO}_{3}(3.96 \mathrm{eV})$ nanopowders through a hydrothermal route exhibiting high photoactivity under UV light for both gas (complete photodegradation of formaldehyde, within 35 minutes of irradiation) and liquid (complete photodegradation of rhodamine B (RhB), within 3 hours of irradiation) phase reaction. ${ }^{77}$ Recently, Nguyen et al. extended the optical absorption of $\mathrm{NaTaO}_{3}$ photocatalyst into visible region by co-doping it with $\mathrm{La} / \mathrm{Bi}$ (Bismuth) through hydrothermal synthesis. ${ }^{78}$ Within the alkali tantalates $\left(\mathrm{ATaO}_{3}, \mathrm{~A}=\mathrm{Li}\right.$, Na or $\left.\mathrm{K}\right)$, potassium tantalate $\left(\mathrm{KTaO}_{3}\right)$ can be a fascinating alternative for binary $\mathrm{TiO}_{2}$ photocatalyst due to its low band gap ( $3.6 \mathrm{eV}$ ), appropriate band edge potentials (bottom of $\mathrm{CB}$ at $-0.7 \mathrm{eV}$ and top of $\mathrm{VB}$ at $2.9 \mathrm{eV}$ vs. NHE at $\mathrm{pH} 0$ ) and proportionately low excitation energy to tap solar energy. ${ }^{79,80}$ Like the above mentioned tantalates, the synthesis of nano $\mathrm{KTaO}_{3}$ photocatalysts through conventional techniques (solid state or alkoxide method) suffers from large size and defect structure resulting from the hindrance in meticulous control of morphology or size of the nanoparticles due to very high temperature $\left(>1000{ }^{\circ} \mathrm{C}\right) .{ }^{81-83}$

Li et al. reported that the size and morphology of $\mathrm{KTaO}_{3}$ have strong influence on the photoreduction of $\mathrm{CO}_{2}$ and protons in water. Here, $\mathrm{KTaO}_{3}$ synthesized by solvothermal method exhibited conjoined nanoflake morphology with low size (15-50 nm) and large surface area $\left(43 \mathrm{~m}^{2} \mathrm{~g}^{-1}\right)$, displayed an outstanding 20 and 7 times exalted yield for $\mathrm{H}_{2}$ and CO compared to the conventional cubic morphology attained in solid state synthesis with large size (200-500 $\mathrm{nm})$ and low surface area $\left(<5 \mathrm{~m}^{2} \mathrm{~g}^{-1}\right)$; without additional sacrificial electron donors and electrical bias. ${ }^{84}$ To conclude, tantalate perovskites have received considerable focus compared to titanate and niobate active oxides due to the appropriate requisite conduction band edge (consisting of Ta $5 \mathrm{~d}$ orbitals) for the generation of solar fuels. ${ }^{85-87}$ However, the compounds of above mentioned $\mathrm{ABO}_{3}$ types are active under UV light and Silver Niobate $\left(\mathrm{AgNbO}_{3}\right)(2.8$ $\mathrm{eV}$ ) has drawn some attention in photocatalysis due to its visible light response. ${ }^{88}$ Such perovskite structured photocatalysts are composed of $\mathrm{Ag} 4 \mathrm{~d}$ orbitals, far below the oxidation potential of water and therefore employed to split water under visible light in the presence of sacrificial agents.$^{89-92}$ Arney et al. reported the replacement of the synthetic solid state route of $\mathrm{AgNbO}_{3}$ by means of a molten salt flux synthetic route. This newly developed flux method resulted in materials which exhibited enhanced photocatalytic activity for $\mathrm{H}_{2}$ generation $\left(5.9 \mu \mathrm{mol} \mathrm{h}^{-1} \mathrm{~g}^{-1}\right)$ from aqueous methanol solution under visible light with respect to the activity displayed by $\mathrm{AgNbO}_{3}$ synthesized via solid state route $\left(3.4 \mu \mathrm{mol} \mathrm{h}{ }^{-1} \mathrm{~g}^{-1}\right){ }^{89}$

\section{Ternary oxide $\left(\mathrm{AB}_{2} \mathrm{O}_{4}\right.$ types) photocatalysts}

The second set of ternary oxide photocatalysts elucidated in this review are $\mathrm{AB}_{2} \mathrm{O}_{4}$ type like calcium indate $\left(\mathrm{Caln} \mathrm{n}_{2} \mathrm{O}_{4}\right.$. Which contain $\mathrm{p}$-block indium (In) metal with a $\mathrm{d}^{10}$ configuration. Such SC have evinced to form a new set of photocatalysts compared to the platitudinous binary/ternary systems containing $\mathrm{d}^{0}$ configuration transition metal ions ( $\mathrm{Ta}, \mathrm{Nb}$ and $\mathrm{Ti}$ ). $\mathrm{Caln}_{2} \mathrm{O}_{4}$ have demonstrated the photodegradation of organic pollutants under visible light. ${ }^{93-95}$ Similarly, the synthesis of nano Caln $\mathrm{O}_{2} \mathrm{O}_{4}$ via conventional Solid State reaction (SSR) suffers from high temperature $\left(>1000^{\circ} \mathrm{C}\right.$ ) and long calcination time (up to $12 \mathrm{~h}$ ). ${ }^{93-96}$ In 2009, Ding et al. reported a solution-combustion synthetic route replacing the traditional route for producing $\mathrm{Caln}_{2} \mathrm{O}_{4}$ nanorods with large specific surface area and high crystallinity. As-synthesized $\mathrm{Caln}_{2} \mathrm{O}_{4}$ photocatalyst exhibits $66 \%$ mineralization of toluene in gas phase within 360 min of irradiation under visible light, which is four times higher than the activity disclosed by $\mathrm{Caln}_{2} \mathrm{O}_{4}$ nanomaterials synthesized by traditional SSR route. Similarly, platinum (Pt) dispersed $\mathrm{Caln}_{2} \mathrm{O}_{4}$ nanorods for water splitting, disclosed a hydrogen generation rate of $1.23 \mu \mathrm{mol} \mathrm{h} \mathrm{h}^{-1}$, which is 24 times higher than the photocatalytic activity displayed by Pt dispersed $\mathrm{CaIn}_{2} \mathrm{O}_{4}$ (synthesized by SSR route). ${ }^{97}$ Still, the solution-combustion methodology suffered 
from high temperature annealing and calcination $\left(>1000^{\circ} \mathrm{C}\right)$ and varying calcination time $(12-24 \mathrm{~h})$. To eliminate such difficulty in the synthesis of $\mathrm{Caln}_{2} \mathrm{O}_{4}$, several techniques were rapidly developed in the subsequent years: optimized solid-state involving sequential calcination, ${ }^{98}$ solvothermal, ${ }^{99}$ co-precipitation ${ }^{100}$ and sol-gel. ${ }^{101,102}$ Newly, Tavares et al. promulgated the synthesis of $\mathrm{Caln}_{2} \mathrm{O}_{4} \mathrm{NCs}$ continuously through ultrasonic spray pyrolysis technique, utilizing laminar flow aerosol reactor as depicted in Fig. 7; exhibiting a precise control of mean particle size. The asdeveloped continuous system yielded $\mathrm{CaIn}_{2} \mathrm{O}_{4} \mathrm{NCs}$ in short production time (residence time of $1 \mathrm{~min}$ ) with well resolved spherical morphology (avg. diameter $511 \mathrm{~nm}$ and surface area of $24 \mathrm{~m}^{2} \mathrm{~g}^{-1}$ ) and good crystallinity, which exhibited enhanced photocatalytic activity for MB degradation under UV-visible irradiation compared to $\mathrm{Caln}_{2} \mathrm{O}_{4}$ nanophotocatalysts produced by SSR and solution-combustion routes. ${ }^{103}$

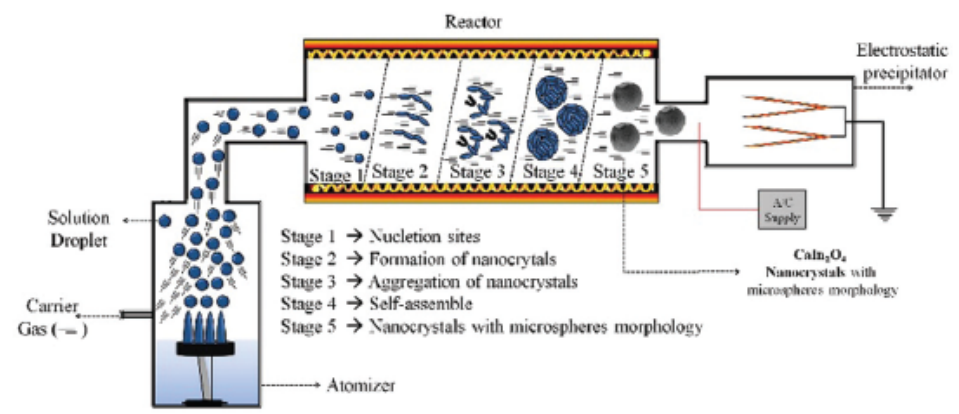

Fig. 7 Pictorial representation of the experimental setup and continuous formation of $\mathrm{Caln}_{2} \mathrm{O}_{4} \mathrm{NCs}$ via one pot ultrasonic spray pyrolysis. ${ }^{103}$ (Reprint with permission from M. T. S. Tavares, M. M. Melo, V. D. Araujo, R. L. Tranquilin, C. R. R. Almeida, C. A. Paskocimas, M. R. D. Bomio, E. Longo and V. F. Motta, Enhancement of the photocatalytic activity and white emission of $\mathrm{Caln}_{2} \mathrm{O}_{4}$ nanocrystals, J. Alloys Compd., 2016, 658, 316-323, Copyright 2019 Elsevier).

\section{Ternary oxide $\left(\mathrm{ABO}_{2}\right.$ types) photocatalysts}

The previously discussed ternary SCs illuminate the influence of surface area on the photocatalytic activity, whereas the SCs discussed here and in the subsequent section details the effect of electronic structure on the photocatalytic activity. The third set of ternary oxide SCs discussed here are visible light active, silver containing group III oxides of $\mathrm{AgMO}_{2}$ types $(\mathrm{M}=\mathrm{Al}, \mathrm{Ga}, \mathrm{In}) .{ }^{104-107}$ This family includes: $\alpha-\mathrm{AgGaO}_{2}(2.38 \mathrm{eV}), \alpha-\mathrm{Ag} \operatorname{lnO} \mathrm{O}_{2}(1.90 \mathrm{eV}), \beta-\mathrm{AgGaO} 2(2.18 \mathrm{eV})$ and $\beta-\mathrm{AgAlO}_{2}(2.95 \mathrm{eV})$ which are indirect SCs. ' $\alpha$ ' refers to the delafossite structure and ' $\beta$ ' to the cristobalite related structure. Maruyama et al. reported the use of a cation-exchange technique for the synthesis of this $\mathrm{AgMO}_{2}(\mathrm{M}=\mathrm{Al}$, $\mathrm{Ga}, \mathrm{In}$ ) SCs. Ouyang et al. performed the photocatalytic evaluation of $\alpha-\mathrm{AgGaO}_{2}, \alpha-\mathrm{AgInO} \mathrm{I}_{2} \beta-\mathrm{AgGaO} \mathrm{O}_{2}$ and $\beta-\mathrm{AgAlO}{ }_{2}$ SCs by studying the gas phase decomposition of isopropanol (IPA) under visible light. ${ }^{107,108}$ The hierarchy of photocatalytic activity was found to be $\alpha-\mathrm{AgGaO}_{2}>\beta-\mathrm{AgAlO}_{2}>\beta-\mathrm{AgGaO}_{2}>\alpha-\mathrm{AgInO} \mathrm{I}_{2} \cdot \mathrm{AgGaO}_{2}$ possessing delafossite crystal structure impart the highest activity ( $88.8 \mathrm{ppm} \mathrm{h}^{-1}$ of acetone produced from IPA decomposition) with respect to other members of $\mathrm{AgMO}_{2} \mathrm{SCs}$.

Delafossite crystal structure exists in two different polytypes, 3-R (rhombohedral) and 2-H (hexagonal), as depicted in Fig. 8. $\mathrm{AgGaO}_{2}$ and $\mathrm{AgInO} \mathrm{I}_{2}$ synthesized here were crystallized in the 3-R polytype form. In both polytypes, there are two individual layers, providing a separate path for electron ( $\mathrm{BO}_{6}$ layers) and hole conduction ( $\mathrm{O}-\mathrm{A}-\mathrm{O}$ dumbbell layer) upon excitation by photons. The repulsion existing between the oxygen anions in the dumbbell (O-A-O) bonds shortens the bond distance between the ' $A$ ' cation and the oxygen anion, which increases the interaction between the metallic (A) cation and the oxygen anion, resulting in the formation of highly dispersed VB. Due to such a dispersion, effective mass of the holes decreases and mobility increases leading to increased separation of charges upon excitation, resulting in superior photocatalytic activity. This dispersed VB characteristic is not seen in cristobalite structure $\left(\beta-\mathrm{AgAlO}_{2}\right.$ and $\left.\beta-\mathrm{AgGaO}_{2}\right)$ which explains the reasons for a lower photocatalytic activity $(5.3$ $\mathrm{ppm} \mathrm{h}^{-1}$ and $2.2 \mathrm{ppm} \mathrm{h}^{-1}$ of acetone produced, respectively) compared to $\alpha-\mathrm{AgGaO}_{2}$. The very low photocatalytic activity of $\alpha-\mathrm{AgInO}_{2}$ (1.3 $\mathrm{ppm} \mathrm{h}^{-1}$ of acetone production) for IPA decomposition can be solely attributed to its very 
low band gap (1.9 eV), not possessing appropriate band edge potentials for oxidation. ${ }^{108}$ Regarding $\alpha$-AgGaO ${ }_{2}$ synthesis, Akhtar et al. also reported for the first time the high pressure ( 10 GPa) direct synthesis of nano $\alpha$ $\mathrm{AgGaO}_{2}$ (3R-polytype) using resistively-heated diamond anvil cell, through solid state reaction for which photocatalytic applications are yet to be explored. ${ }^{109}$

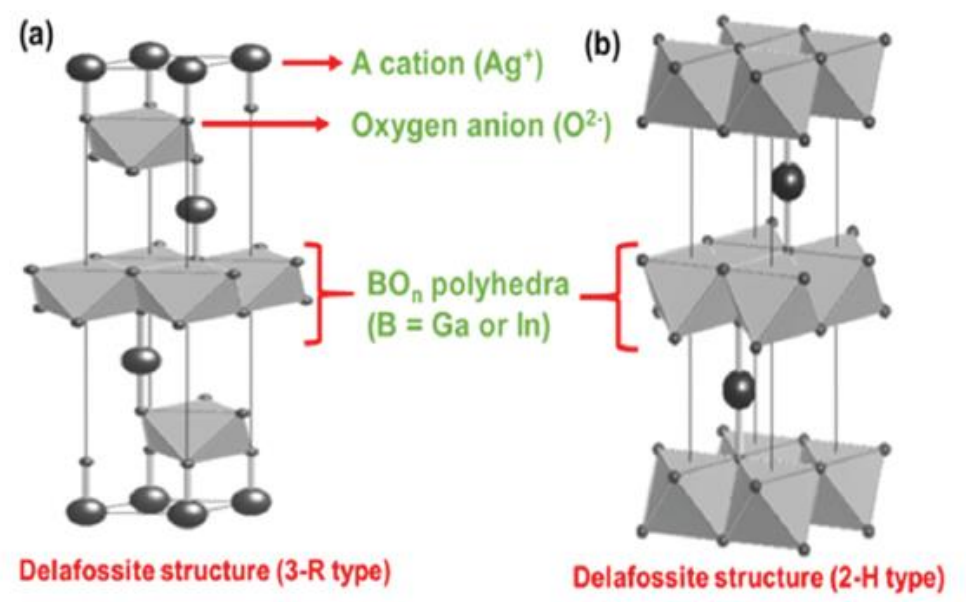

Fig. 8 (a) 3-R polytype of delafossite crystal structure. (b) 2-H polytype of delafossite crystal structure, redrawn based on the images. ${ }^{106}$ ( $(a$ and $b)$ Reprint with permission from Y. Maruyama, H. Irie and K. Hashimoto, Visible light sensitive photocatalyst, delafossite structured $\alpha-\mathrm{AgGaO}_{2}, J$. Phys. Chem. B, 2006, 110, 23274-23278 Copyright 2018 American Chemical Society).

\section{Ternary oxide $\left(\mathrm{ABO}_{4}\right.$ types) photocatalysts}

Bismuth vanadate, $\mathrm{BiVO}_{4}(2.4 \mathrm{eV})$ is a visible light active $\mathrm{SC}$, of high interest due to its polymorphic nature, ferroelastic and electronic properties. Such fascinating properties strongly depend on its crystalline structure. The three polymorphic forms of $\mathrm{BiVO}_{4}$ are scheelite-monoclinic (SM), scheelite-tetragonal (ST) and zircon-tetragonal (ZT). ${ }^{110-112}$ Among the crystalline forms of $\mathrm{BiVO}_{4}, \mathrm{SM}$ exhibits the highest activity for photocatalytic $\mathrm{O}_{2}$ evolution from aqueous silver nitrate solution and photocatalytic degradation of endocrine compounds, especially alkylphenol groups under visible light irradiation. ${ }^{113-115} \mathrm{SM}$ outperforms ST in photocatalysis. In the $\mathrm{SM}^{-\mathrm{BiVO}_{4}}$ structure, a variety of bond lengths between $\mathrm{Bi}-\mathrm{O}$ atoms are observed, unseen in $\mathrm{ST}_{-} \mathrm{BiVO}_{4}$ structures. The presence of such different bond lengths in $\mathrm{Bi}-\mathrm{O}$ atoms leads to distortion of the crystal structure caused by the $6 \mathrm{~s}^{2}$ lone pairs of $\mathrm{Bi}^{3+}$ cations. Specifically, $\mathrm{VO}_{4^{-}}{ }^{3-}$ tetrahedrons are distorted (Fig. 9a). Due to the SM structure distortion, the overlap of $\mathrm{VB}$ orbitals occurs. The overlapping extent of $\mathrm{O} 2 \mathrm{p}$ and $\mathrm{Bi} 6 \mathrm{~s}$ orbitals in VB increases with the increase of the extent of distortion in the crystal structure and results in the increase of charge separation upon photoexcitation, due to the delocalization of electrons and holes. These resulted in enhanced migration of holes to the surface of the SC, leading to superlative photocatalytic activity. Such intensified migration of holes is absent in $\mathrm{ST}^{-\mathrm{BiVO}_{4}}$ (Fig. 9b) semiconductor due to the absence of distortion in the scheelite crystal structure. ${ }^{110,116}$ Traditionally, $\mathrm{SM}^{-\mathrm{BiVO}_{4}}$ are synthesized by solid state reaction at high temperature. Kudo et al. prepared $\mathrm{BiVO}_{4}$ photocatalysts for $\mathrm{O}_{2}$ evolution via room temperature aqueous process, which resulted in nanomaterials with well-defined crystallinity. ${ }^{115} \mathrm{Yu}$ and Kudo reported the hydrothermal route to synthesize $\mathrm{SM}-\mathrm{BiVO}_{4}$ with enhanced surface texture and morphology as compared to nano $\mathrm{BiVO}_{4}$ synthesized via aqueous process route. They successfully enhanced the photocatalytic activity for $\mathrm{O}_{2}$ evolution from aqueous silver nitrate solutions by varying the $\mathrm{pH}$ of the synthetic medium. The variation of the $\mathrm{pH}(1,4$ and 9$)$ of the synthetic medium successfully changed the electronic band gap (2.39, 2.46 and $2.47 \mathrm{eV}$ ) of the resultant nanomaterials, thus positively influencing the activity of photocatalysis. ${ }^{116}$ The synthesis of

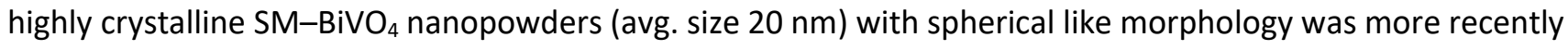
optimized under mechanochemical synthesis. Due to the practical issues associated with separation of photocatalysts from the reactant/product streams in large scale implementations, $\mathrm{BiVO}_{4}$ syntheses have been 
intensively focused on $\mathrm{SM}_{-} \mathrm{BiVO}_{4}$ thin films in this decade. $\mathrm{SM}-\mathrm{BiVO}_{4}$ thin films exhibited efficient separation, stable monoclinic scheelite structure and pre-eminent light absorption capability. ${ }^{117-122}$ Lately in 2017, Venkatesan et al. combined mechanochemical synthesis and Rf-sputtering for the synthesis of $\mathrm{BiVO}_{4}$ films with nano-structural islands which displayed good activity for the degradation (complete degradation in $240 \mathrm{~min}$ ) of rhodamine-6G (Rh6G) under visible light. 123

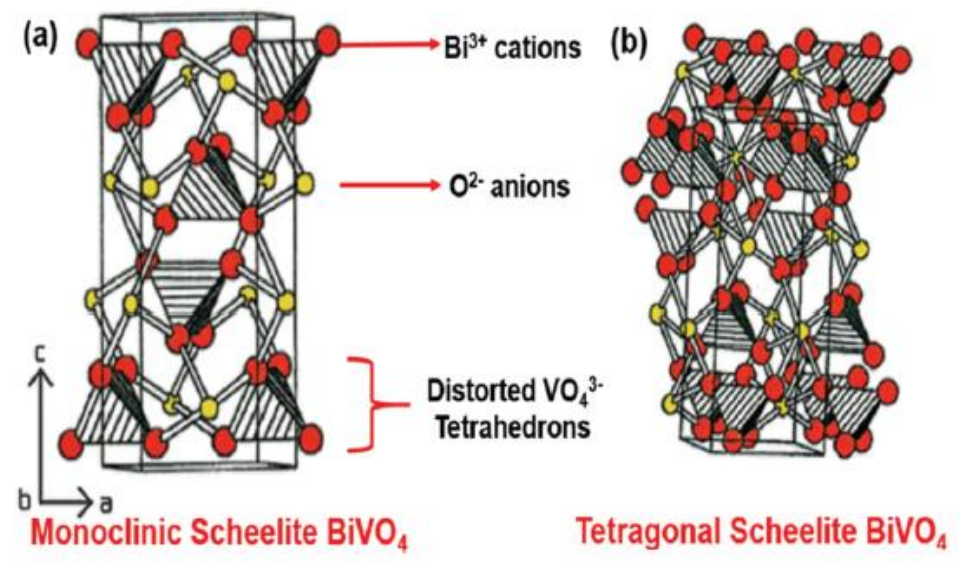

Fig. 9 (a) $\mathrm{SM}$ structure of $\mathrm{BiVO}_{4}$ compound. (b) ST structure of $\mathrm{BiVO}_{4}$ compound. ${ }^{124}$ (Reproduced from Schwarz, et al., Eur. Coat. J., 2016, 9. 26-31, Copyright 2018 Vincentz Network).

Besides the above mentioned SC oxides, aurivillius compounds, $\mathrm{Bi}_{2} \mathrm{~A}_{n-1} \mathrm{~B}_{n} \mathrm{O}_{3 n+3}(\mathrm{~A}=\mathrm{Ca}, \mathrm{Sr}, \mathrm{Ba}, \mathrm{Pb}, \mathrm{Na}, \mathrm{K} ; \mathrm{B}=\mathrm{Ti}, \mathrm{Nb}, \mathrm{Ta}$, $\mathrm{Mo}, \mathrm{W}, \mathrm{Fe}$ ) have also been considered. This particular group possesses a unique special layer structure where $\left(\mathrm{Bi}_{2} \mathrm{O}_{2}\right)^{2+}$ layers are interleaved with perovskite-like $\left(\mathrm{A}_{n-1} \mathrm{~B}_{n} \mathrm{O}_{3 n+1}\right)$ units. ${ }^{125}$ Ternary SC, bismuth tungstate $\left(\mathrm{Bi}_{2} \mathrm{WO}_{6}\right)$ is one of the simplest member $(n=1)$ of aurivillius oxides. $\mathrm{Bi}_{2} \mathrm{WO}_{6}$ possesses interesting physicochemical properties and was extensively explored in photocatalysis in the last decade. Such an intensive study is attributed to its unique structure $\left(\left(\mathrm{Bi}_{2} \mathrm{O}_{2}\right)^{2+}\right.$ layers sandwiched with perovskite-like $\left[\mathrm{WO}_{4}\right]^{2-}$ layers) favouring efficient separation of photogenerated charge carriers upon excitation, leading to exalted photocatalytic activity. ${ }^{126}$ Advanced photocatalytic systems employing $\mathrm{Bi}_{2} \mathrm{WO}_{6} \mathrm{SC}$ are reported in the last part of this review (see section on Z-Scheme photocatalysts).

\section{Ternary chalcogenide photocatalysts}

The final set of ternary $\mathrm{SCs}$ addressed in this review are ternary chalcogenides of the type $A B_{x} C_{y}$ (where $A=C u, A g$, $\mathrm{Zn}$ or $\mathrm{Cd} ; \mathrm{B}=\mathrm{Ga}$ or In; $\mathrm{C}=\mathrm{S}$ or Se or Te). These compounds exhibit high absorption coefficient over a wide spectral range and are effectively feasible for solar photon absorption. Due to their excellent optoelectronic and catalytic properties, they have been successfully implemented in solar cells, light emitting diodes, radiation detection devices and photocatalysis. ${ }^{127-137}$ Among these highly functional chalcogenides, SCs of the group I-III-VI (silver-indiumsulfide $\left(\mathrm{AgInS} \mathrm{S}_{2}\right)$, copper-gallium-sulfide $\left(\mathrm{CuGaS}_{2}\right)$ and copper-indium-sulfide $\left.\left(\mathrm{CuInS}_{2}\right)\right)$ and group II-III-VI (cadmiumindium-sulfide $\left(\mathrm{Cdln}_{2} \mathrm{~S}_{4}\right)$ and zinc-indium-sulfide $\left.\left(Z n \mathrm{n}_{2} \mathrm{~S}_{4}\right)\right)$ have been studied in photocatalysis. Within these two groups, group I-III-VI semiconductors: $\mathrm{AgInS}_{2}, \mathrm{CuGaS}_{2}$ and $\mathrm{CuInS}_{2}$ are highly preferred due to their negligible toxicity, high photoconductivity, high stability, environmental benign composition and visible light activity for many novel reactions. ${ }^{135-143}$ The course of studies on group I-III-VI photocatalysts have specifically focused on the control of morphology and physicochemical properties, thereby influencing its photocatalytic activity. In this perspective, $\mathrm{AgInS}_{2}(1.87-2.14 \mathrm{eV})^{144,145}$ photocatalysts were synthesized by optimized novel techniques in recent times including hydrothermal methods, ${ }^{146}$ one-step aqueous synthesis, ${ }^{147}$ microwave hydrothermal techniques ${ }^{148}$ and microwave heating processes with short reaction times $(\mathrm{ca} .5 \mathrm{~min}) .{ }^{149}$ Strikingly, Hu et al. synthesized $\mathrm{AgInS} 2$ nanoplates and nanotubes through convenient co-precipitation low-temperature $\left(70-190^{\circ} \mathrm{C}\right)$ strategy where the morphology and 
physicochemical properties of $\mathrm{AgInS}_{2}$ photocatalysts were altered by varying (In/Ag) molar ratio of precursors. Synthesized $\mathrm{AgInS}_{2}$ with $(\mathrm{In} / \mathrm{Ag}$ ) molar ratio of 9 exhibited a nanotube-like morphology, low photoluminescence value and maximum photocurrent density $\left(0.011 \mathrm{~mA} \mathrm{~cm}^{-2}\right)$. The maximum photocurrent implies the most efficient separation of electron-hole pairs upon excitation. This novel $\mathrm{AgInS}_{2}$ nanotube displayed regeneration ability and highest visible light activity for complete 2-nitrophenol degradation (within $120 \mathrm{~min}$ ) as compared to other AgInS nanoplates/nanotubes due to the narrow band gap and highest charge separation efficiency. ${ }^{150}$

Similar synthetic studies have been reported for $\mathrm{CuGaS}_{2}$ photocatalysts. Classic synthetic methods (hydrothermal, ${ }^{150}$ solvothermal ${ }^{151}$ and hot injection route ${ }^{151}$ ) suffered from drawbacks including polydispersion and limited scale-up production capabilities. Regulacio et al. introduced a facile non-injection route based on thermal decomposition. This synthesis presented several advantages including high reproducibility, mass production of samples and convenient control of the synthetic domain. As-synthesized nano $\mathrm{CuGaS}_{2}(2.52 \mathrm{eV})$ exhibited promising photocatalytic activity for RhB dye degradation (63\% of dye was degraded in $270 \mathrm{~min}$ ) under visible light irradiation. ${ }^{152}$ Additionally, Liu et al. reported a non-injection route based one-step heating process for the synthesis of one-dimensional (1D) or two-dimensional (2D) $\mathrm{CuGaS}_{2}$ NCs. Here, the morphology tuning could be achieved through the appropriate choice of ligands and precursors. These NCs displayed prominent activity for $\mathrm{H}_{2}$ evolution in the presence of hole scavengers $\left(\mathrm{Na}_{2} \mathrm{~S}\right.$ and $\left.\mathrm{Na}_{2} \mathrm{SO}_{3}\right)$ under simulated solar irradiation. ${ }^{153}$ Most reported ternary $\mathrm{SCs}$ to date have not been synthesized under continuous conditions. In addition to this, the only ternary SCs synthesized under continuous supercritical processes have not been explored in heterogeneous photocatalysed processes to date. ${ }^{154,155}$

\section{Solid solution photocatalysts}

The optical properties of SCS are a reflection of their inherent electronic structure, related to their VB to $C B$ transition. In the case of wide bandgap SCs, their optical gap circumscribes many redox potentials but their implementation is limited due to their activity in the UV region. Certain ternary SCs possess narrow band gap (active in the visible region) but no appropriate band edge potentials to perform diverse reactions. Consequently, the inherent electronic structure in both binary and ternary SCs pure materials does not regulate an optimum balance between visible light activity and required redox potential.

In the heterogeneous photocatalytic field, meticulous modulation of band gap via preparation of solid solution SC are generally more beneficial as compared to doped or loaded SCs (binary or ternary). Optimum formulations of solid solution systems can be successfully accomplished by combining a wide band gap binary/ternary SC with very narrow band gap binary/ternary SC, i.e. $\mathrm{ZnS}-\mathrm{CdS}$ solid solution. ${ }^{156}$ The resultant solid solution $\left(\mathrm{Zn}_{1-x} \mathrm{Cd} \mathrm{d}_{x} \mathrm{~S}(0.2 \leq x \leq 1)\right)$ does not only exhibit activity under visible light but also maintains its suitable band edge potentials to perform the required reactions. Apart from the band gap position, other properties, which have to be considered while synthesizing the solid solutions include similarities in the crystal structure, electronegativity and valence state of the two end members with which the solid solution is fabricated. ${ }^{157}$ Generally, the hybridized CB or VB promotes faster charge transfer due to its dispersed nature and increases the photocatalytic activity. This phenomenon is more pronounced in solid solutions than in ternary or binary photocatalysts. According to IUPAC, solid solution is defined as, "a crystal containing a second constituent, which fits into and is distributed in the lattice of the host crystal. (The term 'solid solution' is not referred for amorphous materials)". ${ }^{158}$ The diverse solid solution photocatalysts reviewed here (see Fig. 10), can be divided into three different categories, depending on the strategy employed for engineering the band gap: 


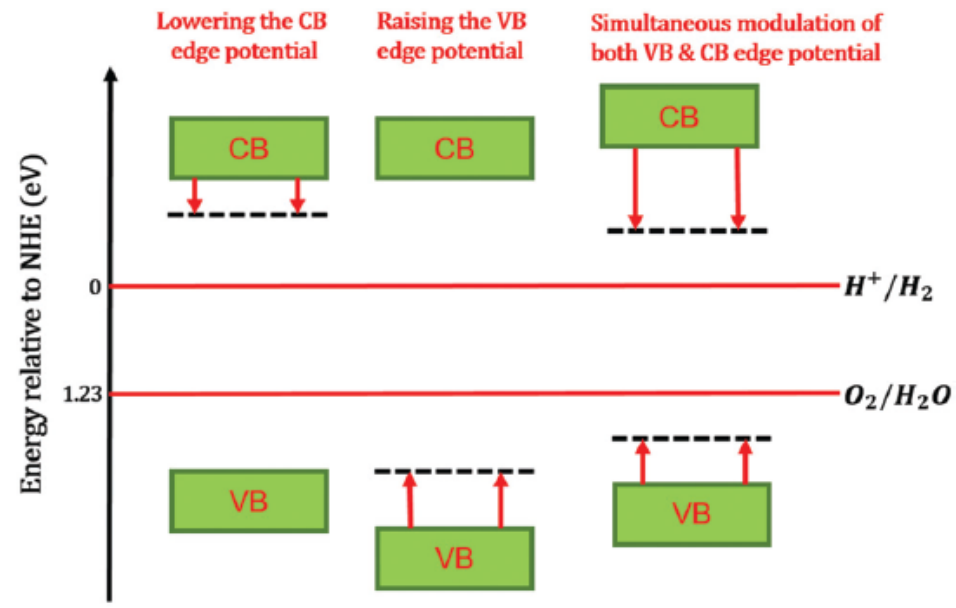

Fig. 10 Different modes of band gap engineering for attaining optimum balance between visible light activity and redox potential of semiconductor band edge.

1. Solid solution through continuous modulation of $\mathrm{CB}$,

2. Solid solution through continuous modulation of VB,

3. Solid solution through continuous modulation of both $\mathrm{CB}$ and VB.

\section{Solid solutions through continuous modulation of $\mathrm{CB}$}

Ternary SCs of the family $\mathrm{AgMO}_{2}(\mathrm{M}=\mathrm{Al}, \mathrm{Ga}, \mathrm{In}$ ) have attracted significant attention in the photocatalytic field due to their dispersed $\mathrm{VB}$ (see section ternary oxides ( $\mathrm{ABO}_{2}$ types) photocatalysts). The solid solution fabricated with $\mathrm{AgMO}_{2}$ SCs can effortlessly extend into the entire spectrum of the visible light and still retains the VB potential. It displays photocatalytic decomposition of various organic compounds due to the strong oxidizing potential. Shuxin et al. improved the visible light activity of $\beta-\mathrm{AgAlO}_{2}(2.83 \mathrm{eV})$ for IPA decomposition through continuous tuning of the $\mathrm{CB}$ edge of $\beta-\mathrm{AgAlO}_{2}$, by combining it with narrow band gap $\beta-\mathrm{AgGaO}_{2}(2.18 \mathrm{eV}) \mathrm{SC}$, resulting in a $\beta-\mathrm{AgAl}_{1-x} \mathrm{Ga}_{x} \mathrm{O}_{2}(0 \leq x \leq$ 1) solid solution. ${ }^{159}$ They synthesized $\beta-\mathrm{AgAl}_{1-x} \mathrm{Ga}_{x} \mathrm{O}_{2}(0 \leq x \leq 1)$ through two-step (sol-gel followed by cation exchange) method. The linear band gap variation of the compound with respect to the composition (see Fig. 11a UVvis absorption spectrum) indicates that continuous solid solution through precise tuning of $C B$ was obtained in this system. Among the various compositions, $\beta-\mathrm{AgAl}_{0.6} \mathrm{Gaa}_{0.4} \mathrm{O}_{2}(2.58 \mathrm{eV})$ exhibited highest photocatalytic activity for IPA decomposition. The rate of acetone production (photo-decomposed product of IPA) by $\beta-\mathrm{AgAl}_{0.6} \mathrm{Ga}_{0.4} \mathrm{O}_{2}$

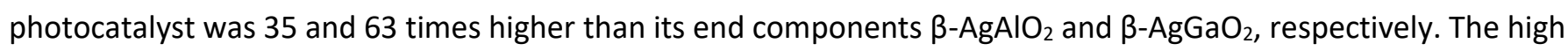
activity is attributed to the novel band gap which customizes an optimum balance between the visible light activity and appropriate redox potential. The colour of the solid solutions with different compositions and acetone evolution rates with respect to band gaps of continuous $\mathrm{CB}$ modulated solid solution is depicted in Fig. $11 \mathrm{~b} .{ }^{159} \mathrm{~A}$ similar CB modulation was achieved recently in the family of $\mathrm{AM}_{2} \mathrm{O}_{6}(A=S n$ and $\mathrm{M}=\mathrm{Nb}$ or Ta) ternary SCs by fabricating the series of $\mathrm{Sn}\left(\mathrm{Nb}_{1-x} \mathrm{Ta}_{x}\right)_{2} \mathrm{O}_{6}(0 \leq x \leq 1)$ solid solutions. $\mathrm{Sn}\left(\mathrm{Nb}_{0.8} \mathrm{Ta}_{0.2}\right)_{2} \mathrm{O}_{6}$ photocatalyst was proved to provide excellent activity and stability for the complete mineralization of $\mathrm{MB}$ dye (98.9\% mineralization efficiency in $120 \mathrm{~min})$ under visible light irradatiation as compared to other members of the $\mathrm{Sn}\left(\mathrm{Nb}_{1-x} \mathrm{Ta}_{x}\right)_{2} \mathrm{O}_{6}(0 \leq x \leq 1)$ solid solutions. ${ }^{160}$ 

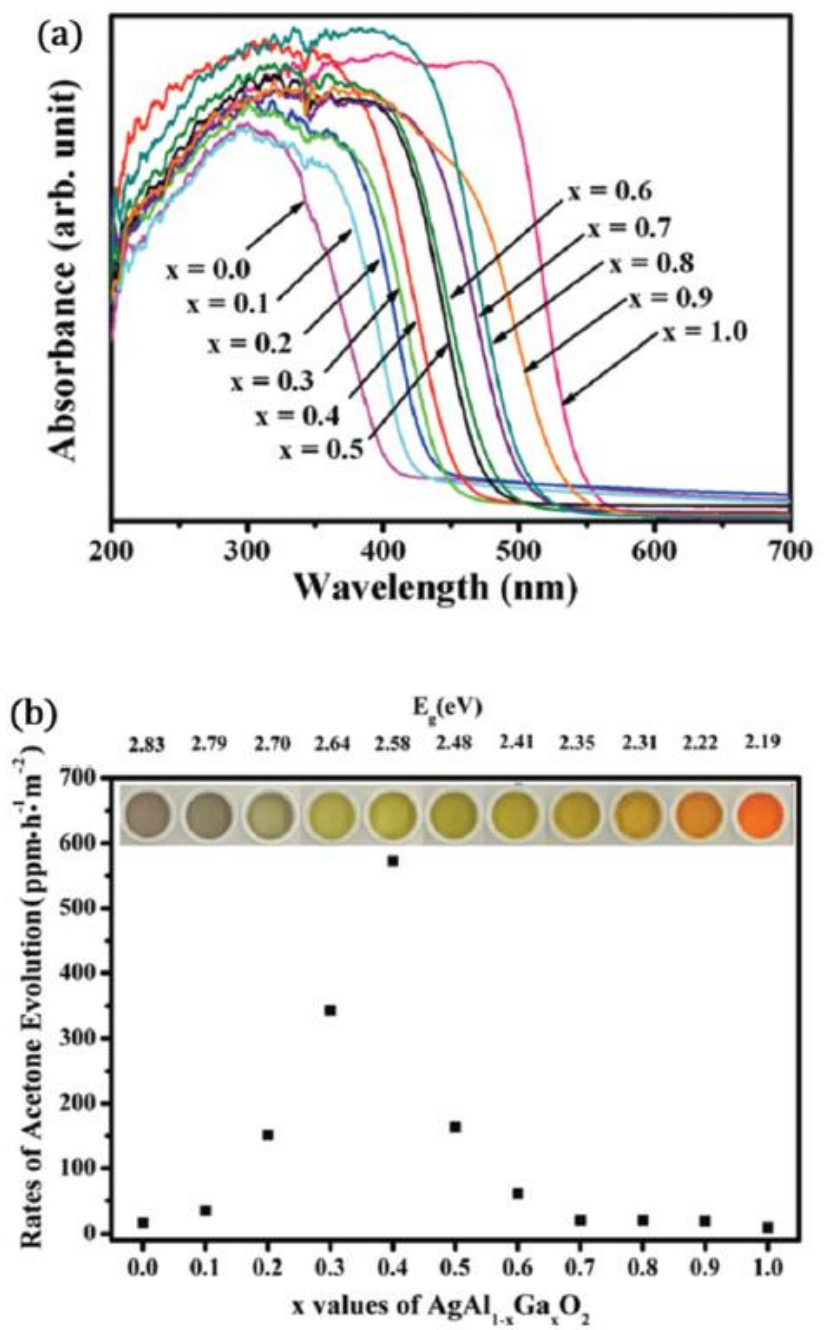

Fig. 11 (a) UV-vis absorption spectrum of $\beta-\mathrm{AgAl}_{1-x} \mathrm{Ga}_{x} \mathrm{O}$ solid solution fabricated from $\beta-\mathrm{AgAlO}_{2}$ and $\beta-\mathrm{AgGaO}_{2}$ ternary oxide $\mathrm{SC}$ s by precise tuning of $\mathrm{CB}$ from $2.83 \mathrm{eV}$ to $2.19 \mathrm{eV}^{159}$ (b) Photocatalytic activity for acetone production. ${ }^{159}$ ( $(\mathrm{a}$ and $\mathrm{b})$ Reprint with permission from S. Ouyang and J. Ye, $\beta-\mathrm{AgAl}_{1-x} \mathrm{Ga}_{x} \mathrm{O}_{2}$ Solid-Solution Photocatalysts: Continuous Modulation of Electronic Structure Toward High-Performance VisibleLight Photoactivity, J. Am. Chem. Soc., 2011, 133, 7757-7763, Copyright 2018 American Chemical Society).

\section{Solid solutions through continuous modulation of VB}

Niobium-based perovskite SCs were extensively explored in photocatalysis, since they suffice the requirement of intensified stability. As their $\mathrm{CB}$ edge potential is far more negative than the potential of $\mathrm{O}_{2} / \mathrm{O}_{2}{ }^{\cdot-} \cdot{ }^{90,161}$ Silver niobate $\left(\mathrm{AgNbO}_{3}\right)(2.8 \mathrm{eV})$ is one such $\mathrm{SC}$ with enhanced stability. It possesses narrow band gap ( $\left.2.8 \mathrm{eV}\right)$ due to its hybridized $\mathrm{VB}$, composed of $\mathrm{Ag} 4 \mathrm{~d}$ and $\mathrm{O} 2 \mathrm{p}$ orbitals and exhibits visible light active activity for producing $\mathrm{O}_{2}$ from silver nitrate solution. Its oxidation potential was however not sufficient to decompose several organic compounds. ${ }^{162}$

Li et al. improved the photo oxidizing ability of $\mathrm{AgNbO}_{3}$ by combination with $\mathrm{NaNbO}_{3}(3.4 \mathrm{eV})$ perovskite $\mathrm{SC}$ through solid state synthetic method, resulting in $\mathrm{Ag}_{x} \mathrm{Na}_{1-x} \mathrm{NbO}_{3}(0 \leq x \leq 1)$ solid solution. The $\mathrm{CB}$ edge potential of both $\mathrm{AgNbO}_{3}$ and $\mathrm{NaNbO}_{3}$ are pinned at the same level $\left(-0.4 \mathrm{eV}\right.$ vs. NHE) ${ }^{90} \mathrm{~A}$ decrease in lattice parameters and $\mathrm{Nb}-\mathrm{O}$ bond length in $\mathrm{NbO}_{6}$ occurs by increasing $\mathrm{NaNbO}_{3}$ content in the solid solution, resulting a decrease of particle size. Simultaneously, the hybridization ratio of $\mathrm{Ag} 4 \mathrm{~d}$ and $\mathrm{O} 2 \mathrm{p}$ decreases resulting in the continuous modulation of $\mathrm{VB}$, shifting the $\mathrm{VB}$ top from $\mathrm{AgNbO}_{3}(+2.39 \mathrm{eV})$ to $\mathrm{VB}$ top of $\mathrm{NaNbO}_{3}(+3 \mathrm{eV})$. These findings indicate that the oxidation potential of the solid solution system is comparatively more positive to that of $\mathrm{AgNbO}_{3}$. Among the continuous range 
of $\mathrm{Ag}_{x} \mathrm{Na}_{1-x} \mathrm{NbO}_{3}(0 \leq x \leq 1)$ solid solutions, $\mathrm{Ag}_{0.6} \mathrm{Na}_{0.4} \mathrm{NbO}_{3}$ photocatalyst evidenced enhanced activity for gaseous IPA decomposition under visible light (activity three times higher with respect to $\mathrm{AgNbO}_{3}$ ) due to an optimum state achieved between oxidation potential, visible light absorption ability and particle size. ${ }^{163}$ Continuous VB modulation without $\mathrm{CB}$ alteration was also reported on $\mathrm{d}^{10}$-(oxy) nitride $\left(\mathrm{Ga}_{1-x} \mathrm{Zn}_{x}\right)\left(\mathrm{N}_{1-x} \mathrm{O}_{x}\right)(0 \leq x \leq 0.25)$ solid solution by Maeda et al. ${ }^{164}$ fabricated from $\mathrm{d}^{10}-\mathrm{ZnO}(3.2 \mathrm{eV})$ whose $\mathrm{CB}$ bottom is composed of hybridized $\mathrm{s}$ and $\mathrm{p}$ metallic cation. The resultant solid solution has heavily dispersed $C B$ with increased mobility from photogenerated electrons, thus intensifying the photocatalytic activity. GaN (3.4 eV) was chosen as another constituent here, as N 2p orbitals possess higher potential energy than $\mathrm{O} 2 \mathrm{p}$ orbitals and similar $\mathrm{CB}$ with respect to $\mathrm{ZnO}$. $\left(\mathrm{Ga}_{1-x} \mathrm{Zn}_{x}\right)\left(\mathrm{N}_{1-x} \mathrm{O}_{x}\right)(0 \leq x \leq 0.25)$ was designed for overall water splitting under visible light irradiation. Such solid solution formation featuring requirements of narrow band gap below $3 \mathrm{eV}$, appropriate band edge potential and stability for overall water splitting could provide an upliftment of the VB, leading to narrow band gap SCs (see Fig. 12b, decrease of band gap with increase of $\mathrm{ZnO}$ content). The upraise of VB potential to $C B$ (without any changes) was hypothesized due to the repulsion existing between $\mathrm{O} 2 \mathrm{p}$ and $\mathrm{Zn} 3 \mathrm{~d}$ orbitals ${ }^{165}$ (Fig. 12a). The authors performed the synthesis of this solid solution through nitridation of oxide precursors $\left(\mathrm{Ga}_{2} \mathrm{O}_{3} \& \mathrm{ZnO}\right)$ at high temperatures $\left(>850^{\circ} \mathrm{C}\right)$ under ammonia flow. As-synthesized solid solution exhibited negligible activity for overall water splitting with co-catalysts including 1 wt\% $\mathrm{Rh}$ (rhodium) and $1.5 \mathrm{wt} \% \mathrm{Cr}$ (chromium) on $\left(\mathrm{Ga}_{1-x} \mathrm{Zn}_{x}\right)\left(\mathrm{N}_{1-x} \mathrm{O}_{x}\right)(0 \leq x \leq 0.25)$ system. Solid solution with a very low $\mathrm{Zn}$ quantity $(\mathrm{Zn} / \mathrm{Ga}=0.14)$ exhibited enhanced photocatalytic $\mathrm{H}_{2}$ and $\mathrm{O}_{2}$ production of $360 \mu \mathrm{mol} \mathrm{h}^{-1}$ and $162 \mu \mathrm{mol} \mathrm{h}{ }^{-1}$, respectively. ${ }^{165}$ The above conventional nitridation method suffered from several drawbacks including long nitridation times, high temperature $\left(>850^{\circ} \mathrm{C}\right)$ and large (micron) sized particles. Recently, Menon et al. replaced the conventional nitridation by solution combustion method, ${ }_{166}$ which yields particles in the nanoscale $(40 \mathrm{~nm})$, the resultant $\left(\mathrm{Ga}_{1-x} \mathrm{Zn} \mathrm{n}_{x}\right)\left(\mathrm{N}_{1-x} \mathrm{O}_{x}\right)$ possessed high zinc content $(\mathrm{Zn} / \mathrm{Ga}=20,30$ and 40$)$. The solid solution with $(\mathrm{Zn} / \mathrm{Ga}=20)$ exhibited overall water splitting under visible light without the aid of a co-catalyst, with apparent quantum yield of $\mathrm{H}_{2}$ production at $0.048 \% .{ }^{166}$ Dharmagunawardhane et al. developed a high pressure $(1 \mathrm{GPa})$ and high temperature $\left(1150-1200{ }^{\circ} \mathrm{C}\right)$ synthetic methodology to synthesize $\left(\mathrm{Ga}_{1-x} \mathrm{Zn}_{x}\right)\left(\mathrm{N}_{1-x} \mathrm{O}_{x}\right)$ solid solutions over the entire compositional range $(x=0.07$ to 0.9$)$ using a talc pressure cell via solid state reaction. They observed the smallest band gap (2.65 $\mathrm{eV})$ and highest photocatalytic activity of $\mathrm{H}_{2}$ evolution $\left(2.3 \mu \mathrm{mol} \mathrm{h}^{-1}\right)$ from water in the absence of co-catalysts, $\mathrm{pH}-$ modifiers and sacrificial agents for $\left(\mathrm{Ga}_{0.49} \mathrm{Zn}_{0.51}\right)\left(\mathrm{N}_{0.49} \mathrm{O}_{0.51}\right)$ solid solution under visible light. ${ }^{167}$
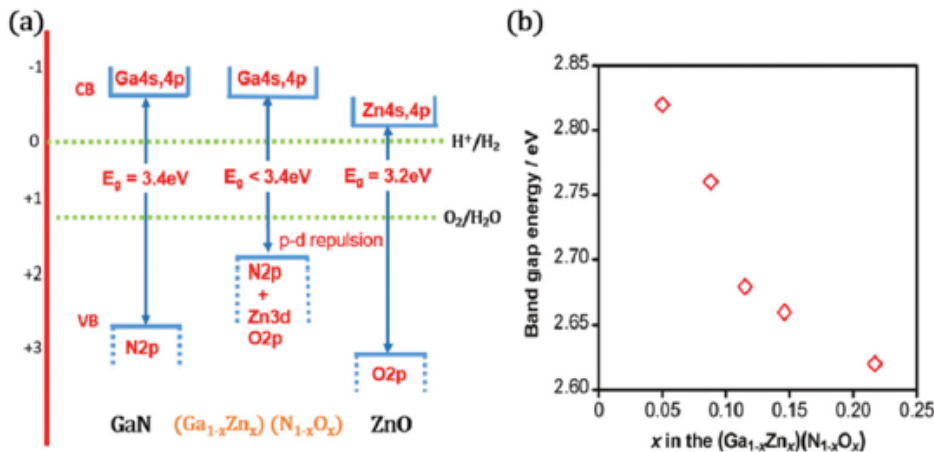

Fig. 12 (a) Schematic depiction of band structure of $\left(\mathrm{Ga}_{1-x} \mathrm{Zn} \mathrm{n}_{x}\right)\left(\mathrm{N}_{1-x} \mathrm{O}_{x}\right)$ solid solution (redrawn based on the article ${ }^{165}$ ). (b) Variation of band gap with respect to $\mathrm{ZnO}$ content in the solid solution. ${ }^{165} \mathrm{Fig} .11(\mathrm{a}$ and b) (Reproduced with permission from ref. 165. Copyright 2018 American Chemical Society).

\section{Solid solutions via continuous modulation of both CB and VB}

Simultaneous regulation of equilibrium between absorption extension into visible region and redox abilities of photocatalysts was achieved in this type of solid solutions prepared via synchronous precise tuning of both VB and $\mathrm{CB}$. Due to the favourable inclination of partial substitution of comprehensive metallic cations and valences at the position of $\mathrm{A}$ and $\mathrm{B}$ elements in $\mathrm{ABO}_{3}$ perovskites, these materials stand as highly promising photocatalysts. Wang et al. performed the precise tuning of both $\mathrm{CB}$ and $\mathrm{VB}$ in $\mathrm{Ag}_{1-x} \mathrm{Sr}_{x}\left(\mathrm{NbO}_{3}\right)_{1-x}\left(\mathrm{TiO}_{3}\right)_{x}(0 \leq x \leq 1)$ solid solutions, formed by combining visible active $\mathrm{AgNbO}_{3}(450 \mathrm{~nm})$ and UV active $\mathrm{SrTiO}_{3}(380 \mathrm{~nm})$ perovskites. ${ }^{168}$ The solid solution was 
synthesized via solid state reaction method. The resultant solid solution's CB is composed of hybridized $\mathrm{Nb} 4 \mathrm{~d}$ and $\mathrm{Ti}$ $3 \mathrm{~d}$ orbitals. As $\mathrm{Nb} 4 \mathrm{~d}$ is more positive than $\mathrm{Ti} 3 \mathrm{~d}$, an increase of $\mathrm{AgNbO}_{3}$ content brings the bottom of $\mathrm{CB}$ band downwards. Similarly, VB of this system was composed of hybridized $\mathrm{Ag} 4 \mathrm{~d}$ and $\mathrm{O} 2 \mathrm{p}$ orbitals where $\mathrm{Ag} 4 \mathrm{~d}$ is more positive than $\mathrm{O} 2 \mathrm{p}$ and it pushes the top VB upwards thus favouring perfectly engineered SC active in the visible region with an optimum balance between redox potentials. The presence of such hybridized CB and VB in this solid solution with continuous dispersion favors enhanced charge carrier transportation upon excitation, leading to increased photocatalytic activity. The solid solution obtained here exhibited continuous modulated $C B$ and $V B$ for the composition $(0 \leq x<0.95)$ and discontinuous $C B$ and $V B$ for the composition $(0.95 \leq x \leq 1) .{ }^{168}$ Discontinuous interbands (dopant levels) are due to very low concentration $\mathrm{AgNbO}_{3}$ in the solid solution. Among the continuous series of solid solutions, $\mathrm{Ag}_{0.75} \mathrm{Sr}_{0.25}\left(\mathrm{NbO}_{3}\right)_{0.75}\left(\mathrm{TiO}_{3}\right)_{0.25}$ evidenced the highest photocatalytic activity for $\mathrm{O}_{2}$ production from silver nitrate solution ( $\left.162 \mu \mathrm{mol} \mathrm{h}^{-1}\right)$, with an apparent quantum efficiency of about $16.4 \%$ under visible light, compared to its two end members. The same photocatalyst displayed the highest activity for IPA decomposition, where it completely mineralize IPA to $\mathrm{CO}_{2}$ within $22 \mathrm{~h}$ of visible light irradiation. ${ }^{168}$

As previously mentioned for perovskite oxides $\mathrm{ABO}_{3}$ type (see section on perovskite photocatalysts), ' $A$ ' site is occupied by a cation larger in size than the cation at the ' $B$ ' site. This smaller cation on the ' $B$ ' site has a stronger interaction with oxygen than the larger cation at ' $A$ ' site. Possibly, perovskites may manifest different optical and electronic properties depending on the electronegativity and ionic radius of the smaller cations at the ' $\mathrm{B}$ ' site. ${ }^{169}$ The confirmation reported by Grinberg et al. that narrow band gap perovskites can be achieved by using two different transition-metal cations on the ' $\mathrm{B}$ ' site ${ }^{170}$ led to the synthesis of perovskites like $\mathrm{Ba}_{2} \mathrm{FeNbO}_{6}$ (BFNO) with mixed $\mathrm{Fe}^{3+}$ and $\mathrm{Nb}^{5+}$ cations on the ' $\mathrm{B}$ ' site. In $\mathrm{Ba}_{2} \mathrm{FeNbO}_{6}(2.29 \mathrm{eV})$, the VBM composed of $\mathrm{Ni} 3 \mathrm{~d}$ and $\mathrm{O} 2 \mathrm{p}$ orbitals while CBM comprised $\mathrm{Fe} 3 \mathrm{~d}$ and $\mathrm{Nb} 4 \mathrm{~d}$. This $\mathrm{VB}$ and $\mathrm{CB}$ straddles the water oxidation and reduction potential, respectively, however leading to low photocatalytic activity due to poor charge separation efficiency. The photocatalytic performance of $\mathrm{Ba}_{2} \mathrm{FeNbO}_{6}$ was improved via preparation of $\mathrm{SrTiO}_{3}-\mathrm{Ba}_{2} \mathrm{FeNbO}_{6}$ solid solution $\mathrm{NCs}$ through a simple one-step molten salt route. ${ }^{170} \mathrm{Here}$ the band gap was precisely tuned from $3.31 \mathrm{eV}$ of $\mathrm{SrTiO}_{3}$ to $2.29 \mathrm{eV}$ of $\mathrm{Ba}_{2} \mathrm{FeNbO}_{6}$ through simultaneous modulation of $\mathrm{CB}$ and $\mathrm{VB}$ edges (Fig. 13). Among the series of solid solutions synthesized, $\mathrm{SrTiO}_{3}-\mathrm{Ba}_{2} \mathrm{FeNbO}_{6}-0.5\left(\mathrm{SrTiO}_{3}\right.$ to $\mathrm{Ba}_{2} \mathrm{FeNbO}_{6}$ optimal molar ratio is $\left.10: 0.5\right)$ exhibited the highest photocatalytic $\mathrm{H}_{2}$ production $\left(7.15 \mu \mathrm{mol} \mathrm{h}{ }^{-1}\right.$ ) from aqueous methanol solution under visible light irradiation. ${ }^{170}$ This $\mathrm{SrTiO}_{3}-\mathrm{Ba}_{2} \mathrm{FeNbO}_{6}{ }^{-}$ 0.5 solid solution exhibited maximum photocurrent signal indicating that its high photocatalytic activity is attributed to efficient separation of electron-hole pairs. Simultaneous regulation of redox potential and visible light activity is achieved facilely in this system. ${ }^{170}$

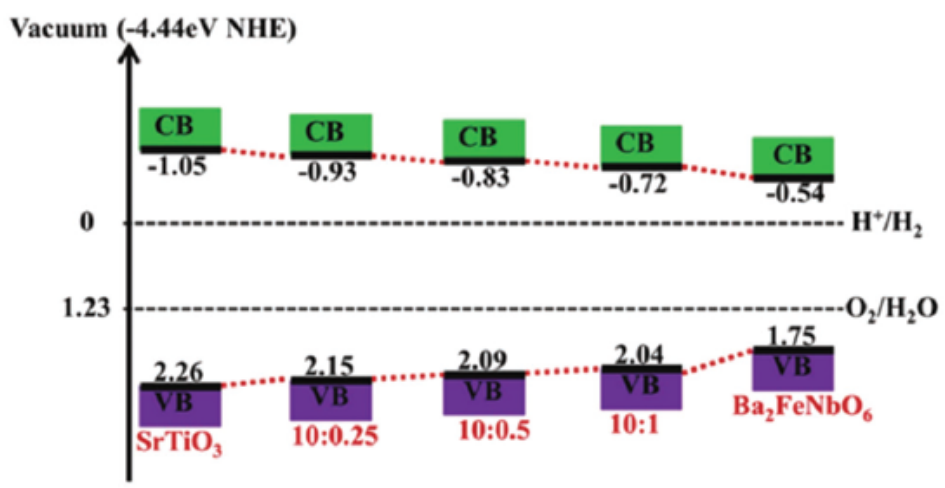

Fig. 13 Depiction of energy level diagram of $\mathrm{SrTiO}_{3}, \mathrm{SrTiO}_{3}-\mathrm{Ba}_{2} \mathrm{FeNbO}_{6}$ solid solutions (ratio $10: 0.25,10: 0.5$ and $10: 1$ corresponds to the molar ratio of $\mathrm{SrTiO}_{3}$ to $\mathrm{Ba}_{2} \mathrm{FeNbO}_{6}$ ). ${ }^{170}$ (Reprint with permission from $\mathrm{G}$. Zhang, S. Sun, W. Jiang, X. Miao, Z. Zhao, X. Zhang, D. Qu, D. Zhang, D. Li, Z. Sun, Adv. Energy Mater., 2017, 7(2), 1600932. Copyright 2019 John Wiley and Son). 
Sulfide-based solid solution photocatalysts have been extensively reported to be synthesized by continuous tuning of both CB and VB for efficient hydrogen production. ${ }^{171-174}$ Binary sulfides including CdS found to be moderately active photocatalysts for $\mathrm{H}_{2}$ production (see section on binary photocatalysts), with inherent issues related to quick recombinations of photogenerated charge carriers and photo-corrosion under visible light (essentially limiting their use at a large scale $\left.{ }^{175-178}\right)$.

The formulation of highly crystalline solid solutions combining wide band gap ZnS with CdS can solve the photostability issues of $C d S$ under visible light irradiation. The synthesis of $C d_{x} Z n_{1-x} S$ solid solutions was achieved employing several techniques such as co-precipitation, ${ }^{179,180}$ cation-exchange ${ }^{181}$ and hydrothermal methods. ${ }^{182,183}$ Such conventional techniques possessed several drawbacks including high deviation of elemental composition of solid solutions compared to theoretical synthesis values, minimum control over band structure and long reaction times to obtain highly crystallized solid solutions. Li et al. circumvented the above mentioned drawbacks via facile thermolysis of complex zinc-cadmium-thiourea to synthesize $\mathrm{Cd}_{x} Z \mathrm{Zn}_{1-x} \mathrm{~S}(0<x<1)$ solid solution NPs at short times of reaction (ca. $30 \mathrm{~min}){ }^{184}$ As synthesized $\mathrm{Cd}_{x} \mathrm{Zn}_{1-\mathrm{x}} \mathrm{S}(0<x<1)(2.3-3.1 \mathrm{eV})$ solid solutions were found to be aggregates of small crystallized NPs (avg. size $=10 \mathrm{~nm}$ ) (Fig. 14a and b). The continuous red shift of steep absorption band edge with increasing CdS content confirmed the precise engineering of both $\mathrm{CB}$ and VB for these solid solutions (Fig. 14d). ${ }^{184}$
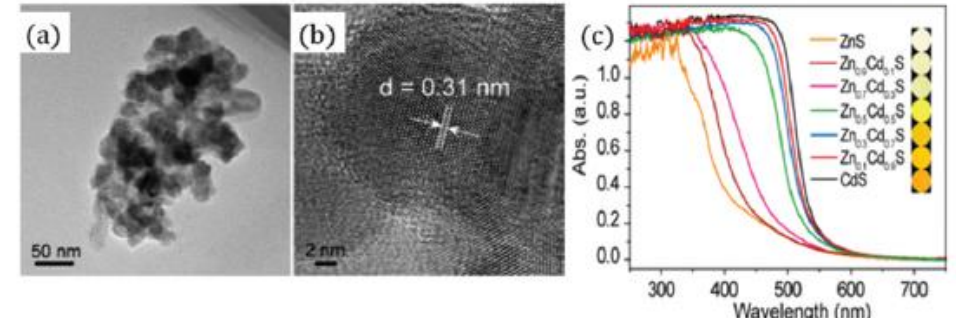

(e)

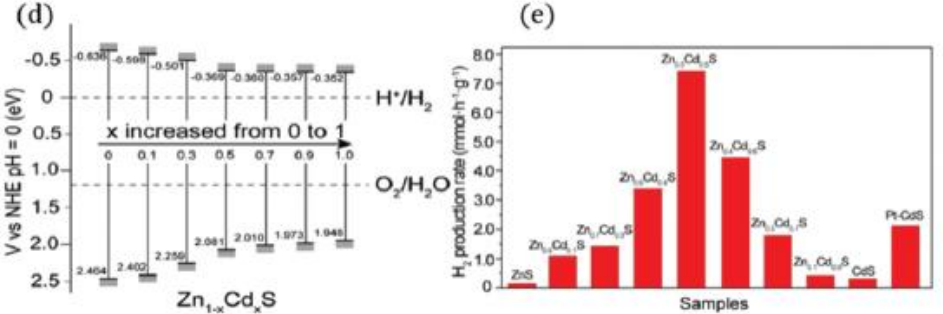

Fig. 14 (a) TEM image of $\mathrm{Zn}_{0.5} \mathrm{Cd}_{0.5} \mathrm{~S}$ solid solution, average diameter of aggregates (50-100 nm). (b) HR-TEM image of $\mathrm{Zn}_{0.5} \mathrm{Cd}_{0.5} \mathrm{~S}$ solid solution, diameter of each NP is about $10 \mathrm{~nm}$. (c) UV-vis diffuse reflectance spectra of $\mathrm{Cd}_{x} \mathrm{Zn}_{1-x} \mathrm{~S}$ solid solutions ( $x=0,0.3,0.5,0.7$ and 0.9). (d) Band gap variation with respect to the composition. (e) $\mathrm{H}_{2}$ production rate with respect to the composition in $\mathrm{Cd}_{x} \mathrm{Zn}_{1-x} \mathrm{~S}$ solid solution. ${ }^{184}$ Fig. $13(\mathrm{a}-\mathrm{d})$ (Reproduced with permission from ref. 184. Copyright 2018 American Chemical Society).

Among the different ranges of solid solution, $\mathrm{Cd}_{0.5} \mathrm{Zn}_{0.5} \mathrm{~S}(2.45 \mathrm{eV})$ exhibited a superior balance between $\mathrm{CB}$ and VB potentials as well as visible light absorption. This photocatalyst exhibited maximum $\mathrm{H}_{2}$ production $\left(7.42 \mathrm{mmol} \mathrm{h}^{-1}\right.$ $\mathrm{g}^{-1}$ ) from water in the presence of sacrificial agents $\left(\mathrm{Na}_{2} \mathrm{~S} \& \mathrm{Na}_{2} \mathrm{SO}_{3}\right)$ in the absence of a co-catalysts $(\mathrm{Pt}) .{ }^{184} \mathrm{This}$ photocatalytic activity exceeded the activities of $\mathrm{CdS}$ and $\mathrm{ZnS}$ by 24 and 54 times, respectively, being much higher than the activity displayed by co-catalyst (Pt) loaded CdS photocatalysts (Fig. 14e). ${ }^{184}$ 
Fu et al. successfully incorporated the $\mathrm{Cd}_{0.5} \mathrm{Zn}_{0.5} \mathrm{~S}$ solid solution (synthesized by the previously disclosed thermolysis route ${ }^{184}$ ) into PAN (polyacrylonitrile) nanofibers and developed leaf-like, bio-inspired flexible mat-shaped $\mathrm{Cd}_{0.5} \mathrm{Zn}_{0.5} \mathrm{~S} @ P A N$ photocatalysts. ${ }^{185}$ This hierarchically porous leaf-like solid solution exhibited a remarkable photocatalytic activity for $\mathrm{H}_{2}$ production from water splitting $\left(475 \mu \mathrm{mol} \mathrm{h}^{-1}\right.$ of $\mathrm{H}_{2}$ per $\left.50 \mathrm{mg}\right)$ at an apparent quantum efficiency of $27.4 \%$ at $420 \mathrm{~nm}$. $\mathrm{Cd}_{0.5} \mathrm{Zn}_{0.5} \mathrm{~S} @ P A N$ photocatalytic activity was reported to be superior to that of $\mathrm{Cd}_{0.5} \mathrm{Zn}_{0.5} \mathrm{~S}$ solid solution NPs due to the enhancement of mass transfer kinetics, multiple reflection and scattering effect of incident light as result of the porous structure. ${ }^{185}$

Ternary chalcogenide SCs of the group I-III-VI (I = Cu, Ag; III = Al, Ga, In; VI = S, Se, Te) have received increasing attention as a new class of materials in the field of solar cells and also for solar driven $\mathrm{H}_{2}$ production (water splitting). ${ }^{186}$ In ternary sulfide SCs including AgInS 2 or CulnS 2 , the VB is composed of $d$-states of Ag or Cu assorted with $p$-states of sulfur, ${ }^{187,188}$ resulting in a VB far more negative to that of $\mathrm{ZnS}$ or CdS.

In these ternary compounds, the VB is precisely tuned by monovalent cations of $\mathrm{Ag}$ or $\mathrm{Cu}$ and the $\mathrm{CB}$ is modulated via Indium doping (Fig. 15a and b). These ternary SCs were combined with wide band gap ZnS for the synthesis of solid solution photocatalysts for optimized $\mathrm{H}_{2}$ evolution.
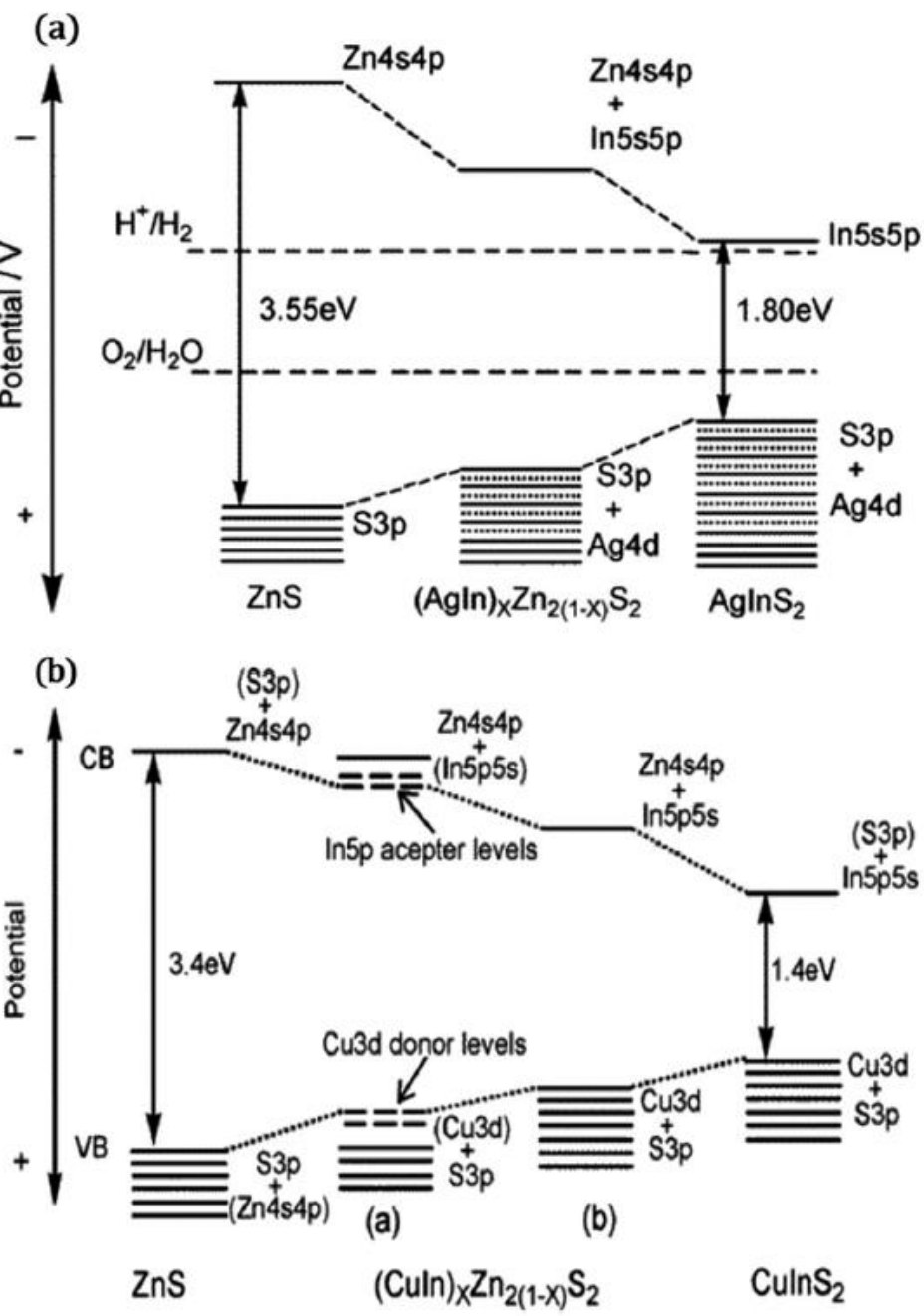

Fig. 15 (a) Band gap modulation in $(\text { Agln })_{x} Z n_{2(1-x)} S_{2}{ }^{189}$ (b) Band gap engineering attained in (Culn $)_{x} Z n_{2(1-x)} S_{2}$ solid solutions ${ }^{190}$ Fig. 14. (a) Reproduced with permission from ref. 189. Copyright 2018 American Chemical Society. Fig. 14(b) (Reproduced with permission from ref. 190. Copyright 2018 American Chemical Society). 
Tsuji et al. reported the synthesis of $(\mathrm{AgIn})_{x} \mathrm{Zn}_{2(1-x)} \mathrm{S}_{2}(0 \leq x \leq 1)(3.55-1.8 \mathrm{eV})$ solid solution through the heat treatment of complex greyish Ag-In-Zn sulfide precursor. ${ }^{189}$ Here, they attempted several different heat treatment strategies, from which an improvement of the photocatalytic activity for the resultant solid solutions was observed. $(\mathrm{AgIn})_{0.22} \mathrm{Zn}_{1.58} \mathrm{~S}_{2}(2.33 \mathrm{eV})$ synthesized via heat treatment under $\mathrm{N}_{2}$ flow exhibited a relevant $\mathrm{H}_{2}$ production $(72 \mu \mathrm{mol}$ $h^{-1}$ ) from aqueous solutions of $\mathrm{K}_{2} \mathrm{SO}_{3}$ and $\mathrm{Na}_{2} \mathrm{~S}$ under visible light irradiation. ${ }^{189}$

The same photocatalyst when synthesized via heat treatment, under sealed quartz ampule tube without $\mathrm{N}_{2}$ flow, provided a remarkably superior activity for $\mathrm{H}_{2}$ production $\left(328 \mu \mathrm{mol} \mathrm{h}{ }^{-1}\right) .{ }^{189}$ The photocatalytic activity was 4.5 times higher than the material synthesized under $\mathrm{N}_{2}$ flow, as the newly proposed heat treatment methodology prevents the volatilization of metallic cations during synthesis. On loading $3 \mathrm{wt} \%$ of co-catalyst (Pt) on the $(\mathrm{AgIn})_{0.22} \mathrm{Zn}_{1.58} \mathrm{~S}_{2}$ photocatalyst (synthesized by heat treatment in sealed quartz tube), the rate for $\mathrm{H}_{2}$ production under visible light was further enhanced three times $\left(944 \mu \mathrm{mol} \mathrm{h}^{-1}\right)$ with a highest apparent quantum yield of $20 \%{ }^{189}$ Subsequently, the same authors employed the above newly modified heat treatment process $\left(850^{\circ} \mathrm{C}\right.$ for $5 \mathrm{~h}$ ) in sealed quartz tube for the synthesis of $(\text { Culn })_{x} Z n_{2(1-x)} S_{2}(0 \leq x \leq 1)(3.5-1.4 \mathrm{eV})$ solid solutions. ${ }^{190}$ For very low CulnS $S_{2}$ content $(x<0.05)$, discontinuous discrete energy levels were formed in the system (Fig. 15b). Above this composition, continuous VB is formed and monotonous red shift to visible region occurs. ${ }^{190}$ Among the solid solutions synthesized, (Culn) $)_{0.09} Z_{1.82} \mathrm{~S}_{2}$ evidenced moderate photocatalytic activity for $\mathrm{H}_{2}$ production $\left(7 \mu \mathrm{mol} \mathrm{h}^{-1}\right)$ from aqueous solutions containing sacrificial agents $\left(\mathrm{K}_{2} \mathrm{SO}_{3}\right)$ under visible light irradiation. ${ }^{190}$ The same photocatalyst with $0.5 \mathrm{wt} \%$ of co-catalysts $(\mathrm{Pt})$ loading displayed an enhanced activity for $\mathrm{H}_{2}$ production $\left(684 \mu \mathrm{mol} \mathrm{h}{ }^{-1}\right)$ with an apparent quantum yield of $12.5 \% .{ }^{190}$

Following the successive visible light activity for $\mathrm{H}_{2}$ production using the above two different chalcopyrite (Ag or $\mathrm{CulnS}_{2}$ )-ZnS photocatalysts, Tsuji et al. developed further the heat treatment technique for solid solution synthesis. ${ }^{138}$ They reduced the heat treatment temperature from $850{ }^{\circ} \mathrm{C}$ down to $600{ }^{\circ} \mathrm{C}$ and increased the heat treatment duration of complex single source solid solution precursor from $5 \mathrm{~h}$ to $20 \mathrm{~h} .{ }^{138} \mathrm{ZnS}-\mathrm{CuInS}_{2}-\mathrm{AgInS} \mathrm{S}_{2}$ solid solutions were synthesised through improved heat treatment (reduced temperature and prolonged heat treatment) and compared in terms of photocatalytic activity to $\mathrm{ZnS}-\mathrm{CuInS}_{2}$ and $\mathrm{ZnS}-\mathrm{AgInS} \mathrm{S}_{2}$ solid solution photocatalysts. Prior to photocatalytic studies, all three different solid solutions were loaded with $0.75 \mathrm{wt} \%$ of ruthenium $(\mathrm{Ru})$ co-catalysts on their surfaces. The $(\mathrm{CuAg})_{0.15} \mathrm{In}_{0.3} \mathrm{Zn}_{1.4} \mathrm{~S}_{2}$ solid solution with the aid of co-catalysts ( $\mathrm{Ru}$ ) exhibited the maximum photocatalytic activity for $\mathrm{H}_{2}$ production $\left(2.3 \mathrm{mmol} \mathrm{h}^{-1}\right)$ from aqueous solution containing sacrificial agents $\left(\mathrm{K}_{2} \mathrm{SO}_{3}\right.$ \& $\left.\mathrm{Na}_{2} \mathrm{~S}\right) \cdot{ }^{138}$

Most of the solid solution nanomaterials synthesized so far have specifically targeted the control of the physicochemical properties by the variation of chemical composition. More specifically, the photoinduced electron transfer rate was heavily altered in these ternary-based solid solution by the electronic energy levels through the composition of the solid solution. Concurrent control of size and composition is a preferable strategy to obtain optimum photochemical properties in ternary based solid solutions. The first synthesis of size controlled solid solution ( $\mathrm{ZnS}-\mathrm{AgInS}_{2}$ ) was reported by Gabka et al. for the production of NCs of $\mathrm{ZnS}-\mathrm{AgInS} \mathrm{S}_{2}$ solid solution photocatalysts of $c a$. 2-10 nm in size. These NCs displayed color tunable photoluminescence (PL) by simultaneous modulation of NC's size, shape and composition. ${ }^{191}$ Subsequently, Tatsuya et al. reported the size controlled synthesis of ZnS-AgInS 2 solid solution NCs with a fixed composition without changing their particle shape via thermal reaction of the metal acetate with thiourea. ${ }^{192}$ Due to quantum size effect, the difference in $\mathrm{H}_{2}$ evolution potential $\left(E\left[\mathrm{H}^{+} / \mathrm{H}_{2}\right],-0.76 \mathrm{~V}\right.$ vs. NHE) and the $\mathrm{CB}$ edge potential of NCs increased with a decrease in particle size. ${ }^{192}$ Each composition of $\mathrm{ZnS}-\mathrm{AgInS} \mathrm{S}_{2}$ solid solution NCs with decreased particle size provided an enhanced $\mathrm{H}_{2}$ evolution rate. However, the $\mathrm{H}_{2}$ production rate decreased with a further decrease in particle size due to the formation of defect sites/deeper trap sites. ${ }^{192}$ The highest photocatalytic activity was observed for $(A g \ln )_{x} Z n_{2(1-x)} S_{2}(0 \leq x \leq 1)$ solid solutions having both optimum sizes of about 4.2-5.5 nm and energy gap of 2.3-2.4 eV. ${ }^{192}$

In conclusion, solid solution photocatalysts can exhibit very high activity under visible/UV irradiation as optimum balance between required redox potentials and absorption band edge. Simultaneous modulation of size and composition has now gained importance for a more precise tuning of the electronic levels depending on the Chunping Xu, Prasaanth Ravi Anusuyadevi, Cyril Aymonier, Rafael Luque, Samuel Marre. Nanostructured materials for photocatalysis. Chemical Society Reviews, Royal Society of Chemistry, 2019, 48 (14), pp.3868-3902. 〈10.1039/C9CS00102F). 〈hal-02185643) 
required photochemical properties. The main drawbacks or limiting steps in the synthesis of solid solution photocatalysts include (i) the precursor preparation step and (ii) the cost of the single source precursor. An overview of the synthetic methodologies and synthesis conditions of solid solution photocatalysts along with heterogeneous photochemical systems is reported in Table 3.

\section{Nanocomposite photocatalysts}

An advanced photocatalyst must exhibit two critical features: (i) an ameliorated light absorption capacity and (ii) an enhanced photocatalytic performance. These crucial features provide insights for design of composite photocatalysts by coupling two or three different SCs together, the coupling based on the energy exchange between SCs with different electronic structures. Unlike SC-metal composite systems, SC-SC coupled systems feature a composite in which both materials individually absorb the photonic radiation, resulting in harvesting more photonic energy. The first crucial requirement of enhanced light absorption is satisfied here.

Whenever a SC is coupled to a different SC, it results in a heterostructure with three possible different types of heterojunctions depending on the respective position of CB \& VB levels of each SC: (i) straddling gap (type I) (ii) staggered gap (type II) and (iii) broken gap (type III) (Fig. 16).

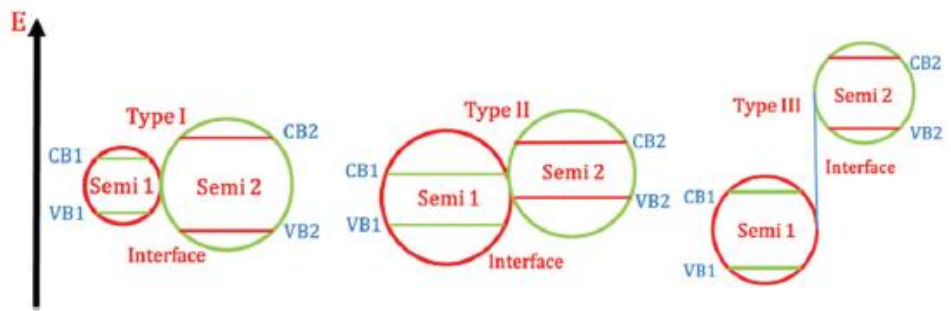

Fig. 16 Schematic representation of energy gap of three types of SC-SC heterojunctions.

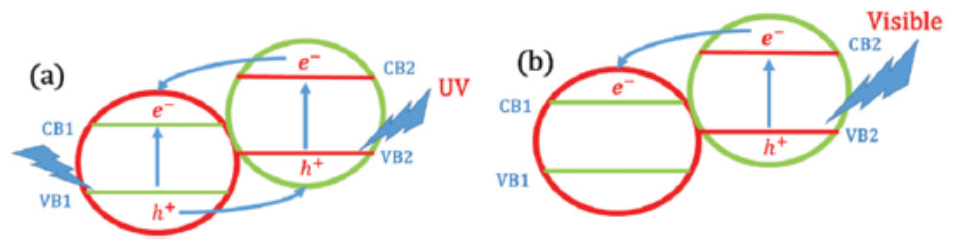

Fig. 17 Band gap diagram of type-II heterojunctions illustrating the photo-generation of charge carriers and efficient separation of them upon (a) UV excitation and (b) visible light excitation.

The vectorial transfer of electrons and holes in these SC-SC coupled heterostructured junctions are determined by the band gap, the electron affinity (bottom edge of $\mathrm{CB}$ ) and the work function (top edge of the $\mathrm{VB}$ ) of the coupled semiconductors.

Within the three types of heterojunctions SCs, type-II hetero-composite system is most desirable for photocatalysis. The difference in chemical potential (arising from the appropriate position of band edge potentials) (VB \& CB of semiconductor $2>V B$ \& CB of semiconductor 1 ) between the two different SCs in type II system results in band bending at the interface of the SCs. Band bending phenomenon instigates an electric field, which drives the electrons and holes of SCs upon photoexcitation in the opposite direction, leading to spatial separation of photon generated charge carriers consequently enhancing their photocatalytic activity. ${ }^{193,194}$

Regularly, such type-II systems are designed in such a way that it results in photocatalyst possessing enhanced light absorption and efficient charge separation. To have an enhanced light absorption, heterojunction composite 
materials are generally composed of one $\mathrm{SC}$ active in the $\mathrm{UV}$ region $\left(\mathrm{TiO}_{2}\right.$ or $\left.\mathrm{ZnO}\right)$ while the other material is active in the visible region ( $\mathrm{CdS}, \mathrm{CdSe}$, etc.). When type-II composite materials are activated by UV radiation, both the band gaps are excited, electrons migrate from the $C B 2$ to $C B 1$, holes migrate from the VB1 to VB2, thus resulting in efficient separation of charge carriers (Fig. 17a).

In the case of visible light excitation, only the narrow band gap material is excited, the electrons from CB2 migrate to CB1 and holes remain within the VB2, resulting in efficient charge separation (see Fig. 17b). Thus in these SC-SC coupled systems having type-II heterojunction, two critical conditions are satisfied, enhanced light absorption and efficient charge separation resulting in higher photocatalytic performance.

\section{Considerations of type-II nanocomposite photocatalytic systems}

Importance of SC $1 / \mathrm{SC} 2$ ratio. The light absorption limit of type-II composites is determined by the band gap of the narrower SC, active in the visible region. The absorption intensity of the composite can be increased by increasing the amount of narrow SC. Nevertheless, this does not necessarily enhance the photocatalytic performance of the composite system, as it has been seen in examples, including AgI-BiOI composite systems. ${ }^{195}$ Consequently, determining the optimal composition of both SCs in type-II systems is crucial to reach an appropriate balance between the intensity of light absorption and photocatalytic performance.

Importance of interfaces. In SC-SC nanocomposite systems formed between diverse SCs, there are possibilities for the presence of defects at the material interface due to lattice mismatch. These defects can trap the photogenerated electrons or holes leading to recombination. This prevents the optimum use of photogenerated electrons and holes for redox reactions. In contrast, the lattice mismatch can lead to an electric field at the interface between the two materials, which separates the charges further leading to higher photocatalytic activity. The quality of the heterogeneous interface stands to be another crucial factor influencing the photocatalytic performance. ${ }^{193}$ In order to obtain high quality interfaces with less number of defects, high temperature annealing is usually employed in the synthetic methodologies. The annealing temperature is critical and determines the quality of the interface, which ultimately affects the photocatalytic performance, as exemplified in the case of $\mathrm{Bi}_{2} \mathrm{O}_{3}-\mathrm{SrTiO}_{3}{ }^{196}$ The quality of the heterojunction interfaces in various nanocomposites can also be improved by careful selection of appropriate synthetic methods.

\section{p-n type junction composite systems}

Apart from conventional type-II heterojunctions, basically made up of n-type SCs, another type of type-II system has been extensively reported formed by coupling $n$-type and $p$-type SCs, resulting in a heterojunction called $p-n$ type junction. This is an exceptional type of heterojunction which possesses the previously mentioned advantages of composite systems (i.e. increased light absorption limit and effective charge carrier separation). Additionally, these $\mathrm{p}-\mathrm{n}$ type junction composites possess an internal electric field at the interface formed between the SCs. This field further intensifies the charge separation process, leading to an enhancement of photocatalytic performance. Specifically, reported $p-n$ junction type-II photocatalysts exhibit a higher reductive activity as compared to its individual constituents, with a lower oxidative activity. This is because under equilibrium conditions, when an internal electric field is formed at the interface of the $p-n$ junction composite material, the $p$-type becomes negatively charged and the n-type becomes positively charged. Upon excitation, the holes start moving towards the negative side and electrons towards the positive side, where the $p$-type semiconductor behaves as a hole trap and scavengers, unfavourable for photocatalytic oxidation reactions.

These $\mathrm{NCs}$ include $\mathrm{Cu}_{2} \mathrm{O} / \mathrm{TiO}_{2}, \mathrm{NiO} / \mathrm{TiO}_{2}, \mathrm{p}-\mathrm{ZnO} / \mathrm{n}-\mathrm{TiO}_{2}, \mathrm{CuBi}_{2} \mathrm{O}_{4} / \mathrm{Bi}_{2} \mathrm{WO}_{6}, \mathrm{CO}_{3} \mathrm{O}_{4} / \mathrm{ZnO}$ and $\mathrm{Cu}_{2} \mathrm{O} / \mathrm{In}_{2} \mathrm{O}_{3} .{ }^{197-201}$

\section{$\mathrm{TiO}_{2}$-Based nanocomposite photocatalysts}

$\mathrm{TiO}_{2}$ photocatalysts have been tremendously studied for several decades due to their very high oxidation ability, high photostability and low cost.202,203 Still, the use of titania systems is hindered due to its wide band gap (3.2 eV) of anatase phase, requiring UV irradiation $(\lambda<380 \mathrm{~nm})$ for photocatalytic activation. 204 On other hand, CdS is a relatively narrow band gap SC $(2.4 \mathrm{eV})$, extensively researched and modified (see section on solid solution photocatalysts) for $\mathrm{H} 2$ production from water splitting reactions under visible light irradiation. The growth of $\mathrm{CdS}$ on 
$\mathrm{TiO}_{2}$ results in a $\mathrm{TiO}_{2} / \mathrm{CdS}$ type II heterojunction, where upon illumination by visible light, photo-generated electrons from $\mathrm{CB}$ of $\mathrm{CdS}$ are transferred to $\mathrm{CB}$ of $\mathrm{TiO}_{2}$ and holes remain within $\mathrm{CdS}$ (Fig. 18b), resulting in a more efficient charge separation as compared to that of the two individual SCs, which ultimately increases photocatalytic efficiency.205 Different types of $\mathrm{TiO}_{2} / \mathrm{CdS}$ nanocomposites have been synthesized by different techniques including (i) CdS QDs sensitized in ordered mesoporous titania through ion-exchange route205 and (ii) CdS NPs coated on $\mathrm{TiO}_{2}$ nanotubes via wet chemical methods. ${ }^{205} \mathrm{Vu}$ et al. additionally reported a non-noble co-catalyst loaded $\mathrm{TiO}_{2} / \mathrm{CdS} \mathrm{NCS}$ $\left(\mathrm{Ni}-\mathrm{TiO}_{2} / \mathrm{CdS}\right){ }^{206}$ This system comprised $\mathrm{TiO}_{2}$ nanorods, NPs of $\mathrm{CdS}$ and $\mathrm{Ni}$ clusters. Capped $\mathrm{TiO}_{2}$ were synthesized through a solvothermal route featuring surfactant-controllable nanorod lengths. On these nanorods, CdS NPs were grown using a colloidal synthesis, resulting in hybrid $\mathrm{TiO}_{2} / \mathrm{CdS}$ nanocomposites. Subsequently, co-catalyst (Ni) clusters were selectively deposited on NCs via a photodepositon route. A schematic illustration of the synthetic route for $\mathrm{Ni}-\mathrm{TiO}_{2} / \mathrm{CdS}$ nanocomposites is shown in Fig. 18 . Ni-TiO $/$ /CdS exhibited high photocatalytic activity for $\mathrm{H}_{2}$ production $\left(151 \mu \mathrm{mol} \mathrm{g}^{-1}\right)$ from aqueous solutions containing sacrificial agents (ethanol), compared to the activity of CdS $\left(3.4 \mu \mathrm{mol} \mathrm{g}^{-1}\right)$ under visible light irradiation. Such activity (44 times higher than CdS) was reported to be achieved due to the enhancement of charge separation upon photoexcitation by charge transfers from $\mathrm{CdS}$ to $\mathrm{TiO}_{2}$ nanorods and then to the co-catalyst (Fig. 18b). Besides traditional nanocomposites prepared by coupling UV (wide band gap) and visible light (narrow band gap) active SCs, nanocomposites synthesized by combining two wide band gap SCs were also found to be active under visible light irradiation. Such visible light activity is due to the introduction of impurities and defect levels in the forbidden gap of the nanocomposite. $\mathrm{TiO}_{2} / \mathrm{ZnO}$ is an example of such visible light active systems, formed by combining two wide band gap UV active $\mathrm{SCs}\left(\mathrm{TiO}_{2}(3.32 \mathrm{eV})\right.$ and $\mathrm{ZnO}$ $(3.37 \mathrm{eV}))$. Zhang et al. synthesized $\mathrm{TiO}_{2} / \mathrm{ZnO}$ nanocomposites via a two-step method consisting of homogeneous hydrolysis and low temperature crystallization. ${ }^{207}$

(a)
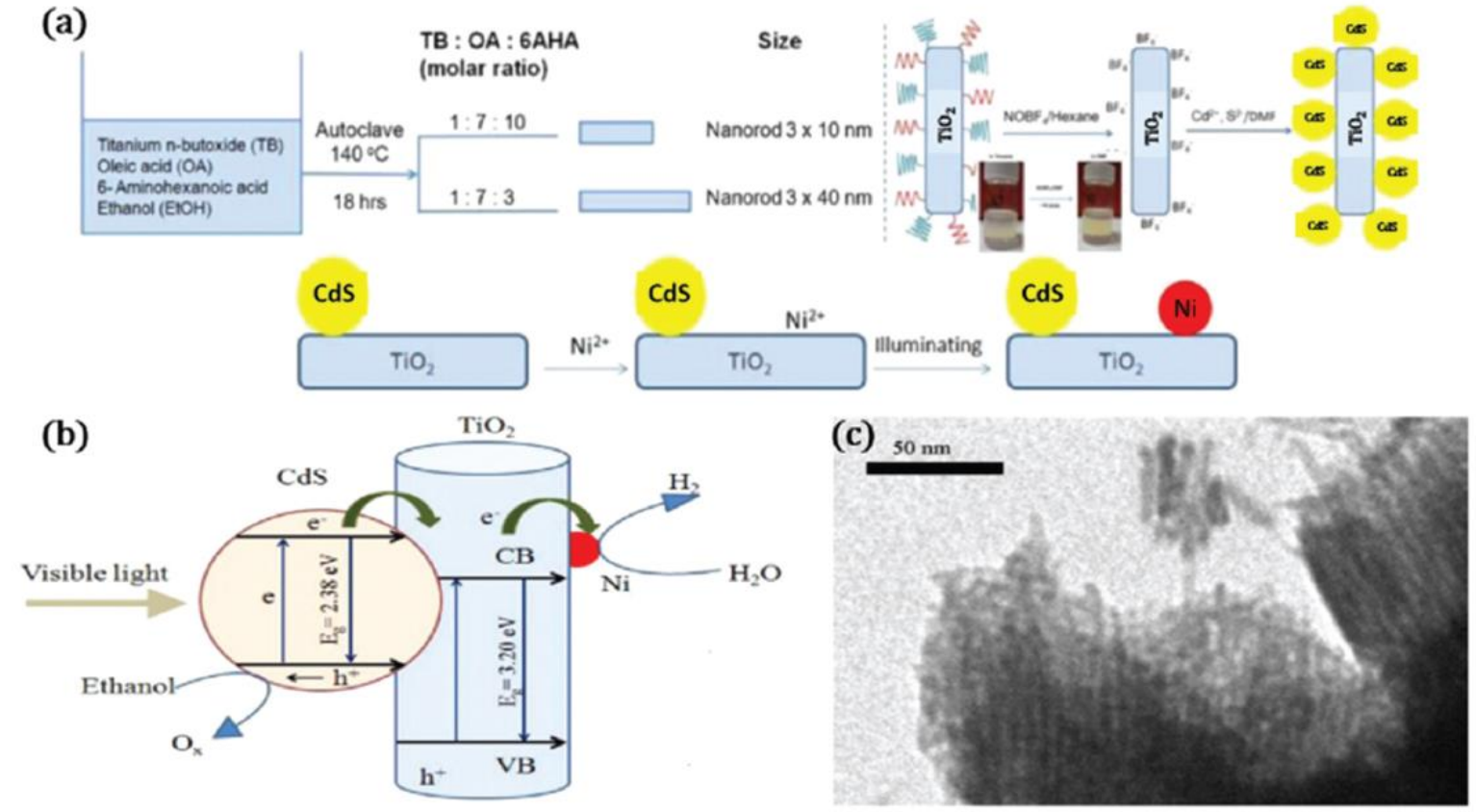

Fig. 18 (a) Illustration of synthetic methodology for obtaining $\mathrm{Ni}-\mathrm{TiO}_{2} / \mathrm{CdS}$ photocatalysts. ${ }^{206}$ (b) Charge transfer pathway in $\mathrm{Ni}-\mathrm{TiO}{ }_{2} / \mathrm{CdS}$ nanocomposite upon visible light irradiation for $\mathrm{H}_{2}$ production from aqueous ethanol solution. ${ }^{206}$ (c) TEM image of $\mathrm{TiO}_{2}$ nanorods. ${ }^{206}$ (a, b and c) (Reproduced with permission from ref. 206. Copyright 2018 American Chemical Society).

The observed absorption red shift of the $\mathrm{TiO}_{2} / \mathrm{ZnO}$ nanocomposite system into the visible region was claimed to be due to the introduction of dopant energy levels in the $\mathrm{TiO}_{2}$ forbidden band gaps by the $\mathrm{Zn}^{2+}$ cations. ${ }^{207}$ Importantly, $\mathrm{TiO}_{2} / \mathrm{ZnO}$ composite exhibited an improved photocatalytic efficiency with respect to $\mathrm{TiO}_{2} / \mathrm{ZnO}$ nanocomposites successfully synthesized through hydrothermal, spin coating and atomic layer deposition techniques (where these strategies were also found to be economically unfavourable in the long $\left.\operatorname{run}^{208-210}\right)$. Hussein et al. synthesized 
mesoporous coupled $\mathrm{TiO}_{2} / \mathrm{ZnO}$ composite with varying composition ( $\mathrm{TiO}_{2}: \mathrm{ZnO}$ ) employing a facile and cheap sol-gel route. As synthesized materials with 30 and $50 \mathrm{wt} \%$ of $\mathrm{ZnO}$ coupled with $\mathrm{TiO}_{2}$ exhibited high photocatalytic activity for $\mathrm{H}_{2}$ production $\left(770 \mu \mathrm{mol} \mathrm{g}{ }^{-1}\right.$ and $739 \mu \mathrm{mol} \mathrm{g}^{-1}$, respectively) from aqueous solutions containing methanol as an electron acceptor, under UV irradiation as compared to the moderate activity of commercially available $\mathrm{TiO}_{2}$, Degussa P25 (356 $\left.\mu \mathrm{mol} \mathrm{g}^{-1}\right){ }^{211}$ Prasannalakshmi et al. reported the synthesis of rod shaped $\mathrm{TiO}_{2} / \mathrm{ZnO} \mathrm{NCs}$ via sol-gel method, which exhibited a high activity for the photocatalytic degradation of organic dyes (brilliant green (BG) and methylene blue $(\mathrm{MB})$ ) under solar irradiation compared to the activity exhibited by their corresponding individual SCs. ${ }^{212}$ Similar to the $\mathrm{TiO}_{2} / \mathrm{ZnO}$ system, $\mathrm{TiO}_{2} / \mathrm{ZnS}$ photocatalyst is yet another interesting visible light active system composed of two different UV active $\mathrm{SCs}: \mathrm{TiO}_{2}(3.2 \mathrm{eV})$ and $\mathrm{ZnS}(3.6 \mathrm{eV})$. The visible light activity is due to the formation of new energy levels as a result of sulphur doping within the forbidden band gap of $\mathrm{TiO}_{2}$.

Štengl et al. synthesized spherical agglomerates of $\mathrm{TiO}_{2} / \mathrm{ZnS}$ nanocomposites consisting of alternate nanosized titania and sphalerite crystalline islands via homogeneous hydrolysis route. ${ }^{213}$ The resultant $\mathrm{TiO}_{2} / \mathrm{ZnS}(2.9 \mathrm{eV})$ nanocomposite displayed the highest activity for photocatalytic degradation of orange II dye under visible irradiation $(\lambda=400 \mathrm{~nm})$ (degradation constant for nanocomposite, $k=0.0069 \mathrm{~min}^{-1}$ ) as compared to the activities of commercially available Degussa P25 (3.1 eV) $\left(k=0.0022 \mathrm{~min}^{-1}\right)$ and pure anatase $(3.2 \mathrm{eV})\left(k=0.0009 \mathrm{~min}^{-1}\right)$. The enhanced photocatalytic activity was attributed to the reduced charge transfer resistance and increased surface area for the reactant adsorption. ${ }^{213} \mathrm{NPs}$ of $\mathrm{TiO}_{2}$ and $\mathrm{TiO}_{2} / \mathrm{ZnS}$ nanocomposites were also recently reported to be synthesized via sol-gel method, where the $\mathrm{TiO}_{2} / \mathrm{ZnS}$ system exhibited enhanced activity for the degradation of organic dyes (BG and $\mathrm{MB}$ ) under solar irradiation compared to $\mathrm{TiO}_{2} \mathrm{NPs}^{214}$

\section{ZnO-Based nanocomposite photocatalysts}

ZnO SCs in nanosize regime possesses certain advantageous features including (i) a high exciton binding energy of 60 meV (as comparison $\mathrm{TiO}_{2}$ has $4 \mathrm{meV}$ ), (ii) a high electron mobility of $200 \mathrm{~cm}^{2} \mathrm{~V}^{-1} \mathrm{~s}^{-1}\left(\mathrm{TiO}_{2}\right.$ has $30 \mathrm{~cm}^{2} \mathrm{~V}^{-1} \mathrm{~s}^{-1}$ ), (iii) a facile adaptation/tuneability of the structure, (iv) an anisotropic growth and (v) an simplicity of crystallization. ${ }^{215-220}$

In spite of such distinct features, both $\mathrm{ZnO}$ and $\mathrm{TiO}_{2}$ suffer from low photocatalytic efficiency due to higher rate of recombination of photoinduced electrons and holes compared to the rate of charge transfer to the surface bound redox reactions. ${ }^{221}$ Additionally, they exhibit very low visible light activity due to their wide band gaps. Coupling SC to $\mathrm{ZnO}$ resulting in type-II band offset is generally of two types. $\mathrm{ZnO}$ can either be coupled to similar binary oxide wide band gap SC (as seen in the case of $\mathrm{TiO}_{2} / \mathrm{ZnO} \mathrm{NC}$ ). The second type of coupling involves growing of lattice matched photosensitizer inorganic crystals on $\mathrm{ZnO}$ surface, which ensures a maximum harvesting of visible light and consequently an enhanced photocatalytic activity. ${ }^{222}$ The sensitizers should possess a narrow band gap and appropriate band edge potentials for the transfer of the photogenerated electrons from its $\mathrm{CB}$ to $\mathrm{ZnO} C B$ under visible light activity, leading to enhanced separation of charge carriers. ${ }^{223}$ Among various inorganic sensitizers, the coupling of $\ln _{2} \mathrm{~S}_{3}$ to $\mathrm{ZnO}$ has been recently reported of interest as $\ln _{2} \mathrm{~S}_{3}$ possesses a narrow band gap (2-2.3 eV) with higher carrier mobility and good stability in photocatalysis. ${ }^{224}$ Khanchandani et al. reported the synthesis of $\mathrm{ZnO} / \mathrm{In}_{2} \mathrm{~S}_{3}$ core/shell nanorods array employing a soft chemistry approach consisting of surface functionalization route by using citric acid as functionalization agent (Fig. 19). ${ }^{225} \mathrm{ZnO}$ nanorods and $\ln _{2} \mathrm{~S}_{3} \mathrm{NPs}$ were synthesized via solvothermal method. $\mathrm{ZnO}$ nanorods were subsequently successfully coated with $\ln _{2} \mathrm{~S}_{3}$ employing a surface functionalization route (see Fig. 19). The one-dimensional $\mathrm{ZnO}$ nanorods structure is preferred here as it provides an optimum geometrical structure facilitating effective transport of charge carries and reduces the charge recombination to a certain extent within the $\mathrm{ZnO}$ nanostructures. ${ }^{226}$ 

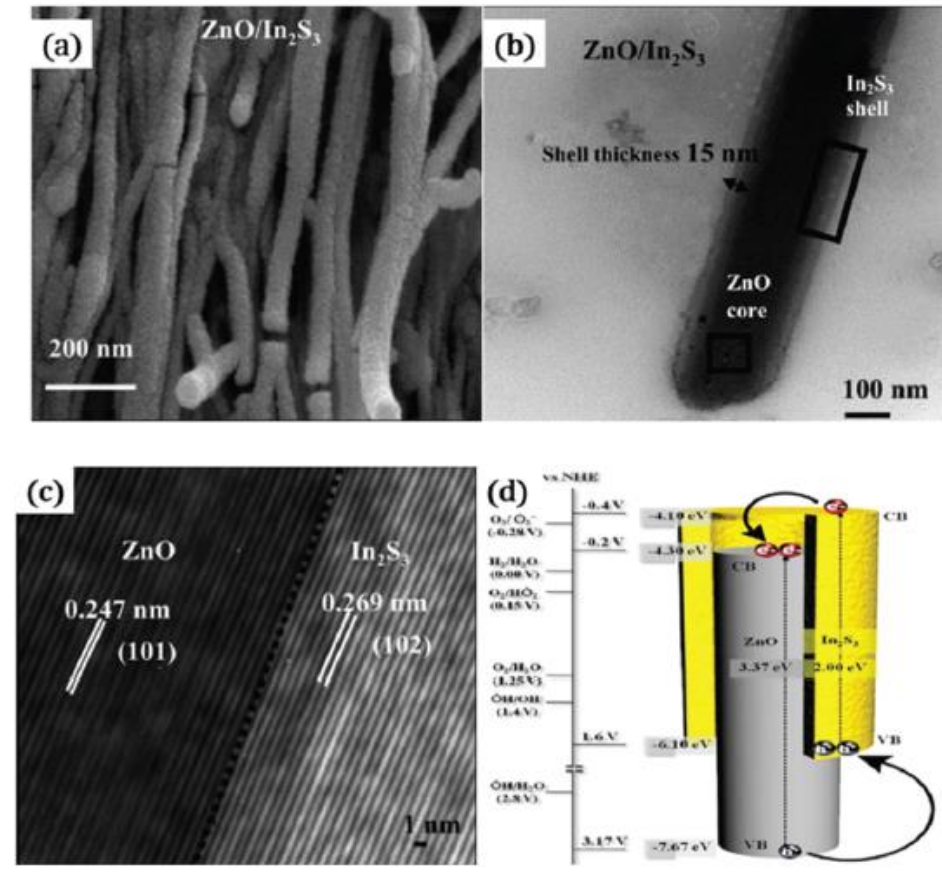

Fig. 19 (a) FESEM image of $\mathrm{ZnO} / \mathrm{ln}_{2} \mathrm{~S}_{3}$ core/shell nanorod arrays. (b and c) TEM and HRTEM of $\mathrm{ZnO} / \mathrm{In}_{2} \mathrm{~S}_{3}$ core/shell NCs. (d) Illustration of charge transfer and separation in NC systems. ${ }^{225}$ (a, b, c and d) (Reproduced with permission ref. 225. Copyright 2018 American Chemical Society).

As synthesized core/shell composites exhibited a type-II band offset as its absorption band edge shifted to the visible region (due to the incorporation of $\ln _{2} \mathrm{~S}_{3}$ ) and exhibited high photocatalytic activity (degradation constant, $k=0.0174$ $\mathrm{min}^{-1}$ ) for RhB dye degradation under visible light irradiation, compared to $\mathrm{ZnO}$ nanorods $\left(k=0.00039 \mathrm{~min}^{-1}\right)$ and $\mathrm{In}_{2} \mathrm{~S}_{3} \mathrm{NPs}\left(k=0.0042 \mathrm{~min}^{-1}\right)$. The enhanced photocatalytic activity of $\mathrm{ZnO} / \mathrm{In}_{2} \mathrm{~S}_{3}$ core/shell NCs (56 times higher than that of $\mathrm{ZnO}$ nanorods and 5 times higher with respect to $\ln _{2} \mathrm{~S}_{3} \mathrm{NPs}$ ) was due to the effectual separation of photoinduced charge carries, attributed to the type-II heterojunction formed between the two different SCs. ${ }^{225}$

Similarly to $\ln _{2} S_{3}$, CdS was used to form a type-II heterojunction nanocomposite with ZnO. As CdS possesses a narrow band (2.4 eV) gap for visible light activation, similar lattice constant to $\mathrm{ZnO}$ and high optical absorption coefficient. Khanchandani et al. extended the same surface functionalization route employed for $\mathrm{ZnO} / \mathrm{In}_{2} \mathrm{~S}_{3}$ nanocomposites to the synthesis of $\mathrm{ZnO} / \mathrm{CdS}$ nanorods core/shell array systems. Citric acid (CA) was used as the surface functionalization agent (Fig. 20). ${ }^{227}$ By varying the CA amount, the shell thickness of CdS was successfully tuned. The influence of the shell thickness on the photocatalytic activity of the nanocomposite was also reported. The authors synthesized $\mathrm{ZnO} / \mathrm{CdS}$ (core/shell) materials with three different shell thickness: $10 \mathrm{~nm}, 20 \mathrm{~nm}$ and $30 \mathrm{~nm}$. The absorption band edge of $\mathrm{ZnO}$ nanorods was red shifted to visible region when they are coated with $\mathrm{CdS}$ shell. The monotonous red shift to the visible region increased with an increase in the shell thickness. As compared to $\mathrm{ZnO}$ nanorods and CdS NPs, the core/shell nanocomposites displayed high activity for the photocatalytic degradation of RhB under simulated solar radiation. ${ }^{227}$ Within all nanocomposites with varying shell thickness, $\mathrm{ZnO} / \mathrm{CdS}$ with maximum shell thickness exhibited optimum photocatalytic activity due to an extended absorption in the visible region. 


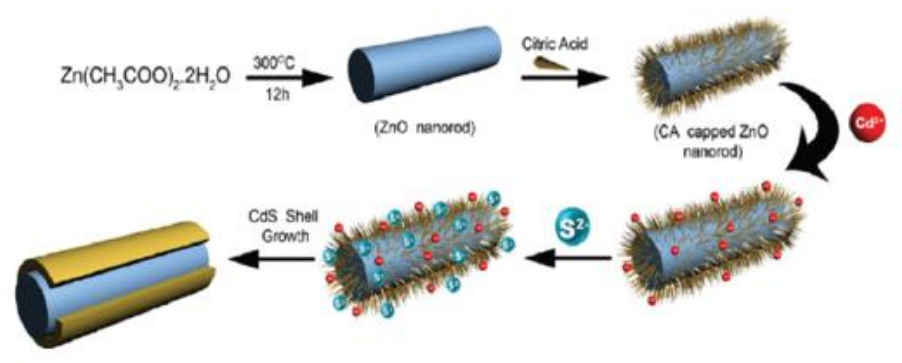

Fig. 20 Schematic depiction of the surface functionalization route for the synthesis of $\mathrm{ZnO} / \mathrm{CdS}$ core/shell NCs. ${ }^{227}$ (Reproduced with permission from ref. 227 (2012) Copyright 2018 American Chemical Society).

The degradation rate constant $\left(k\left(\mathrm{~min}^{-1}\right)\right)$ of $\mathrm{ZnO}$ nanorods, CdS NPs, $\mathrm{ZnO} / \mathrm{CdS}(10 \mathrm{~nm}$ shell thickness), $\mathrm{ZnO} / \mathrm{CdS}$ (20 $\mathrm{nm}$ shell thickness) and $\mathrm{ZnO} / \mathrm{CdS}$ (30 nm shell thickness) are $0.011,0.0035,0.019,0.025$ and $0.039 \mathrm{~min}^{-1}$, respectively.

\section{$\mathrm{SnO}_{2}$-Based nanocomposite photocatalysts}

Tin(iv) oxide $\left(\mathrm{SnO}_{2}\right)$ is also an ideal constituent in nanocomposite systems due to its wide band gap (3.6 eV) and $\mathrm{CB}$ edge potential $\left(E_{\mathrm{CB}}=0 \mathrm{~V}\right.$ vs. $\mathrm{NHE}$, at $\left.\mathrm{pH}=7\right)$, lower than the $\mathrm{CB}$ potential of most SCs implemented in photocatalytic organic mineralization/degradation reactions. Additionally, $\mathrm{SnO}_{2}$ is largely available at a low cost, possesses excellent chemical stability, high optical transparency in the visible range (97\%) and good electrical properties. ${ }^{228-232}$

Wang et al. fabricated $\mathrm{SnO}_{2} / \mathrm{TiO}_{2}$ nanocomposites by hydrothermally growing $\mathrm{SnO}_{2}$ on $\mathrm{TiO}_{2}$ nanofibers (synthesized by electrospinning technique). ${ }^{228}$ In contrast to this two-step synthesis (electrospinning + hydrothermal), Zhang et al. synthesized $\mathrm{SnO}_{2} / \mathrm{ZnO}$ nanocomposites via direct electrospinning technique. ${ }^{233}$ Both $\mathrm{SnO}_{2} / \mathrm{TiO}_{2}$ and $\mathrm{SnO}_{2} / \mathrm{ZnO}$ nanocomposites exhibited high photocatalytic activity for the degradation of RhB under UV light as compared to the reduced activities of their individual constituent SCs.

Iron oxide $\left(\alpha-\mathrm{Fe}_{2} \mathrm{O}_{3}\right)$ phases are frequently coupled to $\mathrm{SnO}_{2}$ and studied in the heterojunction domain for applications in photocatalysis, gas and liquid sensors. ${ }^{234-237} \alpha-\mathrm{Fe}_{2} \mathrm{O}_{3}$ is a n-type semiconductor with a narrow band gap $(2.2 \mathrm{eV})$ exhibiting poor photocatalytic performance due to small diffusion length of holes $(2-4 \mathrm{~nm})$. The efficient separation of photogenerated charges are observed when $\alpha-\mathrm{Fe}_{2} \mathrm{O}_{3}$ is coupled to $\mathrm{SnO}_{2}$.

Kang et al. synthesized necklace-like hierarchical $\mathrm{SnO}_{2} / \mathrm{Fe}_{2} \mathrm{O}_{3}$ nanocomposites employing a chemical vapour deposition route (CVD), growing hierarchically $\mathrm{Fe}_{2} \mathrm{O}_{3}$ hexagonal disks on nanocables consisting of $\mathrm{SnO}_{2}$ as core and epitaxial $\mathrm{Fe}_{2} \mathrm{O}_{3}$ as shell (Fig. 21a and b). As synthesized novel hierarchical $\mathrm{SnO}_{2} / \mathrm{Fe}_{2} \mathrm{O}_{3}$ system exhibited high photocatalytic activity (complete degradation in $2.5 \mathrm{~h}$ ) for the degradation of $\mathrm{MB}$ under visible light as compared to pure $\mathrm{SnO}_{2}$ (synthesized by CVD, exhibited $83 \%$ degradation within $2.5 \mathrm{~h}$ ) and commercially available $\mathrm{Fe}_{2} \mathrm{O}_{3}(58 \%$ degradation of $\mathrm{MB}$ within $2.5 \mathrm{~h}) .{ }^{238}$ 


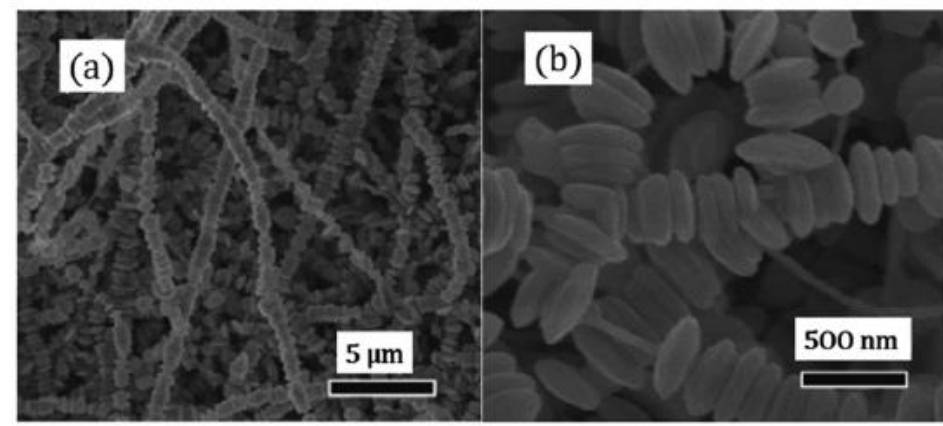

Fig. 21 (a and b) SEM image of hierarchical $\mathrm{SnO}_{2} / \mathrm{Fe}_{2} \mathrm{O}_{3} \mathrm{NCs}$ synthesized by CVD technique. ${ }^{238}$ Reprint with permission from J. Kang, Q. Kuang, Z. X. Xie and L. S. Zheng, Fabrication of the $\mathrm{SnO}_{2} / \alpha-\mathrm{Fe}_{2} \mathrm{O}_{3}$ hierarchical heterostructure and its enhanced photocatalytic property, J. Phys. Chem. C, 2011, 115, 7874-7879, Copyright 2018 American Chemical Society.

Xia et al. synthesized a non-core/shell $\mathrm{SnO}_{2} / \mathrm{Fe}_{2} \mathrm{O}_{3}$ nanocomposite through a co-precipitation technique, where the resultant composite reveals exalted activity for the degradation of acid blue 62 dye under visible light. These $\mathrm{SnO}_{2} / \mathrm{Fe}_{2} \mathrm{O}_{3} \mathrm{NCs}$ degraded $98 \%$ of the dye within one hour, which is 3.6 times higher than the activity revealed $(27 \%$ degradation of dye in one hour) by commercially available titania (Degussa P25) photocatalyst. ${ }^{234}$

$\mathrm{SnO}_{2} / \mathrm{SnS}_{2}$ is yet another visible light active nanocomposite system developed and studied especially for photocatalytically mediated environmental remediation applications. Tin sulfide $\left(\mathrm{SnS}_{2}\right)$ is a n-type narrow band gap SC (2.18-2.44 eV), standing as an ideal compound for dye sensitization studies due to the absence of surface states associated with dangling bonds. These dangling bonds act as traps for the photogenerated electrons. ${ }^{239}$ Tin sulphide has been therefore employed as photocatalyst in the visible light region due to its thermal, oxidative stability in air and stable existence without corrosion in acidic and neutral solutions. ${ }^{240}$ Zhang et al. synthesized non-core/shell type $\mathrm{SnO}_{2} / \mathrm{SnS}_{2}$ nanocomposites with a firm interface contact via in situ oxidation of $\mathrm{SnS}_{2}$ under hydrothermal (in the presence of $\mathrm{H}_{2} \mathrm{O}_{2}$ ) conditions. ${ }^{241}$ By varying the duration of oxidation and the amount of $\mathrm{H}_{2} \mathrm{O}_{2}$, the $\mathrm{SnO}_{2}$ content in the nanocomposite was successfully varied (see HR-TEM image, Fig. 22). As-resultant $\mathrm{SnO}_{2} / \mathrm{SnS}_{2}$ (18.1 mass\% of $\mathrm{SnO}_{2}$ ) exhibited high photocatalytic activity (degradation constant, $k=9.260 \mathrm{~min}^{-1}$ ) for $\mathrm{MO}$ degradation under visible light as compared to the activity of $\mathrm{SnS}_{2}\left(k=5.941 \mathrm{~min}^{-1}\right)$ (synthesized by hydrothermal reactions) and physical mixture of $\mathrm{SnO}_{2} / \mathrm{SnS}_{2}\left(7.094 \mathrm{~min}^{-1}\right) \cdot{ }^{241}$
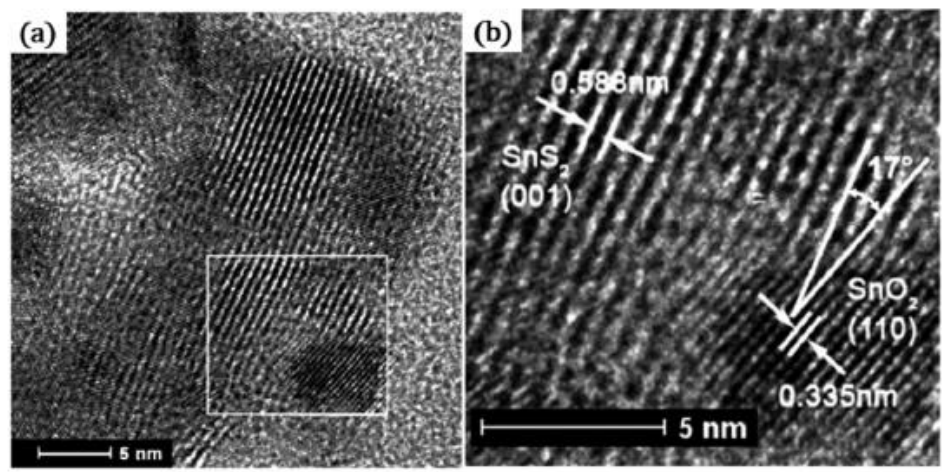

Fig. 22 (a) HR-TEM of $\mathrm{SnS}_{2} / \mathrm{SnO}_{2}\left(18.1 \mathrm{wt} \%\right.$ of $\mathrm{SnO}_{2}$ ). (b) Enlargement of the interface observed in figure. ${ }^{241}(\mathrm{a}$ and $\mathrm{b}$ ) (Reproduced with permission from ref. 241. Copyright 2018 American Chemical Society). 


\section{Magnetically separable nanocomposite photocatalysts (Fe304-based systems)}

Photocatalysts with magnetic supports or magnetically separable materials $\left(\mathrm{Fe}_{3} \mathrm{O}_{4}\right)$ coupled to $\mathrm{SCs}$ forming a nanocomposite can be easily separated from the liquid phase by applying an external magnetic field. This allows overcoming the limitations associated with separation techniques, resulting in high recovery and reusability of the photocatalysts. ${ }^{242}$ Importantly, iron oxide $\left(\mathrm{Fe}_{3} \mathrm{O}_{4}\right)$ undergoes phase transition, when subjected to heat treatment at higher temperature $\left(400^{\circ} \mathrm{C}\right)$. This phase transition leads to a loss of the magnetic properties. Since most of the magnetic nanocomposites were synthesized via sol-gel process (where heat treatment is crucial) the preparation of highly and stable photoactive titania-magnetic nanocomposite with enhanced magnetic properties is rather challenging. ${ }^{243}$ The essential criteria to design highly photocatalytic active magnetic nanocomposite system using $\mathrm{Fe}_{3} \mathrm{O}_{4}(0.1 \mathrm{eV}) \mathrm{SC}$ involves the construction of nanocomposites with special structures or the development of special types of interface phase junction (e.g. insertion of an insulation layer) between the magnetic materials and the active photocatalysts.

In the perspective of active SC photocatalysts, bismuth oxyhalides $\mathrm{BiOX}(\mathrm{X}=\mathrm{Cl}, \mathrm{Br}$ or I) of the group $\mathrm{V}-\mathrm{VI}-\mathrm{VII}$ ternary SCs have attracted significant attention in recent times due to their optical and crystalline properties. BiOX SCS possess tetragonal matlockite structures in which $\left[\mathrm{Bi}_{2} \mathrm{O}_{2}\right]$ layers are interleaved between halogen layers, resulting in a unique open layered structure and complex band structure. Such crystalline structure possesses large space between the layers $\left(\left[\mathrm{Bi}_{2} \mathrm{O}_{2}\right]\right.$ and halogen layers), which facilitates the separation of photo-induced electron-hole pairs. Additionally, it exhibits low recombination probability of photo induced electron-hole pairs due to its indirect band gap, thus resulting in a significantly improved photocatalytic activity. ${ }^{244-246}$ Extensive reviews have been published on BiOX (X $=\mathrm{Cl}, \mathrm{BR}, \mathrm{I}) \mathrm{SCs}$, detailing their recent synthetic developments and photocatalytic applications: organic pollutants degradation, fuel production and removal of heavy metals. ${ }^{247-250}$

Amongst $\mathrm{BiOX}(\mathrm{X}=\mathrm{Cl}, \mathrm{BR}, \mathrm{I}) \mathrm{SCs}$, BiOCl exhibits the highest photocatalytic activity under UV irradiation, with comparably higher activity to that of $\mathrm{TiO}_{2}$ for the degradation of dyes. Its activity under visible light irradiation can be additionally improved via preparation of heterojunction nanocomposites. ${ }^{251} \mathrm{Zhang}$ et al. synthesized a $\mathrm{Fe}_{3} \mathrm{O}_{4} / \mathrm{BiOCl}$ nanocomposite via colloidal synthesis, where $\mathrm{BiOCl}$ (bismuth oxychloride) flakes are inlaid with $\mathrm{Fe}_{3} \mathrm{O}_{4} \mathrm{NPs}$ (see Fig. $23 \mathrm{~b}$ and TEM image in Fig. 24b).

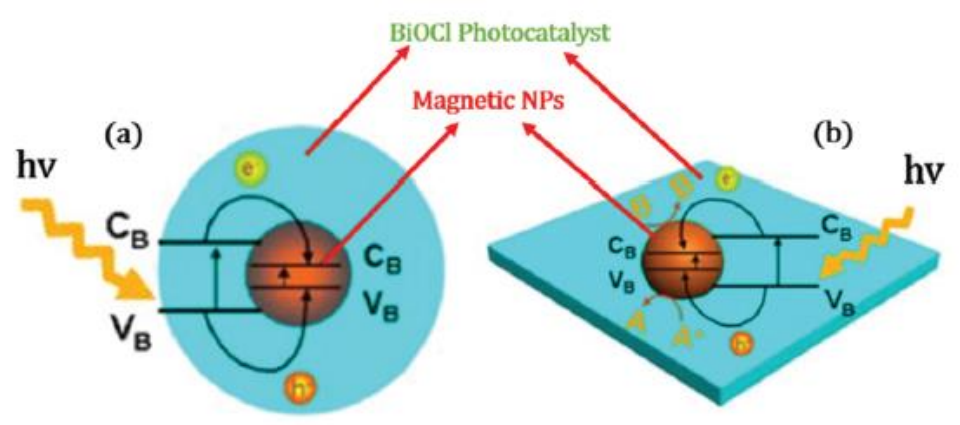

Fig. 23 (a) Illustration of conventional core shell $\mathrm{Fe}_{3} \mathrm{O}_{4} / \mathrm{BiOCl} \mathrm{NCs}$ with charge transfer route. (b) Coupled structure of $\mathrm{Fe}_{3} \mathrm{O}_{4} / \mathrm{BiOCl} \mathrm{NCs,} \mathrm{where}$ $\mathrm{Fe}_{3} \mathrm{O}_{4} \mathrm{NPs}$ are inlaid in the $\mathrm{BiOCl}$ nanoflakes. ${ }^{252}$ Reproduced with permission from ref. 252. (Copyright 2018 Elsevier). 


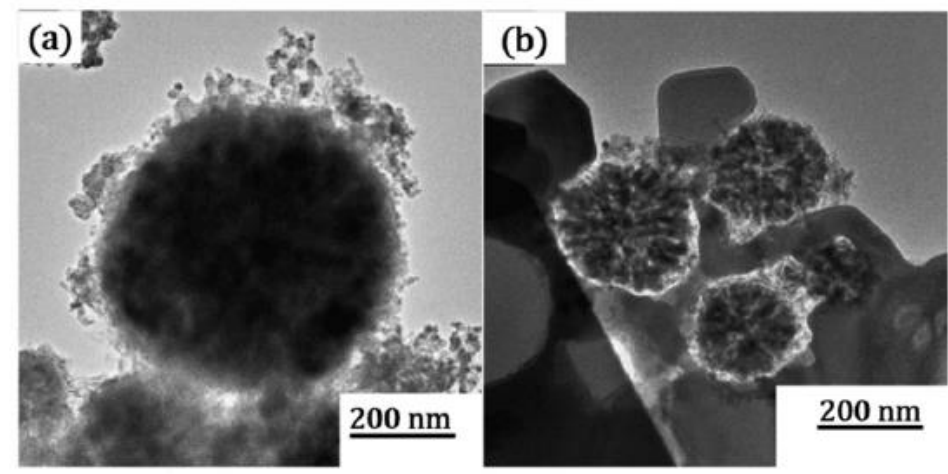

Fig. 24 (a) TEM image of conventional core/shell $\mathrm{Fe}_{3} \mathrm{O}_{4} / \mathrm{BiOCl} \mathrm{NCs}$. (b) TEM image of coupled $\mathrm{Fe}_{3} \mathrm{O}_{4} / \mathrm{BiOCl} \mathrm{NCs}^{252}$ (Reproduced with permission from ref. 252. Copyright 2018 Elsevier).

The as-obtained $\mathrm{Fe}_{3} \mathrm{O}_{4} / \mathrm{BiOCl}$ structure exhibited similar photocatalytic activity for the degradation of RhB dye under visible light as compared to the activity of $\mathrm{BiOCl}$ nanoflakes. Here, facile separation of photocatalysts could be achieved using an external magnetic field and the recycled catalysts maintained their photocatalytic activity even after five consecutive runs. ${ }^{252}$ In this particular system, the photocatalytic activity of $\mathrm{BiOCl}$ was preserved upon combination with the magnetic semiconductor due to the special type of coupled heterostructure, where the rate of charge transfer to redox reactions is higher than the rate of recombination, despite this being a type-I heterojunction..$^{252}$

\section{Chalcogenide nanocomposite photocatalysts (CdS/ZnS nanocomposites)}

Similar to $\mathrm{TiO}_{2} / \mathrm{Fe}_{3} \mathrm{O}_{4}$ and $\mathrm{Fe}_{3} \mathrm{O}_{4} / \mathrm{BiOCl}$ possessing type-I heterojunction, $\mathrm{CdS} / \mathrm{ZnS}$ nanocomposites are another type of hybrid heterostructures with type-I phase junction extensively employed in heterogeneous photocatalysis.

$\mathrm{CdS} / \mathrm{ZnS}$ nanocomposite was successfully synthesized using metal organic chemical vapour deposition (MOCVD) 253,254 $^{250}$ and wet chemical synthetic methods consisting of surface functionalization routes. ${ }^{255,256}$ Wang et al. synthesized 1-D (dimensional) CdS/ZnS nanocomposite with nanowire morphologies through a two-step mild solution method consisting in a solvothermal reaction. ${ }^{257}$ This synthetic strategy did not require any pre-treatment of the core's surface (CdS) to introduce any functional groups prior to shell growth. As synthesized CdS/ZnS core/shell nanowires (Fig. 25b) exhibited good photocatalytic activities for the degradation of 4-chlorophenol (4CP) (89\% of 4CP was degraded in $12 \mathrm{~h}$ ) under visible light compared to the activity of CdS nanowires (74\% degradation in $12 \mathrm{~h}$ ) and anatase- $\mathrm{TiO}_{2}$ (30\% degradation in $12 \mathrm{~h}$ of irradiation). ${ }^{257}$ Additionally, CdS/ZnS core/shell exhibited maximum photocatalytic activity for the degradation of MB dye under visible light irradiation (complete degradation in $6 \mathrm{~h}$ of irradiation) with respect to uncoated $\mathrm{CdS}$ nanowires (63\% of degradation in $6 \mathrm{~h}$ ) and anatase- $\mathrm{TiO}_{2}$ ( $68 \%$ degradation in $6 \mathrm{~h}) .{ }^{257}$ Despite being a type-I heterojunction, the present CdS/ZnS core/shell system exhibited enhanced photocatalytic activity because of the passivation of surface states in the CdS cores by the ZnS shell, which acts as surface traps for the photogenerated charge carriers. ${ }^{257}$ 


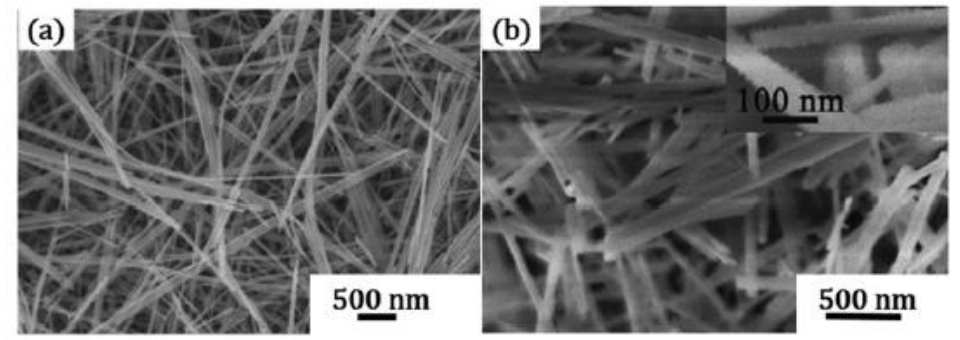

Fig. 25 (a) SEM image of CdS nanowires with $45 \mathrm{~nm}$ diameter. (b) SEM of $\mathrm{CdS} / \mathrm{ZnS}$ core/shell NCs with $60 \mathrm{~nm}$ diameter and shell thickness of 5-10 nm. The inset figure depicts the surface of the shell, which consists of ZnS NPs. ${ }^{257}$ ( $a$ and $b$ ) (Reproduced with permission from ref. 257 OPEN ACCESS, Copyright 2018 Springer).

\section{Mesoporous $\ln _{2} \mathrm{O}_{3} / \mathrm{Ta}_{2} \mathrm{O}_{5}$ nanocomposite systems}

Mesoporous tantalum oxide derived photocatalysts can exhibit fascinating mass transport properties. Intrinsically, they possess large surface, thin walls and good light harvesting capabilities. Potentially, they stand as ideal candidates for photocatalytic $\mathrm{H}_{2}$ production from water splitting reactions. Takahara et al. synthesized mesoporous $\mathrm{Ta}_{2} \mathrm{O}_{5}$ through a ligand-assisted templating method, which unveils photocatalytic activity for overall water decomposition. ${ }^{258}$ In contrast to mesoporous $\mathrm{Ta}_{2} \mathrm{O}_{5}$ materials, highly crystallized $\mathrm{Ta}_{2} \mathrm{O}_{5}$ materials provided negligible $\mathrm{H}_{2}$ production and no $\mathrm{O}_{2}$ production. The high photocatalytic activity of the mesoporous material is due to the efficient migration of electrons and holes through the thin walls of mesoporous $\mathrm{Ta}_{2} \mathrm{O}_{5}$, where the rate of migration of photogenerated charge carriers is higher in mesoporous $\mathrm{Ta}_{2} \mathrm{O}_{5}$ than the migration occurring in highly crystallized $\mathrm{Ta}_{2} \mathrm{O}_{5}$ samples, from the lattice to the surface. ${ }^{258}$ Even though the mesoporous structure possesses such advantageous features, it is highly limited because of the collapse of the porous structure and the decrease of the specific surface area during the template removal process, due to its very low thermal stability. ${ }^{258}$ Such limitation could be resolved by the introduction of a second component into the mesoporous structure..$^{259,260}$

Xu et al. synthesized mesoporous heterostructured $\ln _{2} \mathrm{O}_{3} / \mathrm{Ta}_{2} \mathrm{O}_{5} \mathrm{NCs}$ via one-step sol-gel process using pluronic (P123), triblock copolymer surfactant, as structural directing agent. The incorporation of $\ln _{2} \mathrm{O}_{3}(2.7 \mathrm{eV})^{261}$ into the mesoporous $\mathrm{Ta}_{2} \mathrm{O}_{5}(3.9-4 \mathrm{eV})^{261}$ resulted in the formation of a type-II system with reduced band gap energy, rendering the photocatalyst active in the visible region. Subsequently, the thermal stability of mesoporous $\operatorname{Ta}_{2} \mathrm{O}_{5}$ was greatly enhanced after the formation of the nanocomposite. The as synthesized mesoporous $\ln _{2} \mathrm{O}_{3} / \mathrm{Ta}_{2} \mathrm{O}_{5}$ exhibited a relevant photocatalytic activity for $\mathrm{H}_{2}$ generation $\left(189 \mu \mathrm{mol} \mathrm{h}^{-1} \mathrm{~g}^{-1}\right)$ from aqueous methanol solution under simulated solar irradiation as compared to the activity of non-porous $\ln _{2} \mathrm{O}_{3} / \mathrm{Ta}_{2} \mathrm{O}_{5} \mathrm{NCs}$ synthesized without template $\left(54 \mu \mathrm{mol} \mathrm{h}^{-1} \mathrm{~g}^{-1}\right)$ and pure crystalline $\mathrm{Ta}_{2} \mathrm{O}_{5}\left(84 \mu \mathrm{mol} \mathrm{h}{ }^{-1} \mathrm{~g}^{-1}\right) \cdot{ }^{261}$ Compared to non-mesoporous $\ln _{2} \mathrm{O}_{3} / \mathrm{Ta}_{2} \mathrm{O}_{5}$ nanocomposites, mesoporous systems exhibited high activity due to their large specific surface area, which provides more active sites for $\mathrm{H}_{2}$ production. The photogenerated electrons and holes have to travel short distance in mesoporous structure due to very thin walls, which is not observed in the other two photocatalysts. ${ }^{261}$ The same authors further investigated the three dimensional mesoporous $\ln _{2} \mathrm{O}_{3} / \mathrm{Ta}_{2} \mathrm{O}_{5} \mathrm{NC}$ systems as a function of the wt\% of $\mathrm{In}_{2} \mathrm{O}_{3}$ incorporation and the calcination temperature employed in the heat treatment. ${ }^{262} \mathrm{~A}$ thin doping layer was found to be formed at the interface of the mesoporous $\ln _{2} \mathrm{O}_{3} / \mathrm{Ta}_{2} \mathrm{O}$, due to the substitution of $\mathrm{In}^{3+}$ by $\mathrm{Ta}^{5+}$, resulting in the formation of $p$-type conduction. Contrastingly the doping of $\mathrm{Ta}^{5+}$ in $\ln _{2} \mathrm{O}_{3}$ results in the formation of $n$-type conduction. ${ }^{262} \mathrm{~A} \mathrm{p}-\mathrm{n}$ junction type-II heterostructure is thus formed in this mesoporous composite system (Fig. 26a). The heterojunction area in the nanocomposite increased with an increasing amount of $\ln _{2} \mathrm{O}_{3}$ (wt\%). ${ }^{262}$ The maximum area of heterojunction was observed for $20 \mathrm{wt} \%$ of $\ln _{2} \mathrm{O}_{3}$, beyond which the heterojunction area decreased together with the photocatalytic performance in the materials. Regardless, the mesoporous nanocomposite with varying $\ln _{2} \mathrm{O}_{3}$ ( $w t \%)$ still provided a comparatively higher activity to that of pure crystalline $\mathrm{Ta}_{2} \mathrm{O}_{5}$ photocatalysts. ${ }^{262}$ The mesoporous $\mathrm{In}_{2} \mathrm{O}_{3} / \mathrm{Ta}_{2} \mathrm{O}_{5} \mathrm{NCs}$ with $20 \mathrm{wt} \%$ of $\mathrm{In}_{2} \mathrm{O}_{3}$ was synthesized at varying calcination temperature $(450,550$, $\left.650,750^{\circ} \mathrm{C}\right) .{ }^{262} \mathrm{An}$ increase in calcination temperature from $450^{\circ} \mathrm{C}$ resulted in a decrease in specific surface area and 
pore volume, with a complete destruction of the mesoporous structure observed at $750{ }^{\circ} \mathrm{C}$ leading to the formation of crystallized NCs with very low photocatalytic activity (Fig. 26b). ${ }^{262}$
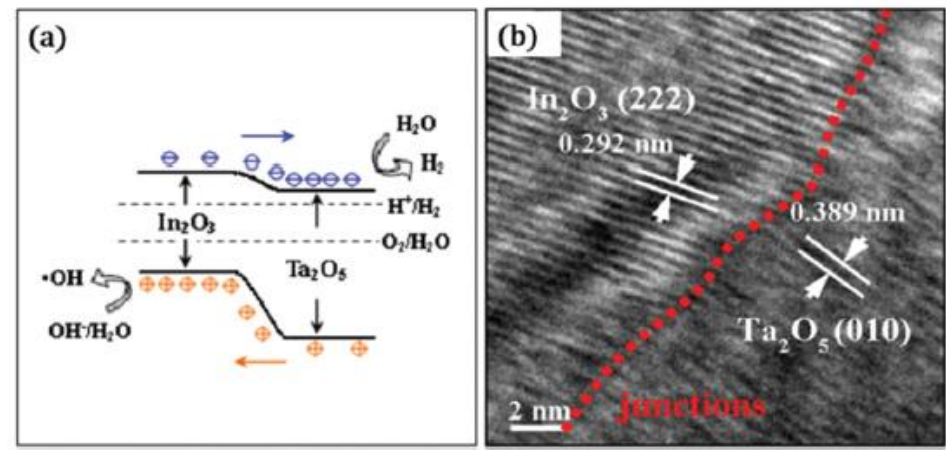

Fig. 26 (a) Illustration of charge transfer route in mesoporous $\ln _{2} \mathrm{O}_{3} /$ $\mathrm{Ta}_{2} \mathrm{O}_{5} \mathrm{NCs}$ with $\mathrm{p}-\mathrm{n}$ junction type II heterojunction. (b) HR-TEM image of the interface region between $\ln _{2} \mathrm{O}_{3}$ and $\mathrm{Ta}_{2} \mathrm{O}_{5}$ materials in $\ln _{2} \mathrm{O}_{3} / \mathrm{Ta}_{2} \mathrm{O}_{5}$ $\mathrm{NCs}$ (with 20 wt\% $\ln _{2} \mathrm{O}_{3}$ ) calcined at $7500^{\circ} \mathrm{C}^{262}$ ( $\mathrm{a}$ and b) (Reproduced from ref. 262. Copyright 2018 Elsevier).

Results confirmed that the onset of destruction of the mesoporous structure started from $650{ }^{\circ} \mathrm{C}$, below which the three dimensional novel structure was retained. ${ }^{262}$

To conclude, differing from other families of photocatalysts, the synthesis of nanocomposite generally takes place in two consecutive steps. The first step involves the synthesis of base SC materials as "support" and the second step involves the growth of a different SC material on the denoted support material. The transformation of two consecutive steps into a direct single step method is now under intensive research in the field of photocatalysis, in order to tune the interface of two different semiconductor materials to enhance the photocatalytic activity. Nanocomposite system fabrication can be considered as essential in the future design of advanced photocatalytic systems. Such design mostly involves surface passivation (elimination of trap states) of core and creation of type-II heterojunction for efficient charge separation. Table 4 summarizes a number of relevant photocatalytic nanocomposite systems with their synthetic approaches along with their photochemical applications. The diverse modified/unmodified SCs reported in the field of heterogeneous photocatalysis have been segregated and the synthetic development within each family was specifically rationalized.

\section{Z-Scheme photocatalysts}

\section{1st generation Z-scheme photocatalytic systems}

Heterogeneous photocatalysis for overall water splitting process can be achieved via two different systems, namely (1) a conventional type consisting of a single SC (modified/unmodified) material which carries out the overall water splitting to produce $\mathrm{H}_{2}$ and $\mathrm{O}_{2}$ via one-step excitation upon exposure to photons (Fig. 27) and (2) two different photocatalytic active SCs activated via a two-step photoexcitation mechanism under light irradiation. The latter system is denoted as Z-scheme photocatalytic system as it mimics the naturally occurring Z-scheme process in photosynthesis of plants, where $\mathrm{H}_{2} \mathrm{O}$ and $\mathrm{CO}_{2}$ are converted to carbohydrates and $\mathrm{O}_{2}$ under solar irradiation. ${ }^{263-265}$ 


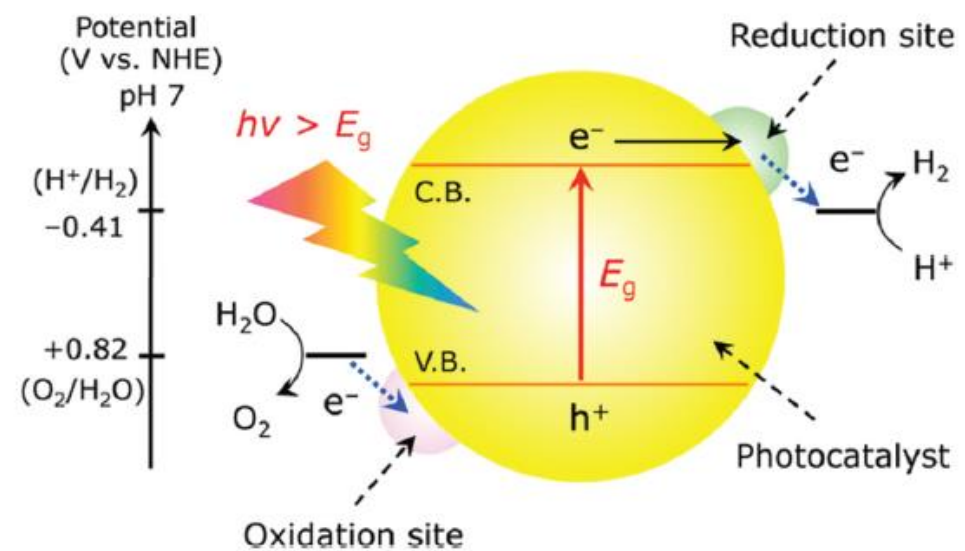

Fig. 27 Schematic representation of one-step photoexcitation system using single semiconductor material for overall water splitting ${ }^{266}$ (Reprint with permission from K. Maeda, K. Domen, Photocatalytic water splitting: recent progress and future challenges, J. Phys. Chem. Lett., 2010, 1. 2655-2661. Copyright 2019 American Chemical Society).

From the one-step photoexcitation system (Fig. 27), it is obvious that reduction and oxidation sites on the SC refers to the active sites generated by specifically co-catalysts loaded to perform the water redox reactions. Irrespective of the system employed for overall water splitting, the loading of co-catalysts $\left(\mathrm{Pt}, \mathrm{NiO}_{x}\right.$ or $\mathrm{Rh}$ ) on the $\mathrm{SC}$ is the main prerequisite to promote water splitting even in the presence of SCs able to perform overall water splitting without cocatalysts. ${ }^{267}$

The two-step photoexcitation system (Z-scheme) was first instigated and explored by Bard et al. in $1979^{268}$ in which a dual photocatalytic system was reported where one $\mathrm{SC}$ is used specifically for $\mathrm{H}_{2}$ generation and the other one for $\mathrm{O}_{2}$ generation, simultaneously, from water splitting. The utility of photons is more efficient in Z-scheme systems as the Gibbs free energy change required to activate the different SCs is reduced with respect to the energy required for a one-step photoexcitation system. ${ }^{268}$ This provides highly efficient photocatalysts with stronger oxidation and reduction capabilities on either side of the system. ${ }^{266,269}$ Upon irradiation to photons, both SCs are excited resulting in the generation of electrons and holes (Fig. 28). The photogenerated electrons remain on the $\mathrm{H}_{2}$ photocatalyst with higher reduction potential and the holes remain on the $\mathrm{O}_{2}$ photocatalyst with higher oxidation potential, resulting in the optimization of the redox potential of the system. The interaction between these two SCs takes place via transfer of electrons from the $\mathrm{CB}$ of the $\mathrm{O}_{2}$ photocatalyst to $\mathrm{VB}$ of the $\mathrm{H}_{2}$ photocatalyst through a pair of reversible redox mediators ( $A$ and $D) .{ }^{270}$ The photocatalysis in such system takes place in the liquid phase and it is designated as liquid-phase Z-scheme photocatalytic system, belonging to the 1st generation of Z-scheme systems. ${ }^{271,272}$ 


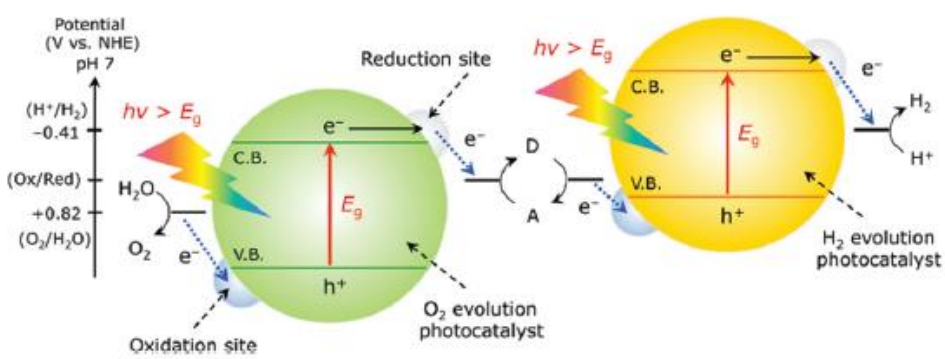

Fig. 28 Schematic depiction of Z-scheme two-step photoexcitation route for overall water splitting reaction; $E_{g}$ is the energy band gap; $D$ is the electron donating species and $A$ is the electron accepting species. ${ }^{270}$ (reprint with permission from K. Maeda, K. Domen, Photocatalytic water splitting: recent progress and future challenges, J. Phys. Chem. Lett., 2010, 1. 2655-2661. Copyright 2019 American Chemical Society).

The main downside of this Z-scheme is the occurrence of the reduction of ' $A$ ' and oxidation of ' $D$ ' molecules on the surface of the photocatalyst where the oxidation and the reduction of water is taking place, respectively. Optimum selectivity control is the key factor for these systems due to which the number of liquid phase Z-scheme systems displaying optimum photocatalytic activity is highly limited.

Thermodynamically, the reaction of electron donor $(A)$ and electron acceptor $(D)$ with the photogenerated electrons in the $\mathrm{CB}$ of the $\mathrm{H}_{2}$ photocatalyst and holes in the $\mathrm{VB}$ of the $\mathrm{O}_{2}$ photocatalyst is more favourable to occur as compared to the water splitting reaction. ${ }^{273}$ These backward reactions must be suppressed in order to increase the effective number of photogenerated electrons and holes for water splitting reaction. Domen et al. reported a Zscheme system consisting of Pt-loaded $\mathrm{ZrO}_{2} / \mathrm{TaON}$ and $\mathrm{Pt}$-loaded $\mathrm{WO}_{3}$ as $\mathrm{H}_{2}$ and $\mathrm{O}_{2}$ photocatalysts respectively, with $\mathrm{IO}_{3}{ }^{-} / \mathrm{I}^{-}$as redox mediator. ${ }^{274} \mathrm{In}$ this system, the backward reactions with redox mediators were significantly minimized displaying a high quantum efficiency of $6.3 \%$ at $420 \mathrm{~nm} .{ }^{274}$ The photocatalytic activity of the 1 st generation Z-scheme system is predominantly dependent on the concentration of the redox mediators, ${ }^{270,275}$ the side reactions of the redox system (i.e. $\mathrm{pH}$-dependent of the reactant solution) ${ }^{276}$ and the interactions of the redox mediators with co-catalysts. ${ }^{277}$ Additionally, the redox mediators absorb the visible light and reduce the light absorption of the SCs. Besides, the liquid redox mediators suffer from lack of long-term stability and activity.

In order to eliminate the drawbacks associated with the above system and to render the Z-scheme photocatalysis viable for gas and solid-phase reaction, liquid redox mediated-free Z-scheme systems became an important prerequisite for an efficient system in the photocatalytic field. This led to the beginning of 2 nd generation Z-scheme photocatalytic systems.

\section{2nd generation Z-scheme photocatalytic systems}

Z-Scheme systems without liquid redox mediators ( $A$ and $D$ ) and with spatial fixation of SCs form all-solid-state (ASS) Z-scheme photocatalytic systems which constitute 2 nd generation Z-scheme systems. These systems' applications are viable for gas-phase as they eliminate the drawbacks of the 1st generation Z-scheme systems. Noble metal nanoparticles ( $\mathrm{Ag}$ or $\mathrm{Au}$ ) are generally employed as electron mediators for an efficient charge-carrier separation by transport through the interface between $\mathrm{SC}_{2}$ and $\mathrm{SC}_{1}{ }^{278,279}$ (Fig. 29). Primarily, these noble metal nanoparticles (Ag or $\mathrm{Au}$ ) act as photosensitizers due to localized surface plasmon resonance (SPR) effect. This system was firstly introduced by Tada et al. which reported the design of anisotropic $\mathrm{CdS}-\mathrm{Au}-\mathrm{TiO}_{2}$ nanojunctions by a facile photodeposition technique for the reduction of methylviolgen $\left(\mathrm{MV}^{2+}\right){ }^{280}$ Both $\mathrm{SCs}\left(\mathrm{CdS}\right.$ and $\left.\mathrm{TiO}_{2}\right)$ were photoexcited upon exposure to UV irradiation. The electrons from the $\mathrm{CB}$ of $\mathrm{TiO}_{2}$ were transferred to $\mathrm{Au}$ then to the $\mathrm{VB}$ of $\mathrm{CdS}$ and subsequently recombined with photogenerated holes in the VB of $\mathrm{CdS}$. This results in the generation of electrons and holes with high reduction and oxidation potential on $\mathrm{CdS}$ and $\mathrm{TiO}_{2}$ photocatalyst, respectively. ${ }^{280}$ The vectorial 
electron transfer $\left(\mathrm{TiO}_{2} \rightarrow \mathrm{Au} \rightarrow \mathrm{CdS}\right.$, similar to the electron pathway in Fig. 29) not only improved the photocatalytic activity but also the photostability of CdS SC. ${ }^{280}$

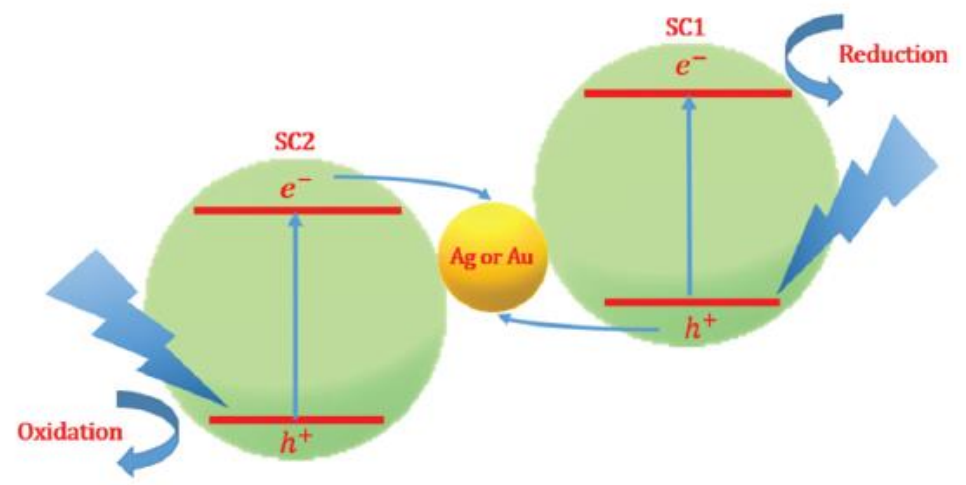

Fig. 29 Schematic depiction of charge carrier pathway in ASS-Z-scheme photocatalytic system (2nd generation Z-scheme photocatalytic systems).

Cheng et al. synthesized $\mathrm{Ag}_{3} \mathrm{PO}_{4} / \mathrm{Ag} / \mathrm{SiC}$ ASS Z-scheme photocatalysts by a simple in situ precipitation technique at room temperature. ${ }^{281}$ As synthesized photocatalysts with Ag NPs as charge transmission bridges (electron mediators) exhibited a similar vectorial electron transfer $\left(\mathrm{Ag}_{3} \mathrm{PO}_{4} \rightarrow \mathrm{Ag} \rightarrow \mathrm{SiC}\right)$ as compared to that reported in the previous system and provided a higher photocatalytic activity for the degradation methyl orange and phenol under visible light irradiation with respect to $\mathrm{Ag}_{3} \mathrm{PO}_{4} / \mathrm{Ag}$ and $\mathrm{SiC} / \mathrm{Ag}$ nanocomposites due to the efficient separation of electronhole pairs in the Z-scheme system. ${ }^{281}$ The localized surface plasmon resonance (SPR) effect of Au/Ag on these systems led to the development of plasmonic ASS Z-scheme photocatalytic systems under visible light irradiation. ${ }^{282-}$ 284

Cheng et al. synthesized plasmonic Z-scheme $\alpha / \beta-\mathrm{Bi}_{2} \mathrm{O}_{3}-\mathrm{Ag}-\mathrm{AgCl}$ photocatalysts utilising a deposition-precipitation technique coupled with a photo-reduction process. ${ }^{285} \mathrm{In}$ the case of this plasmonic photocatalyst, only $\mathrm{Bi}_{2} \mathrm{O}_{3}\left(E_{\mathrm{g}}\right.$ of $\alpha-$ $\mathrm{Bi}_{2} \mathrm{O}_{3}=2.71 \mathrm{eV}$ and $\left.\beta-\mathrm{Bi}_{2} \mathrm{O}_{3}=2.48 \mathrm{eV}\right)$ was excited, while $\mathrm{AgCl}(3.25 \mathrm{eV})$ is not activated under visible light irradiation $(\lambda>420 \mathrm{~nm})$. At the same time, the photogenerated electron-hole pairs appeared in Ag NPs due to the plasmonic effect. Here, the vectorial electron transfer was reported to take place from the $C B$ of $A g$ NPs to the $C B$ of $A g C l$, where the reduction reaction occurs and the photogenerated electrons from the $\mathrm{CB}$ of $\mathrm{Bi}_{2} \mathrm{O}_{3}$ recombined with the plasmon-induced holes of Ag NPs. ${ }^{285} \alpha / \beta-\mathrm{Bi}_{2} \mathrm{O}_{3}-\mathrm{Ag}-\mathrm{AgCl}$ exhibited enhanced photocatalytic activity as compared to $\alpha / \beta-\mathrm{Bi}_{2} \mathrm{O}_{3}$ nanowires for the degradation of Rhodamine $\mathrm{B}$ and acid orange 7 dyes. The higher photodegradation activity was attributed to the hierarchical nanostructures with large surface area, the profuse interfacial active sites, the enhanced absorption of visible light due to SPR effect of Ag NPs and the efficient separation of electron-hole pairs. $^{285}$

In essence, only one SC is generally activated in plasmonic Z-scheme systems, while the SPR effect of the noble metal NPs always plays a significant role. When both SCs are excited, the noble metal particles primarily act as electron mediators. However, ASS Z-scheme systems are composed of costly noble metals which also reduce the light absorption capability of SCs. These drawbacks have limited their large scale implementation and alternatives for redox mediators-free Z-scheme systems have been sought, resulting in the development of third-generation Zscheme systems, detailed hereafter.

\section{3rd generation Z-scheme photocatalytic systems}

3rd generation of Z-scheme photocatalysts (direct Z-scheme photocatalysts) do not require any redox medium for charge migration, generally comprising two different SCs. Structurally, a direct Z-scheme photocatalyst is analogous 
to a type-II SC-SC coupled heterojunction system (see section on nanocomposites), but the charge-carrier migration mechanism is rather different to that disclosed in type-II systems.

In a classical type-II heterojunction photocatalyst, the $\mathrm{CB}$ and the $\mathrm{VB}$ levels of $\mathrm{SC}_{2}$ are comparatively higher to the $\mathrm{CB}$ and $V B$ levels of $S_{1}$. Upon exposure to photons irradiation, the photogenerated electrons transfer from the $\mathrm{CB}$ of $\mathrm{SC}_{2}$ to the $\mathrm{CB}$ of $\mathrm{SC}_{1}$, while the holes move from the $\mathrm{VB}$ of $\mathrm{SC}_{1}$ to the $\mathrm{VB}$ of $\mathrm{SC}_{2}$ (Fig. 30b). This results in a spatial separation of electron-hole pairs. However, the electrons and holes accumulated in the $\mathrm{CB}$ of $\mathrm{SC}_{1}$ and the $\mathrm{VB}$ of $\mathrm{SC}_{2}$, respectively, possess low reduction and oxidation potentials. In this regard, the redox ability of the overall photocatalyst is largely reduced.
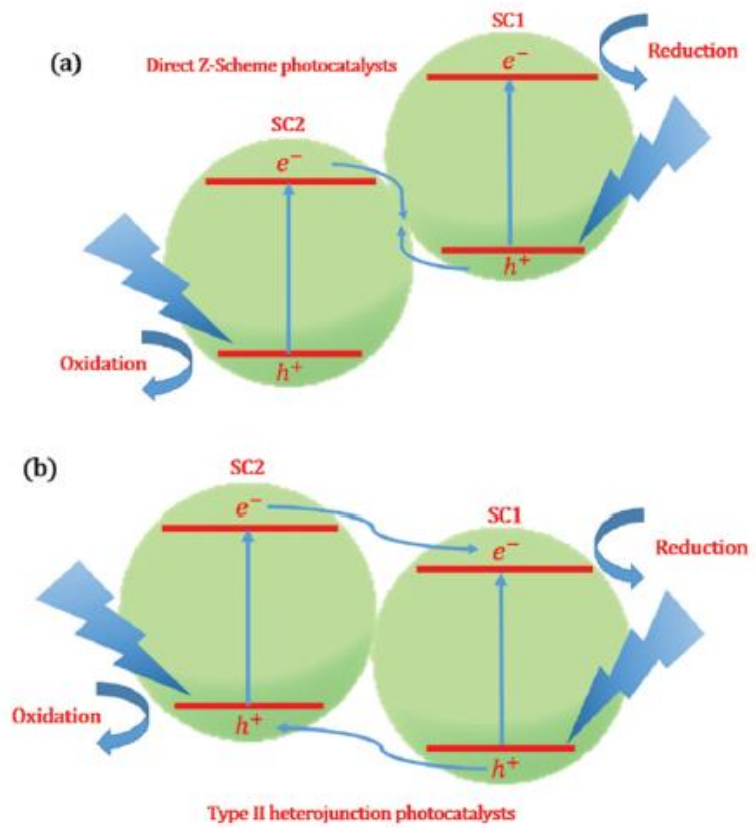

Fig. 30 (a) Schematic illustration of charge carrier separation in direct Z-scheme photocatalytic system (3rd generation Z-scheme system). (b) Charge carrier migration mechanism in type-II heterojunction photocatalysts.

In contrast, the photogenerated electrons in $\mathrm{SC}_{2}$ with low reduction potential combine with the photogenerated holes in the $\mathrm{VB}$ of $\mathrm{SC}_{1}$ with low oxidation potential in direct Z-scheme photocatalytic systems. This results in the accumulation of electrons and holes with higher reduction and oxidation potentials, respectively, in $\mathrm{SC}_{1}$ and $\mathrm{SC}_{2}$ (Fig. 30a). The spatial separation of charge carriers takes place in direct Z-scheme photocatalysts, facilitating the system to achieve optimum redox capabilities. ${ }^{286-288}$

The charge carrier's migration mechanism in direct Z-scheme is homogeneous (similarly to both ASS Z-scheme and liquid-phase Z-scheme systems) but in the absence or need for any redox mediator (liquid or solid NPs). Direct Zscheme systems hence avoid the backward reactions taking place in 1st generation Z-scheme photocatalysts. Additionally, direct Z-scheme systems facilitate the migration of the charge carriers directly across the interface of two SCs, thereby reducing the transformation distance with respect to 2 nd generation Z-scheme photocatalysts, eventually ending up in avoiding unfavourable reactions. Direct Z-scheme systems also avoid the light shielding effect of noble metal NPs-based redox mediators.

Due to structural similarities between Z-scheme and type-II heterojunctions photocatalysts, the charge transfer mechanism in SC-SC coupled systems has been investigated in detail to differentiate between direct Z-scheme and type-II heterojunctions. Currently, several characterization techniques have been employed to obtain deep insights 
into the charge carrier migration process, namely internal electric field simulation, effective-mass calculation, $\mathrm{X}$-ray photoelectron spectroscopy, radical species trapping test and photocatalytic reduction tests. ${ }^{272}$

Direct Z-scheme photocatalysts were firstly reported by Yu et al. by demonstrating the high photocatalytic activity of g- $\mathrm{C}_{3} \mathrm{~N}_{4} / \mathrm{TiO}_{2}$ nanocomposites under UV irradiation for the degradation of formaldehyde in air. ${ }^{289}$ The contact interface between $\mathrm{SCs}\left(\mathrm{g}-\mathrm{C}_{3} \mathrm{~N}_{4}\right.$ and $\left.\mathrm{TiO}_{2}\right)$ was directly achieved by coupling g- $\mathrm{C}_{3} \mathrm{~N}_{4}$ with $\mathrm{TiO}_{2} \mathrm{NPs}$ by calcination $\left(550^{\circ} \mathrm{C}\right.$ for $60 \mathrm{~min}$ ) of mixtures of $\mathrm{TiO}_{2} \mathrm{NPs}$ and urea. After this seminal study, additional research efforts were reported on direct Z-scheme photocatalysts by several researchers across the globe. Li et al. employed a similar calcination technique $\left(600{ }^{\circ} \mathrm{C}, 120 \mathrm{~min}\right.$ ) on the mixture of bulk g- $\mathrm{C}_{3} \mathrm{~N}_{4}$ and nanotube titanic acid (NTA) to successfully synthesize visible light active direct Z-scheme g- $\mathrm{C}_{3} \mathrm{~N}_{4} / \mathrm{TiO}_{2}$ nanocomposites. ${ }^{290}$ During thermal treatment, bulk g- $\mathrm{C}_{3} \mathrm{~N}_{4}$ was oxidized to g- $\mathrm{C}_{3} \mathrm{~N}_{4}$ nanosheets and NTA got dehydrated, resulting in the formation of novel-anatase $\mathrm{TiO}_{2} \mathrm{NPs}$. The thin nanosheets of g- $\mathrm{C}_{3} \mathrm{~N}_{4}$ provided high surface area and short bulk diffusion length for the spatial separation of charge carriers. ${ }^{290}$ The visible light activity originated from the doping of $\mathrm{TiO}_{2} \mathrm{NPs}$ during the heat treatment. As synthesized direct Z-scheme scheme photocatalyst $30 \%-\mathrm{g}-\mathrm{C}_{3} \mathrm{~N}_{4} / \mathrm{TiO}_{2}$ (prepared from the precursor mixture containing $30 \mathrm{wt} \%$ of bulk g- $\left.\mathrm{C}_{3} \mathrm{~N}_{4}\right)$ exhibited high activity for the photo-oxidation of propylene under visible light $(\lambda \geq$ $420 \mathrm{~nm}$ ). This activity was attributed to the large surface area of the nanocomposite, the effective spatial separation of charge carriers and the morphology of photocatalysts (conjunction of thin nanosheets $\mathrm{g}_{-} \mathrm{C}_{3} \mathrm{~N}_{4}$ and $\mathrm{TiO}_{2}$ nanoparticles). ${ }^{290}$

The contact interfaces between two SCs described in the above two cases were established via chemical interactions, which resulted in firm interfaces. A similar type of intimate interface contact has been also achieved and reported in two-dimensional (2D) composites consisting of $2 \mathrm{D} / 2 \mathrm{D} \mathrm{g}-\mathrm{C}_{3} \mathrm{~N}_{4} / \mathrm{MnO}_{2}$ heterostructured direct Zscheme photocatalysts, directly synthesized via wet-chemical approach. ${ }^{291}$ As-synthesized photocatalysts exhibited higher photocatalytic activity for the degradation of phenol and rhodamine B dye as compared to individual g- $\mathrm{C}_{3} \mathrm{~N}_{4}$ and $\mathrm{MnO}_{2}$ photocatalysts. ${ }^{291}$ The interface formation between two different SCs in direct Z-scheme photocatalytic system can also be accomplished via physical interactions based on the electrostatic attractions generated by opposite charges.

Xu et al. constructed 2D/2D $\alpha-\mathrm{Fe}_{2} \mathrm{O}_{3} / \mathrm{g}-\mathrm{C}_{3} \mathrm{~N}_{4}$ direct Z-scheme photocatalysts via electrostatic self-assembling of g- $\mathrm{C}_{3} \mathrm{~N}_{4}$ nanosheets with hematite $\alpha-\mathrm{Fe}_{2} \mathrm{O}_{3}$ nanoplates. ${ }^{292}$ The resultant $\alpha-\mathrm{Fe}_{2} \mathrm{O}_{3} / \mathrm{g}-\mathrm{C}_{3} \mathrm{~N}_{4}\left(10\right.$ wt $\% \alpha-\mathrm{Fe}_{2} \mathrm{O}_{3}$ ) heterostructures possessed intimate contact interfaces and displayed 13 times higher $\mathrm{H}_{2}$ evolution rate from water containing triethanolamine (hole scavenger) with respect to $\mathrm{g}-\mathrm{C}_{3} \mathrm{~N}_{4}$ photocatalysts under visible light irradiation. ${ }^{292}$ This high activity was attributed to the firm interface achieved through physical contact, where spatial separation charge carries occurred through Z-scheme mechanism.

Direct Z-scheme photocatalysts can provide three relevant advantages including (1) an efficient spatial separation of charge carriers upon excitation, (2) the generation (accumulation) of charge carriers with high redox ability and (3) and affordable and potentially cost-competitive fabrication cost. As a result, these materials display high photocatalytic activities for a wide range of applications (water splitting, degradation of pollutants, etc.).

With regards to the current development of direct Z-scheme photocatalytic systems, the construction of 2D/2D heterostructures is highly preferred due to the generation of contact interfaces between SCs over a large surface. Very recently, Hu et al. constructed a 2D/2D heterojunction of black phosphorus (BP)/ $\mathrm{Bi}_{2} \mathrm{WO}_{6}$ (bismuth tungstate) monolayer nanosheets by the decoration of sandwich structure-like $\mathrm{Bi}_{2} \mathrm{WO}_{6}$ on the surface of $\mathrm{BP}$ nanoflakes through a simple wet chemical approach. ${ }^{125}$ The resultant nanocomposite material possessed intimate interfaces in contact and a homogeneous distribution of $\mathrm{Bi}_{2} \mathrm{WO}_{6}$ nanosheets on the $\mathrm{BP}$ surface. $12 \mathrm{wt} \% \mathrm{BP} / \mathrm{Bi}_{2} \mathrm{WO}_{6}$ nanocomposite displayed an outstanding photocatalytic rate for $\mathrm{H}_{2}$ evolution $\left(21042 \mu \mathrm{mol} \mathrm{g}^{-1}\right)$ from water splitting and removal nitric oxide (up to 67\%), comparably 9.15 times and 2.15 times to that of monolayer BP nanosheets. The high photocatalytic activity was attributed to the novel heterojunction interfaces established between monolayers of $\mathrm{Bi}_{2} \mathrm{WO}_{6}$ nanosheets and $\mathrm{BP}$ flakes, enhanced light absorption and the efficient separation of charge carriers. ${ }^{125}$ 


\section{Miscellaneous}

Apart from the above discussed four categories of photocatalysts, there has been recently an increasing attention on piezoelectric semiconductors in photocatalysis. ${ }^{293-297}$ Conventionally, the term "piezoelectric" represents a group of materials (i.e. certain metal oxides) featuring non-centrosymmetric structures, that is, materials which do not possess centre of symmetry in their crystal structure. Such material possess the ability to enhance the rate of photochemical processes upon mechanical deformation by exhibiting spontaneous polarization by the induction of an electric field throughout the crystal. Due to such polarization potential, free charge carriers or photogenerated electrons or holes are spatially separated resulting in the observed enhancement in photocatalytic activity. Piezophotocatalysis (based on piezoelectric semiconductor photocatalysts) involves the synergy of photonic energy and mechanical energy to achieve enhanced photocatalytic rates. ${ }^{297}$ Within the perspective of synthetic approaches, such piezophotocatalysts can be designed via tailored synthesis of pure semiconductor possessing both piezoelectric and photonic properties and hybrid nanocomposites involving the conjunction of two different materials featuring piezo and photonic properties. The former case includes some recently reported materials including zinc tin oxide $\left(\mathrm{ZTO}-\mathrm{ZnSnO}_{3}\right)$ nanowire arrays, ${ }^{298} \mathrm{ZnO}$ nanowires, ${ }^{299}$ sodium niobate $\left(\mathrm{NaNbO}_{3}\right)$ and nanostructured films. ${ }^{300}$ The latter case involves hybrid system such as barium titanate/silver phosphate $\left(\mathrm{BaTiO}_{3} / \mathrm{Ag}_{3} \mathrm{PO}_{4}\right)$ nanocomposites where the piezo properties of $\mathrm{BaTiO}_{3}$ is combined with the photochemical properties of $\mathrm{Ag}_{3} \mathrm{PO}_{4}$, resulting in novel nanocomposite piezophotocatalysts. ${ }^{301}$

In most of the cases, the mechanical energy required for piezophotocatalysis is provided by ultrasonic irradiation. The pros of such mechanical forces relies in the generation of periodic compression stress, which prevents the screening of piezoelectric generated charges by photogenerated charge carriers. ${ }^{302}$ Even though these novel piezophotocatalysts provide enhanced separation of charge carriers leading to enhanced photocatalytic activity, the photocatalytic applications of piezophotocatalysts are mostly limited to date to pollutant removal reactions and not extended - for instance - to $\mathrm{CO}_{2}$ reduction, novel organic molecules synthesis, etc. The field of piezophotocatalysis is still in its infancy and needs intensive fundamental research and engineering efforts to unleash its full potential.

Mechanical forces provided by ultrasonic waves and/or reactive extrusion (e.g. mechanochemistry) can result in the generation of defects on the surface of semiconductor materials. ${ }^{303}$ Nevertheless, there is still a need for more fundamental studies in such processes for elucidating the reasons behind the enhanced activity and the relationship between the mechanical force and the generated defects. Additionally, the development of reactor systems for an optimum input of mechanical energy (ultrasonic vibration, reactive extrusion-mechanochemistry-) and light energy is still far from being practical, as currently, no continuous flow photoreactor system involving both energies simultaneously has been reported to date.

\section{Challenges \& future prospects}

\section{Challenges for continuous synthesis of nanophotocatalysts}

Concerning the four different families of photocatalytic materials, continuous synthetic processes have been successfully reported for conventional pure semiconductor photocatalysts $\left(\mathrm{TiO}_{2}\right.$ and $\left.\mathrm{ZnO}\right)$. Several studies are ongoing to improve the yield of the reported process and concurrently new synthetic techniques using supercritical medium are rapidly reported for synthesizing unconventional photocatalysts $\left(\mathrm{GaN}\right.$ and $\left.\mathrm{CeO}_{2}\right)$ by several research groups. In the perspective of ternary SCs, synthetic explorations (continuous flow synthesis) has not spurred as seen in binary photocatalysts. Currently, the implementation of single source precursor and facilely operated flow systems has been studied for continuous synthesis of ternary SCs. Regarding solid solution photocatalysts, tremendous research is carried out in reducing the cost of single source precursors by elucidating or creating new synthetic strategies. Continuous synthetic shift from batch to flow, for solid solution lies completely in the dormant phase because of the non-availability of ready-made, stable and oxidation free single source precursors. Finally, for type-II and direct Z-scheme photocatalysts continuous consecutive synthesis of core (base SC) and shell using a dual reactor set up is the current area of focus. 
Implementation of photocatalysts in heterogeneous photocatalysis

Heterogeneous photocatalysis involves a multiphase system involving the interaction between different phases (solid-gas, solid-liquid and solid-liquid-gas) through mass transfer (adsorption) upon mixing and charge transfer (redox reactions) upon exposure to light. Therefore, the design of a reactor for heterogeneous photocatalysis extensively depends on the photochemistry to which the system is subjected and the source of electromagnetic radiations. The design of the photoreactor is always targeted to achieve high photocatalytic activity by ensuring efficient illumination of the solid photocatalytic SC along with the synchronous enhancement of both mass transfer rate from photocatalysts surface and heat transfer rate from the reaction vessel. The composition and chemistry of phases involved in such systems determine the compatible materials for the construction of the photoreactor. ${ }^{303-308}$ The different multiphasic systems employed in heterogeneous photocatalysis are: (i) the solid-gas (organic/inorganic) system, (ii) the solid-liquid system and (iii) the solid-liquid-gas system. Broadly the photoreactors studied are of two types: batch and flow reactors. The batch reaction vessel used in this multiphasic systems are made up of either quartz, pyrex and sometimes stainless steel materials. The position of the irradiation source can be either internal or external irradiation. ${ }^{12,24,64,297}$ The effective utilization of photocatalysts within batch and flow reactors are achieved by two different methods: suspension and immobilization. In the former system, the photocatalytic material is suspended in the fluid (especially liquid) phase with the help of magnetic stirring, toroidal or non-toroidal agitation promoted by gas molecules. This suspension of the photocatalytic materials in the liquid phase (aqueous or non-aqueous) is called "slurry system". In the immobilized system, the photocatalysts are bonded to inert surfaces, either through a physical or a chemical bonding.

\section{Strategies for efficient implementation of photocatalysts in flow reactors}

Flow reactors have been developed in the last two decades due to the attainment of higher throughput, enhanced mass and photon transfer. Comparatively, flow photoreactors provide reduction of safety hazards and simplify operation compared to batch reactors. ${ }^{309,310}$ Flow systems based on solid-gas (diphasic) or solid-fluid (liquid and/or gas) (diphasic or triphasic) initially progressed in the direction of immobilized system due to a simple separation of photocatalysts from the reactive mixture. The solid photocatalysts immobilized/mobilized on glass beads could be packed into Pyrex or borosilicate/glass tube in case of packed bed reactors (PBR) $)^{310,311}$ or successfully fluidized in the annular space between two tubes in fluidized bed reactors ${ }^{312}$ (Fig. 31a). Solid photocatalysts could be perfectly immobilized through various techniques on the walls of the reactor (see Fig. 31b), in case of an annular reactor, ${ }^{313-315}$ honeycomb monolith reactors ${ }^{294}$ and uniformly coated or dispersed in plate reactor. ${ }^{316,317}$ Behnajady et al. reported a continuous flow tubular photocatalytic reactor with immobilized photocatalysts for the degradation of acid red 27 (AR27) (an anionic monoazo dye). ${ }^{318}$ Commercially available $\mathrm{TiO}_{2}$ (Degussa P25) was herein immobilized on a glass plate and inserted inside the tubular reactor. The immobilization was carried out using a heat attachment methodology. 


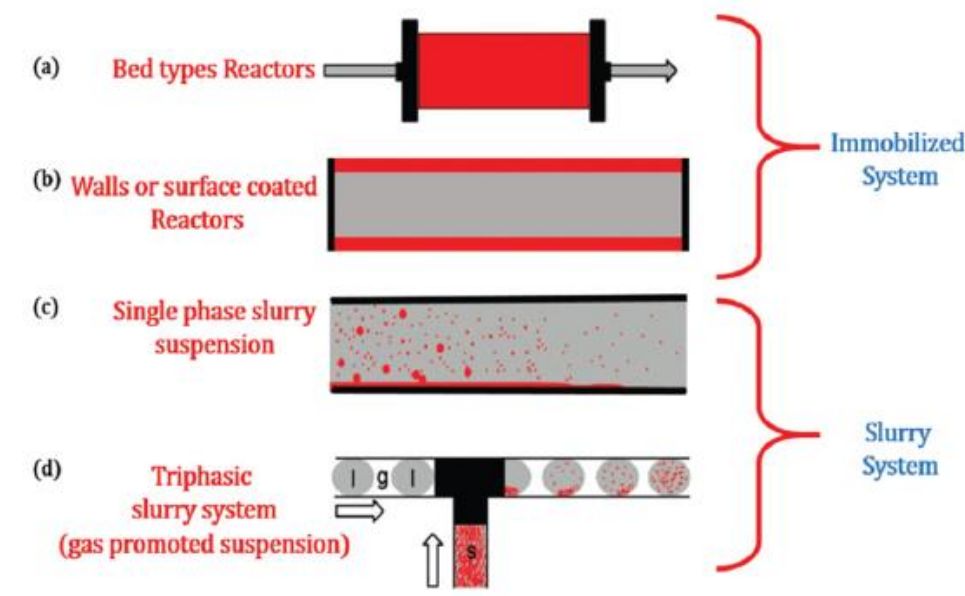

Fig. 31 Strategies applied for the efficient implementation of photocatalysts in flow reactors redrawn, based on the artice. ${ }^{325}$ (Reproduced with permission from ref. 325. Copyright 2018 John Wiley and Sons).

Li et al. also reported the use of double cylindrical shell (DCS) photoreactor with an immobilized monolayer of $\mathrm{TiO}_{2}$ coated on silica gel beads. ${ }^{319}$ The design of this photoreactor was similar to the annular reactor. Another relevant reported immobilized system was denoted as labyrinth bubble photoreactor, studied by Hao et al. in which $\mathrm{TiO}_{2}$ photocatalysts was immobilized on quartz glass particles and a labyrinth fluid flow arrangement was achieved by the arrangement of parallel baffle plates within the reaction vessel. ${ }^{320}$

Effective utilization of photons under flow conditions can be achieved via optimum positioning of the irradiation source either internally within the reaction vessel (annular and PBR system) or externally with respect to the reaction vessel (plate reactor or fluidized bed reactor).

In both solid-liquid (diphasic) and solid-liquid-gas (triphasic) systems, slurry reactors are highly advantageous as compared to immobilized photocatalytic reactor systems due to enhanced higher photocatalytic activity. This enhanced behaviour of slurry systems is due to the intrinsic furnishing of high total surface area of photocatalysts per unit volume. The implementation of immobilized systems at large scale still remains a significant challenge. The complex design of the irradiation source, according to the requisite length of the upscale system has limited research from developing further these systems. Even though the slurry system is highly economical in terms of fabrication and operation, its major and only limitation is the requirement for downstream separation of the photocatalytic materials from the product/liquid stream. ${ }^{321}$

Priya and Kanmani developed a two different novel batch slurry (BG) and batch slurry recycle reactors fitted with continuous supply of inert gas (BRRwCG) for water splitting reaction under solar irradiation. ${ }^{322}$ Both reactor materials were made up of plexiglas material, transparent to the solar spectrum wavelength $(290-700 \mathrm{~nm})$. The photocatalytic material was successfully suspended in BG through magnetic stirring. Analogously, the suspension was achieved in BRRWCG through continuous bubbling of the reactant solution by an inert gas. Simultaneously, a part of the reactant solution was recirculated using a peristaltic pump (Fig. 31d). The catalyst composition in both reactors was kept identical and it was found that BRRWCG exposed higher photocatalytic activity as compared to BG due to the enhanced mass transfer and photon distribution. ${ }^{322}$ Slurry rectors with continuous single phase (no gas promoted agitation, Fig. 31c) suffer from severe limitations of photon and mass transfer when they are upscaled to achieve higher throughput.

McCullagh et al. developed a novel continuous flow slurry reactor for the degradation of MB dye under UV irradiation. ${ }^{323}$ This novel system coupled the usage of 'Drum Reactor' design and pelletized titania photocatalytic particles. The commercially available Hombikat pellet titania catalyst was employed which avoids any downstream processing to separate the photocatalysts from the liquid phase. 


\section{Challenges for effective flow photoreactors}

Research for novel photoreactors and effective utilization of photocatalysts has pushed scientists more into microreactor fabrication and design. These microreactors provide enhanced mass transfer compared to the conventionally mentioned large scale photocatalytic reactors. Due to high surface-to-volume ratio achieved in this system, as a result of their small dimensions. ${ }^{324-326}$ Simultaneously, they provide the opportunity for low catalyst loading, enhanced heat transfers and homogeneous photon distribution. ${ }^{326-328}$

Concerning slurry reactors, there is currently a rapid research effort going on to replace the mechanically attained suspension by air or reactive gas agitation attained suspension. These systems are currently given preference because of the rapid development of microreactors which leads to low catalyst loading. Similarly, advanced progress in downstream separation equipment have also motivated researchers to switch towards continuous flow slurry reactors without any immobilization. As example, Rakhshaee et al. designed a plug flow reactor (PFR) in which nanohematite $\left(\alpha-\mathrm{Fe}_{2} \mathrm{O}_{3}\right)$ photocatalysts were successfully suspended in the liquid phase with air promoted suspension. ${ }^{329}$

\section{Conclusions}

Several modified/unmodified SCs studied to date in heterogeneous photocatalytic field have been described in this work. These highly efficient photocatalysts were classified into four different categories depending on their composition, band gap engineering and charge carrier migration mechanisms. Currently developed synthetic strategies for each photocatalyst have been reviewed along with the rationale behind the new synthetic approach and its advantages over conventional synthetic routes. Their photocatalytic performance was also discussed and compared with conventional systems, finding significant advantages in the interface engineered systems as compared to traditional photocatalysts. Importantly, photoreactor systems (nature of photons source used and type of reaction vessel, types of reactor) were also briefly covered in the future prospects section, with a particular emphasis on flow photochemical processes and reactors, believed to the way forward in the field. We hope the proposed overview can provide a comprehensive compilation of key studies to progress the state-of-the-art in the field and look forward to additional advances in the design of advanced versatile (nano)photocatalysts in the future with several relevant applications.

\section{Conflicts of interest}

The authors declare no conflict of interest.

\section{Acknowledgements}

This work has received funding from the European Union's Horizon 2020 research and innovation program under the Marie Sklodowska-Curie grant agreement No 641861: Photo4Future project. The publication has been prepared with support from RUDN University Program 5-100.

\section{Notes and references}

1. M. A. Rauf And S. S. Ashraf, Chem. Eng. J., 2009, 151, 10 -18.

2. J. M. HeRRMANn CATAL. TODAY, 1999, 53, $115-129$.

3. C. ACAR , I. DINCER AND C. ZAMFIRESCU, INT. J. ENERGY RES., 2014, 31,135 -147.

4. Z. ZHANG AND J. T. YATES, CHEM. ReV., 2012, 112 , $5520-5551$.

5. C. GAO , J. WANG , H. Xu AND Y. XIONG , CheM. SOC. ReV., 2017, 46, $2799-2823$.

6. J. Kou , C. LU , J. WANG , Y. CHen , Z. XU AND R. S. VARMA , CheM. ReV., 2017, 117 , 1445 -1514.

7. A. L. LinsebigleR , G. Lu AND J. T. YATES, CheM. ReV., 1995, 95 , 735 -758.

8. J. Schneider , M. MAtusoka , M. TAKeuChI , J. Zhang , Y. Horiuchi , M. Anpo And D. W. Bahnemann , Chem. Rev., 2014, 114, $9919-9986$.

9. W. Y. TeOH , L. MÄdleR , D. Beydoun , S. E. Pratsinis And R. Amal, Chem. Eng. SCI., 2005, 60 , 5852 -5861.

10. W. Y. TEOH MATERIALS, 2013, 6 , $3194-3212$.

11. L. MÄdler , H. K. Kammler , R. Mueller and S. E. Pratsinis , J. Aerosol SCI., 2002, 33 , 369 -389.

12. Z. SHu , X. JIAO AND D. Chen , CRYStEngComm, 2012, 14, 1122 -1127. 
13. M. V. Carevic, N. D. Abazovic, M. N. Mitric, G. Ciric-Marjanovic, M. D. Mojovic , S. P. Ahrenkiel And M. I. Comor , Mater. CHEM. PHYS., 2018, 205, $130-137$.

14. S. N. Basahel, T. T. Al , M. Mokhtar and K. Narasimharao, Nanoscale Res. Lett., 2015, 10,1 -13.

15. F. Zandiehnadem, R. A. Murray and W. Y. Ching , Physica B+C, 1988, $150,19-24$.

16. R. Y. HONG , J. H. LI , L. L. CHEN , D. Q. LIU , H. Z. LI , Y. ZHENG AND J. DING , POWDER TECHNOL., 2009, 189 , 426 -432.

17. Y. ZhAl , S. ZhANG AND H. PANG , MATER. LetT., 2007, 61, 1863 -1866.

18. S. B. Khan , M. Faisal, M. M. Rahman And A. JAmal, SCl. Total EnVIRON., 2011, 409 , 2987 -2992.

19. Y. Rolg , S. MArre , T. CARdinal And C. Aymonier, ANGeW. Chem., INT. Ed., 2011, 50 , $12071-12074$.

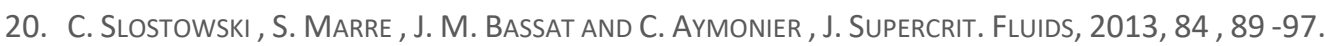

21. Z. Ye, L. KONG , F. CHEN , Z. CHEN , Y. LIN AND C. LIU , OPTIK, 2018, 164 , 345 -354.

22. E. Monroy, F. Omnes and F. Calle , Wide-BAndgap Semiconductor Ultraviolet Photodetectors, Semicond. SCI. TeChnOl., 2003, 18, R33.

23. I. A. BAnerJee , L. Yu And H. MAtsui , J. Am. Chem. Soc., 2005, 127 , 16002 -16003.

24. J.-S. HU , L.-L. ReN , Y.-G. GUO , H.-P. LIANG , A.-M. CAO , L.-J. WAN AND C.-L. BAI , ANGEW. CheM., INT. ED., 2005,44 , 1269 -1273.

25. S. LIU , H. ZHANG AND M. T. SWIHART , NANOTECHNOLOGY, 2009, 20 , 235603.

26. M. LUO , Y. LIU , J. HU , H. LIU AND J. LI , ACS APPL. MATER. INTERFACES, 2012, 4 , 1813 -1821.

27. W. XU, S. ZHU , Y. LIANG , Z. LI , Z. CUI , X. YANG AND A. INOUE , SCI. REP., 2015, 5 , 1 -11.

28. D. JING AND L. GUO , J. Phys. CHeM. B, 2006, 110, $11139-11145$.

29. L. Cheng , Q. XIANG , Y. LiAO AND H. Zhang, Energy ENVIRON. SCI., 2018, 11, 1362 -1391.

30. F. QIu , Z. Han , J. J. Peterson, M. Y. OdoI , K. L. Sowers and T. D. Krauss, Nano LetT., 2016, 16, 5347 -5352.

31. M. A. Holmes, T. K. TOWnSend ANd F. E. OSterloh , Chem. COMmun., 2012, 48, 371 -373.

32. I. YONENAGA PHYS. B, 2001, 308-310, 1150-1152.

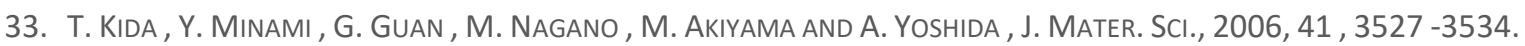

34. H. S. JUNG , Y. J. HONG , Y. LI , J. CHO , Y.-J. KIM AND G.-C. YI, ACS NANO, 2008, 2, 637 -642.

35. M. TABAta , K. Maeda , M. Higashi , D. Lu , T. TAKatA , R. Abe ANd K. Domen, LANGMUIR, 2010, 26 , 9161 -9165.

36. W.-J. ChUN , A. ISHIKAWA , H. FuJISAWA , T. TAKATA , J. N. KONDO , M. HARA , M. KAWAI, Y. MATSUMOTO AND K. DOMEN , J. PhyS. CHEM. B, 2003, $107,1798-1803$.

37. G. Hitoki , A. ISHIKAWA , T. TAKATA , J. N. Kondo , M. HARA AND K. DOMEN , Chem. LetT., 2002, 736 -737.

38. Y. He , J. E. Thorne, C. H. Wu , P. MA , C. Du , Q. DONG , J. GuO AND D. WANG , CheM, 2016, 1, 640-655.

39. Q. ZHANG AND L. GAO, LANGMUIR, 2004, $20,9821-9827$.

40. S. S. K. MA , T. HisATOMI, K. MAedA , Y. Moriya ANd K. DOMEN , J. AM. Chem. SOC., 2012, 134, 19993 -19996.

41. S. CAO , J. LoW , J. Yu AND M. JaRonieC , Adv. MATER., 2015, 27 , 2150 -2176.

42. J. Wen , J. XIE , X. Chen AND X. LI , APPL. SURF. SCI., 2017, 391, $72-123$.

43. X. Wang , K. Maeda , A. Thomas, K. Takanabe, G. Xin , J. M. Carlsson, K. Domen and M. Antonietti , Nat. Mater., 2009,8 , 76 -80 .

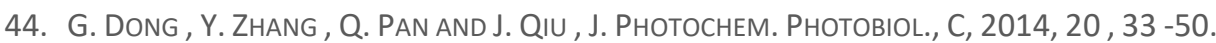

45. M. ChU , K. HU , J. WANG , Y. LIU , S. Ali , C. QIN AND L. JING , APPL. CATAL., B, 2019, 243 , 57 -65.

46. S. YE, R. WANG , M. WU AND Y. YUAN, APPL. SURF. SCI., 2015, 358, 15 -27.

47. S. YIN , J. HAN , T. ZHOU AND R. XU , CATAL. SCI. TECHNOL., 2015, 5, 5048 -5061.

48. Z. ZHAO, Y. SUn AND F. DONG , NANOSCALE, 2015, 7 , 15 -37.

49. Y. Zheng , L. LIN , B. WANG ANd X. WANG , ANGeW. Chem., INT. Ed., 2015, 54 , 12868 -12884.

50. J. LiU , H. WAng And M. Antonietti , Chem. Soc. Rev., 2016, 45 , 2308 -2326.

51. W.-J. ONG , L.-L. TAN , Y. H. NG , S.-T. Yong AND S.-T. CHAI , CHEM. REV., 2016, 116, 7159 -7329.

52. F. DING , D. YANG , Z. TONG , Y. NAN , Y. WANG , X. ZOU AND Z. JIANG , ENVIRON. SCI.: NANO, 2017, 4,1455 -1469.

53. A. NASerI, M. SAmadi , A. Pourjavadi , A. Z. Moshfegh and S. Ramakrishna, J. Mater. Chem. A, 2017, $5,23406-23433$.

54. H. Dong , X. GuO , C. YANG AND Z. Ouyang , Appl. CATAL., B, 2018, 230 , 65 -76.

55. B. Giroire, S. Marre , A. Garcia , T. Cardinal And C. Aymonier , React. Chem. Eng., 2016, 1, 151 -155.

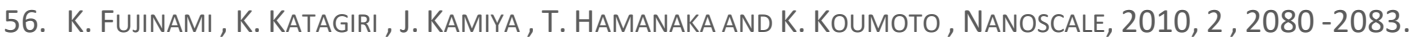

57. T. Ohno , T. Tsubota , Y. Nakamura And K. Sayama, Appl. Catal., A, 2005, 288, 74 -79.

58. S. Ahuja And T. R. N. Kutty , J. Рнотоснем. РнотовіOL., A, 1996, 97 , 99 -107.

59. X. Wei , G. Xu , Z. Ren , C. Xu , W. Weng , G. Shen And G. Han , J. AM. Ceram. Soc., 2010, 93 , 1297 -1305.

60. P. C. HUYNH AND V. MINH , AIP CONF. PROC., 2017, 1878, 020012.

61. G. WU , P. LI , D. XU , B. LUO , Y. HONG , W. SHI AND C. LIU , APPL. SURF. SCI., 2015, 333 , 39 -47.

62. K. DOMEN , A. KUdO AND T. ONISHI , J. CATAL., 1986, 102 , 92 -98.

63. Q. LI , K. Domen, S. Naito , T. ONISHI AND K. TAMARU , Chem. LetT., 1983, 321 -324.

64. L. Chen, S. ZhANG , L. WANG , D. XUE AND S. YIN , J. CRYST. GROWTH, 2009, $311,746-748$.

65. D. K. LeE , I. S. CHO , D. K. YIM , J. H. NOH, K. S. HONG AND D. W. KIM , J. CERAM. SOC. JPN., 2010, $118,876-880$.

66. M. KobAYASHI , Y. SUZUKI , T. Goto , S. H. ChO , T. SeKINO , Y. ASAKURA AND S. JIN , J. CERAM. SOC. JPN., $2018,126,135$-138.

67. A. Kudo Catal. Surv. Asia, 2003, 7,31 -38. 
68. H. Kato and A. Kudo , J. Phys. Chem. B, 2001, 105 , $4285-4292$.

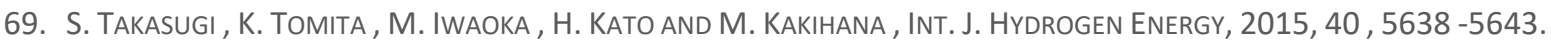

70. C.-C. Hu , H.-H. HuANG AND Y.-C. HuANG , J. ENERgy CheM., 2017, 26 , 515 -521.

71. A. Kudo AND H. Kato , Chem. Phys. LetT., 2000, 331, $373-377$.

72. X. LI AND J. ZANG , CATAL. COMMUN., 2011, $12,1380-1383$.

73. H. Sudrajat , S. BABel , I. Thushari ANd K. Laohhasurayotin , J. Alloys Compd., 2019, 775 , 1277 -1285.

74. V. Jeyalakshmi, S. Tamilmani, R. Mahalakshmy and P. Bhyrappa , J. Mol. Catal. A: Chem., 2016, 420, 200 -207.

75. N. TONG , Y. WANG , Y. LIU , M. LI , Z. ZHANG , H. HUANG , T. SUN , J. YANG , F. LI AND X. WANG , J. CATAL., 2018,361 , 303 -312.

76. C. C. Hu AND H. Teng , Appl. Catal., A, 2007, 331 , $44-50$.

77. Y. HE, Y. ZHU AND N. WU , J. SOlID STATE CHEM., 2004, 177, 3868 -3872.

78. M. Ben Ali , F. Barka-Boualfel , H. Elhouichet , B. Sieber , A. Addad , L. Boussekey, M. Ferid And R. Boukherroub , J. Colloid INTERFACE SCI., 2015, 457, 360 -369.

79. I. Paulauskas, J. E. Katz , N. S. LeWis , L. Boatner And G. M. Brown , J. Electrochem. Soc., 2009, 156 , 580 -587.

80. B. ModAK AND S. K. GHOSH , J. Phys. CHEM. C, 2016, 120 , 6920 -6929.

81. T. Su , H. JIANG AND H. Gong , J. SOlID STATE CHEM., 2011, 184 , 2601 -2604.

82. X. SHAO , X. YIN AND J. WANG , J. COlloid INTERFACE SCI., 2018, 512 , 466 -473.

83. D. R. Modeshia AND R. I. WALton , Chem. SOC. ReV., 2010, 39 , $4303-4325$.

84. K. LI , A. D. HANDOKO , M. KhraisheH AND J. TANG , NANOSCALE, 2014, 6, 9767 -9773.

85. O. A. Carrasco-Jaima , L. M. Torres-Martinez and E. Moctezuma , J. Photochem. Photobiol., A, 2018, 358 , 167 -176.

86. X. XU , G. LIU AND A. K. AZAD , INT. J. Hydrogen ENERGY, 2015, 40 , 3672 -3678.

87. T. TAKASHIMA , T. SANO AND H. IRIE , EleCtROCHEMISTRY, 2016, 84 , 784 -788.

88. G. LI , S. YAN , Z. WANG , X. WANG , Z. LI , J. YE AND Z. ZOU , DALTON TRANS., 2009, $8519-8524$.

89. D. Arney, C. Hardy , B. Greve and P. A. Maggard , J. Photochem. Photobiol., A, 2010, 214 , 54 -60.

90. H. Kato , H. KobAyAshi AND A. KUdo , J. Phys. CheM. B, 2002, 106, 12441 -12447.

91. A. Kudo INT. J. HYdROGEN ENERGY, 2006, 31, 197 -202.

92. W. WANG , G. LI , Y. BAI , N. YANG AND W. ZhANG , J. Phys. Chem. Solids, 2011, 72 , 1457 -1461.

93. J. TANG , Z. ZOU , J. YIN AND J. YE , CHEM. Phys. LetT., 2003, 382 , 175 -179.

94. J. TANG , Z. Zou , M. KATAgIRI , T. KAKO AND J. YE, CATAL. TOdAY, 2004, 93-95, 885 -889.

95. W. K. ChANG , K. K. RAO , H. C. KUO , J. F. CAI AND M. S. Wong , Appl. CATAL., A, 2007, 321 , 1 -6.

96. J. TANG , Z. ZOU AND J. YE , CHEM. MATER., 2004, 4 , 1644 -1649.

97. J. DING , S. SUN , J. BAO , Z. LUO AND C. GAO, CATAL. LETT., 2009, $130,147-153$.

98. W.-K. ChANG , D.-S. SUn, H. ChAN , P.-T. HuANG , W.-S. Wu , C.-H. LIN , Y.-H. TSENG , Y.-H. ChenG , C.-C. TSENG AND H.-H. ChANG , NANOMEDICINE, 2012, 8, $609-617$.

99. J. Ding , W. YAN , S. SUn , J. BAo AND C. GaO, INT. J. Hydrogen Energy, 2013, $39,119-126$.

100.Y. Zhang , R. SelvaraJ , M. SillanPäÄ, Y. KIM AND C.-W. TAI , Ind. Eng. Chem. ReS., 2014, 53, 11720 -11726.

101.T. LI , C. GUO , Y. YANG , L. LI AND N. ZHANG , ACTA MATER., 2013, 61, 7481 -7487.

102.T. LI , C. GUO , H. JIAO , L. LI AND D. K. AgRAWAL, OPT. COMMUN., 2014, 312 , 284 -286.

103. M. T. S. Tavares, M. M. Melo, V. D. Araujo, R. L. Tranquilin, C. R. R. Almeida , C. A. Paskocimas, M. R. D. Bomio, E. longo AND F. V. MOTTA , J. AlLoys COMPD., 2016, 658 , 316 -323.

104.Y. MARUyAmA , H. IRIE AND K. HASHimoto , J. Phys. Chem. B, 2006, 110, $23274-23278$.

105.S. OuYANG , H. ZhANG , D. LI , T. Yu , J. Ye AND Z. ZOU , J. Phys. CheM. B, 2006, 110, 11677 -11682.

106.Y. MARuyama, H. IRIE AND K. HASHimoto , J. Phys. Chem. B, 2006, 110 , $23274-23278$.

107.S. OUYANG , Z. LI , Z. OUYANG , T. YU , J. YE AND Z. ZOU , J. PhYS. CheM. C, 2008, 112 , 3134 -3141.

108.S. Ouyang, N. Kikugawa, D. Chen , Z. Zou And J. Ye, J. Phys. Chem. C, 2009, 113 , 1560 -1566.

109. M. Akhtar, M. Menon , M. Sunkara , G. Sumanasekera ANd A. Durygin , J. Alloys Compd., 2015, 641 , 87 -92.

110.S. Tokunaga , H. Kato ANd A. Kudo , Chem. MATER., 2001, 13, $4624-4628$.

111.J. D. Bierlein And A. W. Sleight, Solid State Commun., 1975, 16 , 69 -70.

112.P. R. Bodart , Y. Dumazy, J. P. Amoureux And C. Fernandez, Magn. Reson. Chem., 1999, 37 , 223 -226.

113.S. KohtANI , J. HiRo , N. YAMAMOTO , A. Kudo , K. TOKUMURA ANd R. NAKAgAKI , CATAL. COMmUn., 2005, 6 , 185 -189.

114.S. KohtanI , M. KoshiKo , A. Kudo , K. TOKUMURA , Y. ISHIGAKI , A. TORIBA , K. HAYAKAWA ANd R. NAKAgAKI , Appl. CATAL., B, 2003, $46,573-586$.

115. A. KUDO , K. OMORI AND H. KATO , J. AM. CHEM. SOC., 1999, 121 , 11459 -11467.

116.J. Yu AND A. KUdO , AdV. FUnCt. MATER., 2006, 16, 2163 -2169.

117. M. R. dA Silva , L. H. Dall'Antonia , L. V. A. Scalvi , D. I. dos SANtos , L. O. Ruggiero and A. URbano , J. Solid State

ELECTROCHEM., 2012, $16,3267-3274$.

118. B. ZHOU , J. QU , X. ZHAO AND H. LIU , J. ENVIRON. SCI., 2011, 23 , $151-159$.

119.S. SARKAR, N. S. DAS AND K. K. ChatTOPADhyAY, Solid STATE SCI., 2014, 33 , 58 -66.

120. M. LI , L. ZHAO AND L. GUO, INT. J. HYDROGEN ENERGY, 2010, 35 , $7127-7133$.

121.B. XIE , C. He , P. CAI AND Y. XIONG , ThIn SOlid FILMS, 2010, 518, 1958 -1961. 
122.W. LUO , Z. WANG , L. WAN , Z. LI , T. Yu AND Z. Zou , J. Phys. D: ApPl. Phys., 2010, 43 , 405402.

123. R. Venkatesan, S. Velumani , K. Ordon , M. Makowska-Janusik, G. Corbel And A. Kassiba , Mater. Chem. Phys., 2018,205 , $325-333$.

124.B. S. SCHWARZ, H. WIRTH AND O. SCHMIDT-PARK, EUR. COAT. J., 2016, 9 , 26 -31.

125.J. Hu , D. Chen , Z. MO , N. LI , Q. XU , H. LI , J. HE , H. XU AND J. LU , ANGeW. Chem., INT. Ed., 2019, 131 , 2095 -2099.

126. N. Zhang , R. CiRiminna , M. PAgliaro ANd Y.-J. XU , Chem. SoC. ReV., 2014, 43, 5276 -5287.

127.Z. Chen, D. LI, W. Zhang, Y. SHAO, T. Chen, M. SUn AND X. Fu, J. Phys. CheM. C, 2009, 113, 4433 -4440.

128. W. WANG , T.-W. NG , W.-K. Ho , J. HuANG , S. LIANG , T. AN , G. LI , J. C. Yu AND P. K. Wong , ApPl. CATAL., B, 2013,129 , 482 490.

129.F.-Y. LeE, K.-Y. YANG , Y.-C. WANG , C.-H. LI , T. R. LEE AND T.-C. LEE, RSC AdV., 2014, 4 , 35215 -35223.

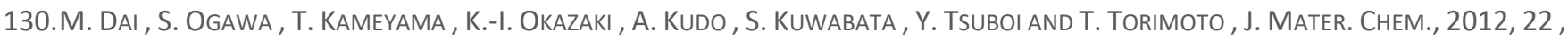
$12851-12858$.

131.S. K. Apte , S. N. Garaje , R. D. Bolade , J. D. Ambekar , M. V. Kulkarni , S. D. Naik , S. W. Gosavi , J. O. Baeg and B. B. Bale , J. MATER. CHEM., 2010, 20, 6095 -6102.

132.T. A. Kandiel, D. H. Anjum , P. Sautet , T. Le Bahers and K. TAkanabe , J. Mater. Chem. A, 2015, 3 , 8896 -8904.

133. N. XIAO , L. ZHU , K. WANG , Q. DAI , Y. WANG , S. LI , Y. SUI , Y. MA , J. LIU , B. LIU , G. ZOU AND B. ZOU , NANOSCALE, 2012,4 , 7443 7447.

134. M. Tabata , K. Maeda , T. Ishihara , T. Minegishi , T. TAkata And K. Domen , J. Phys. Chem. C, 2010, 114,11215 -11220.

135. C. Coughlan , M. Ibañez , O. Dobrozhan , A. Singh , A. Cabot And K. M. Ryan , Chem. ReV., 2017, 117, 5865 -6109.

136.J. Kolny-Olesiak AND H. Weller , ACS APPL. MATER. INTERfACES, 2013, 5, 12221 -12237.

137.M. D. Regulacio AND M.-Y. HAN , ACC. Chem. ReS., 2016, 49 , 511 -519.

138.I. TSUJ , H. KATO AND A. KUdO , ANGEW. CHEM., INT. ED., 2005, 44 , 3565 -3568.

139. M. NANU , J. SChOONMAN AND A. GoOSSENS, NANO LeTt., 2005, 5, 1716 -1719.

140.I. TSUJ , H. KATO AND A. KUdO, CheM. MATER., 2006, 18, 1969 -1975.

141.S. C. ERWIN AND I. ŽUtIC, NAT. MATER., 2004, 3 , 410 -414.

142.D. Aldakov , A. Lefrançois And P. Reiss , J. Mater. Chem. C, 2013, 1, 3756 -3776.

143. H. ZHONG , Z. BAI AND B. ZOU , J. Phys. CheM. LetT., 2012, 3 , 3167 -3175.

144.J. LiU ANd E. HuA, MAter. SCI. Semicond. Process., 2015, 40 , 446 -452.

145.D. HuANG AND C. Persson , Chem. Phys. LetT., 2014, 591, 189-192.

146.X. HU , T. CHEN , Y. XU , M. WANG , W. JIANG AND W. JIANG , J. LUMIN., 2018, 200,189 -195.

147.Z. LUO , H. ZHANG , J. HUANG AND X. ZHONG , J. Colloid INTERFACE SCI., 2012, 377, 27 -33.

148. W. Zhang , D. LI , Z. Chen, M. Su , W. LI , Q. Lin AND X. Fu , MAter. Res. Bull., 2011, 46 , 975 -982.

149.A. Hossein , C. Khavar And M. Jafarisani , INT. J. Heal. Stud., 2017, 3 , $19-25$.

150.J. Q. Hu , B. Deng , C. R. WANG , K. B. TANG ANd Y. T. QIAN , Solid StATE Commun., 2002, 121 , 493 -496.

151.J. ZHONG , Y. ZHAO , H. YANG , J. WANG , X. LIANG AND W. XIANG , APPL. SURF. SCI., 2011, 257, 10188 -10194.

152.M. D. RegulaCiO , C. YE , S. H. LIM , Y. ZHENG , Q.-H. XU AND M.-Y. HAN , CRYSTENGCOMM, 2013, 15, 5214 -5217.

153.Z. LIU , J. LIU , Y. HUANG , J. LI , Y. YUAN , H. YE , D. ZHU , Z. WANG AND A. TANG , NANOSCALE, 2019, 11,158 -169.

154.G. Philippot , M. Albino, U.-C. Chung , M. Josse , C. ElisSAlde , M. MAglione ANd C. Aymonier, Mater. Des., 2015,86 , 354 360.

155.G. Philippot , C. Elissalde , M. Maglione And C. Aymonier , Adv. Powder TeChnol., 2014, 25 , 1415 -1429.

156.Z. Mei , M. Zhang , J. SChneider , W. WANG , N. Zhang , Y. Su , B. Chen , S. WANG , A. L. Rogach And F. PAN , CATAL. SCI. TeChnOL., $2017,7,982-987$.

157.S. Guo AND C. T. LIU , Prog. NAt. SCI. MAter. INT., 2011, 21 , $433-446$.

158. IUPAC. Compendium of Chemical TeRminology 2ND ed. (THE 'Gold BOOK’), BlaCKWell SCI. PuBl., OXford, 2014.

159.S. OUYANG AND J. YE , J. AM. CHEM. SOC., 2011, 133, $7757-7763$.

160.J. Ren , S. Ouyang , H. Chen , N. Umezawa , D. Lu , D. WANG , H. Xu ANd J. Ye , Appl. CATAL., B, 2015, 168-169 , 243 -249.

161.D. E. SCAIFE SOL. ENERGY, 1980, $25,41-54$.

162.L. YANG , J. LIU , H. CHANG AND S. TANG , RSC ADV., 2015, 1, $59970-59975$.

163.G. LI , T. KAKO , D. WANG , Z. ZOU AND J. YE , J. SOlID STATE CHEM., 2007, 180 , $2845-2850$.

164.K. MAeda , T. TAKatA , M. HARA , N. SAito , Y. INOUE , H. KobAyASHI AND K. DOMEN , J. AM. Chem. SOC., $2005,127,8286$-8287.

165.K. MAEDA AND K. DOMEN , CHEM. MATER., 2010, 22 , 612 -623.

166.S. S. MenON, R. ANitha , B. GuptA , K. BASkAR AND S. Singh , AIP CONF. Proc., 2016, $1731,50025$.

167. H. A. N. Dharmagunawardhane, A. James, Q. Wu , W. R. Woerner, R. M. Palomino, A. Sinclair , A. Orlov and J. B. Parise, RSC ADV., 2018, 8 , $8976-8982$.

168. D. WANG , T. KAKO AND J. YE , J. Phys. CheM. C, 2009, 113, 3785 -3792.

169.W. F. ZHANG , J. TANG AND J. Ye , CHEM. PhYS. LeTt., 2006, 418, $174-178$.

170.I. Grinberg , D. V. West , M. Torres, G. Gou , D. M. Stein , L. Wu. , G. Chen , E. M. Gallo , A. R. AkbasheV , P. K. Davies , J. E. SPANIER AND A. M. RAPPE, NATURE, 2013, 503, 509-512.

171.Z. HAN , G. Chen , C. LI , Y. Yu ANd Y. Zhou , J. MAter. Chem. A, 2015, 3 , $1696-1702$. 
172.Y.-Y. Hsu , N.-T. Suen, C.-C. Chang , S.-F. Hung , C.-L. Chen, T.-S. ChAN , C.-L. DONG , C.-C. Chan , S.-Y. Chen AND H.-M. Chen, ACS APPL. MATER. INTERFACES, 2015, 7, $22558-22569$.

173. H. Kaga , Y. TSutsul , A. NAgAne, A. IWASEA And A. Kondo , J. Mater. Chem. A, 2015, 5 , 21815.

174.S. ZHAO, J. HUANG , Q. HUO , X. Zhou AND W. Tu , J. Mater. Chem. A, 2016, 4 , 193 -199.

175. M. Matsumura , S. Furukawa , Y. SAHo ANd H. TSUbOMURA , J. Phys. Chem., 1985, 89 , 1327 -1329.

176.J. Fu , B. Chang , Y. TIAN , F. XI AND X. DONG , J. MATER. Chem. A, 2013, 1, 3083 -3090.

177.Y.-L. Min , G.-Q. HE , Q.-J. Xu AND Y.-C. Chen , J. MATER. Chem. A, 2014, 2 , $2578-2584$.

178.J. ZHANG , Y. WANG , J. JIN , J. ZHANG , Z. LIN , F. HUANG AND J. YU , ACS APPL. MATER. INTERFACES, 2013, 5 , 10317 -10324.

179.C. XING , Y. ZHANG , W. YAN AND L. GUO, INT. J. HYDROGEN ENERGY, 2006, 31 , $2018-2024$.

180. F. del Valle , A. IShiKawa, K. Domen, J. A. Villoria de la Mano, M. C. Sanchez-Sanchez, I. D. Gonzalez, S. Herreras, N. Mota, M. E. Rivas, M. C. Alvarez Galvan , J. L. G. Fierro and R. M. Navarro , Catal. Today, 2009, 143 , 51 -56.

181.J. Yu , J. ZHANG AND M. JARONIEC, GREEN CHEM., 2010, 12 , 1611 -1614.

182. Q. NIE, Q. YUAN , Q. WANG AND Z. XU , J. MATER. SCI., 2004, 39 , 5611 -5612.

183.J. Yu , B. YANG AND B. CHENG , NANOSCALE, 2012, 4 , $2670-2677$.

184.Q. LI , H. MENG , P. ZHOU , Y. ZHENG , J. WANG , J. YU AND J.-R. GONG , ACS CATAL., 2013, 3 , 882 -889.

185.J. Fu , B. ZHU , W. YOU , M. JARONIEC AND J. YU , APPL. CATAL., B, 2018, 220 , 148 -160.

186.J. Klaer , J. Bruns, R. Henninger , K. Siemer , R. Klenk, K. Ellmer AND D. Braeunig , Semicond. SCI. TeChnOL., 1998,13 , 1456 1458.

187.S. N. Rashkeev and W. R. L. Lambrecht , Phys. Rev. B: Condens. Matter Mater. Phys., 2001, 63 , 165212.

188. A. A. LavrentieV , B. V. Gabrel'yan And I. Y. Nikiforov , J. Struct. Chem., 2000, 41,418 -426.

189.I. TSUJ , H. KaTO , H. KobayASHI AND A. KUdO , J. AM. CheM. SOC., 2004, 126, 13406 -13413.

190.I. TSUJ , H. KATO , H. KobayASHI AND A. KUdO , J. Phys. CHEM. B, 2005, 109 , 7323 -7329.

191.G. GabKa , P. Bujak , K. Giedyk , A. Ostrowski , K. Malinowska , J. Herbich , B. Golec , I. Wielgus and A. Pron , INORg. Chem., $2014,53,5002-5012$.

192. T. Kameyama , T. TAkahashi , T. MachidA , Y. Kamiya , T. Yamamoto , S. Kuwabata And T. ToRimoto , J. Phys. Chem. C, 2015,119 , $24740-24749$.

193.Y. WANG , Q. WANG , X. Zhan , F. WANG ANd M. SAFdAR , NANOSCALE, 2013, 5, 8326 -8339.

194. H. MCDANIEL, P. E. HEIL , C. L. TSAI , K. KIM AND M. SHIM , ACS NANO, 2011, 5 , $7677-7683$.

195. H. CHENG , B. HUANG , Y. DAI , X. QIN AND X. ZHANG , LANGMUIR, 2010, 26, 6618-6624.

196. H. ZhANG , S. OUYANG , Z. LI , L. LIU , T. YU , J. YE AND Z. ZOU , J. PHYS. ChEM. SOlIDS, 2006, 67 , 2501 -2505.

197.L. HuAng , F. Peng , H. WANG , H. Yu ANd Z. LI , CATAl. Commun., 2009, $10,1839-1843$.

198.C. Shifu , Z. SUJuAN, L. Wel AND Z. WeI , J. HAZARD. MATER., 2008, 155, 320 -326.

199.C. Dong , X. Xiao , G. Chen , H. Guan And Y. WAN, Mater. Chem. Phys., 2016, 155 , 1 - 8.

200. L. Wei , C. SHIFU , Z. HuAYE AND Y. XIAOling , J. EXP. NANOSCI., 2011, 6 , 102 -120.

201.L. WeI AND C. SHIFU , J. EleCtrochem. SOC., 2010, 157 , H1029.

202.J. C. Colmenares, R. Luque , J. M. CAmpelo , F. Colmenares , Z. Karpinski ANd A. A. Romero, Materials, 2009,2 , 2228 -2258.

203.X. Chen AND S. S. MAO, CHEM. ReV., 2007, 107, $2891-2959$.

204.J. L. Gole , J. D. Stout , C. Burda , Y. Lou And X. Chen , J. Phys. Chem. B, 2004, 108 , $1230-1240$.

205. K. R. Gopidas, M. Bohorquez And P. V. KAMAT , J. Phys. Chem., 1990, 94 , 6435 -6440.

206.T. T. D. Vu , F. MIGHRI , A. AJI AND T.-O. Do , IND. ENG. CheM. ReS., 2014, 53, 3888 -3897.

207.M. ZHANG , T. AN , X. LIU , X. HU , G. Sheng AND J. FU , MATER. LetT., 2010, 64 , 1883 -1886.

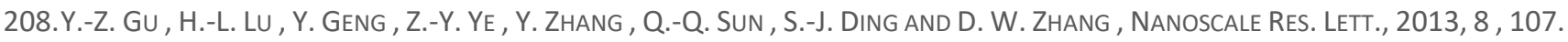

209. R. LIU , H. Ye , X. XIONg AND H. LIU , MATER. Chem. PhyS., 2010, 121, 432 -439.

210.T.Potlog, V.BotNARIUC, S.RAEVSCHI, M.DOBRomiR AND D.LUCA, 3RD INTERNATIONAL CONFERENCE ON NANOTECHNOLOGIES AND BIOMEDICAL ENGINEERING, 2016.

211.A. M. Hussein , L. MAhoney, R. Peng , H. Kibombo , C.-M. Wu , R. T. KoOdAli ANd R. Shende , J. Renewable Sustainable Energy, 2013, $5,1-13$.

212.P. Prasannalakshmi and N. Shanmugam, Mater. SCI. Semicond. Process., 2017, 61, 114 -124.

213.V. Štengl, S. BAKARdjIeVA , N. Murafa , V. Houskova ANd K. LANG , Microporous Mesoporous Mater., 2008,110 , 370 -378.

214.P. Prasannalakshmi And N. Shanmugam, Spectrochim. Acta, Part A, 2017, 175,1 - 10.

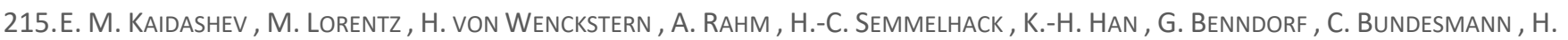
Hochmuth AND M. GRUNDMANN , Appl. Phys. LetT., 2003, 82 , 3901 -3903.

216.K. L. ChOPRA AND S. R. DAS , THIN-FILM SOL. CELLS, 1983, 414, $457-481$.

217.J. B. Asbury , Y. WANG AND T. LIAN , J. Phys. CHEM. B, 1999, 103, $6643-6647$.

218.Q. SHEN , X. ZHAO , S. ZHOU , W. HOU AND J.-J. ZHU , J. PHYS. CHEM. C, 2011, 115, 17958 -17964.

219.T. P. Chou , Q. Zhang , G. E. Fryxell and G. CAO , AdV. MAter., 2007, 19 , $2588-2592$.

220.Q. Zhang, T. P. ChOU , B. Russo, S. A. JeneKhe AND G. CAO, ANGEW. CHeM., INT. Ed., 2008, 47 , 2402 -2406.

221.T. Xu , L. ZHANG , H. Cheng AND Y. ZHU , Appl. CATAL., B, 2011, 101, 382 -387.

222.J. NAYAK, H. Lohani ANd T. K. Bera, CuRr. Appl. Phys., 2011, 11, 93 -97. 
223.H. ZHOU , Y. QU , T. ZeID AND X. DUAN , ENERgy ENVIRON. SCI., 2012, 5 , 6732 -6743.

224.X. GAN , X. LI , X. GAO , J. QIU AND F. ZHUGE , NANOteChnology, 2011, 22 , 305601.

225.S. Khanchandani, S. Kundu , A. Patra And A. K. Gangul , J. Phys. Chem. C, 2013, 117, 5558 -5567.

226. M. Guo , P. DiaO , X. WANG And S. CAI , J. Solid StATE Chem., 2005, 178 , 3210 -3215.

227.S. Khanchandani , S. Kundu , A. PAtra and A. K. Ganguli , J. Phys. Chem. C, 2012, 116 , 23653 -23662.

228.C. WANG , C. SHAO , X. ZHANG AND Y. LIU , INORG. CHEM., 2009, 48 , 7261 -7268.

229.S. WU , H. CAO , S. YIN , X. LIU AND X. ZhANG , J. PHYS. CheM. C, 2009, $113,17893-17898$.

230.Q. KUANG , C. LAO , Z. L. WANG , Z. XIE AND L. ZHENG , J. AM. CHEM. SOC., 2007, 129, $6070-6071$.

231.C. WANG , C. WANG , Y. ZHOU , M. GE , X. XU , Z. ZHANG AND J. Z. JIANG , J. AM. CHEM. SOC., 2010, 132 , 46 -47.

232. M. LAW , H. KIND, B. MesSer , F. KIM AND P. YANG , ANGEW. CheM., INT. Ed., 2002, 41, 2405 -2408.

233.Z. ZHANG , C. SHAO , X. LI , L. ZHANG , H. XUE , C. WANG AND Y. LIU , J. PHYS. CheM. C, 2010, 114, $7920-7925$.

234. H. XIA , H. ZHUANG , T. ZHANG AND D. XIAO , MATER. LeTt., 2008, 62 , $1126-1128$.

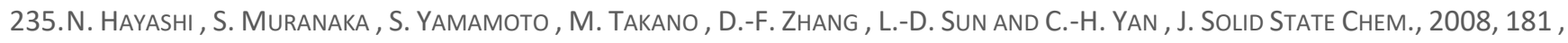
$3283-3286$.

236. M. Rumyantseva , V. Kovalenko, A. Gaskov , E. Makshina , V. Yuschenko , I. IVAnova , A. Ponzoni , G. Faglia And E. Comini , SENS. ACtUATORS, B, 2006, 118, $208-214$.

237.Y.-J. Chen, C.-L. ZHU , L.-J. WANG , P. GAO , M.-S. CAO AND X.-L. SHI , NANOTECHNOLOGY, 2009, $20,45502$.

238.J. KANG , Q. KUANG , Z.-X. XIE AND L.-S. ZHENG , J. Phys. CHEM. C, 2011, 115 , 7874 -7879.

239. N. TAkeda And B. A. Parkinson, J. Am. Chem. Soc., 2003, $125,5559-5571$.

240.Y.-C. ZHANG , Z.-N. DU , S.-Y. LI AND M. ZHANG , APPL. CATAL., B, 2010, 95 , 153 -159.

241.Y.-C. ZhANG , Z.-N. DU , K.-W. LI , M. ZhANG AND D. D. DIONYSIOU , ACS APPL. MATER. INTERfACES, 2011, 3, 1528 -1537.

242.D. Beydoun, R. AMAL, G. K.-C. Low And S. McEvoy, J. Phys. Chem. B, 2000, 104,4387 -4396.

243.S. Xu , W. Shangguan, J. YuAn, J. Shi And M. Chen, SCI. TeChnol. AdV. MATER., 2007, 8 , 40 -46.

244. Y. Yu , C. CAO , H. LIU , P. LI , F. WeI , Y. JIANG AND W. SONG , J. MATER. CheM. A, 2014, 2 , 1677 -1681.

245.Y. LIU , W.-J. SON , J. LU , B. HUANG , Y. DAI AND M.-H. WANGBO , ChEM. - EuR. J., 2011, 17 , 9342 -9349.

246. L.Ye, IN BIOX (X = CL, BR, ANd I) Photocatalysts, Semiconductor Photocatalysis, Ed. W. CAO, InTeChopen, 2016,

HTTPS://WWW.INTECHOPEN.COM/BOOKS/SEMICONDUCTOR-PHOTOCATALYSIS-MATERIALS-MECHANISMS-AND-APPLICATIONS/BIOX-X-CL-BRAND-I-PHOTOCATALYSTS.

247.Y. YAng , C. Zhang , C. LAI , G. Zeng , D. HuAng , M. Cheng , J. WANG , F. Chen, C. Zhou And W. Xiong , Adv. Colloid Interface SCI., 2018, $254,76-93$.

248.L. Ye , Y. SU , X. JIN , H. XIE AND C. ZHANG , ENVIRON. SCI.: NANO, 2014, 1,90 -112.

249.J. LI , Y. YU AND L. ZHANG , NANOSCALE, 2014, $6,8473-8488$.

250. H. Cheng , B. HuANG AND Y. DAI , NANOSCALE, 2014, 6, $2009-2026$.

251.W. LIN , X. YU , Y. ZHu AND Y. ZhANG , FRONT. CheM., 2018, 6 , 1 -13.

252.L. Zhang , W. WANG , L. Zhou , M. Shang ANd S. SUn , Appl. CATAL., B, 2009, 90 , 458 -462.

253.Y.-J. HSU , S.-Y. LU AND Y.-F. LIN , AdV. FUNCT. MATER., 2005, 15 , 1350 -1357.

254.Y.-J. HSU , S.-Y. LU AND Y.-F. LIN , CHEM. COMMUN., 2004, 2102 -2103.

255.M. R. KIM , Y. M. KANG AND D. J. JANG , J. PHYS. CHEM. C, 2007, 111, $18507-18511$.

256. A. DattA , S. K. PANDA And S. Chaudhuri , J. Phys. Chem. C, 2007, 111, $17260-17264$.

257. L. WANG , H. WeI , Y. FAN , X. LIU AND J. ZhAN, NANOSCALE Res. LetT., 2009, 4 , 558 -564.

258. Y. TAkahara , J. N. Kondo , T. TAKata , D. Lu ANd K. Domen , Chem. Mater., 2001, 13 , 1194 -1199.

259.J. H. PAN AND W. I. LeE , CHEM. MATER., 2006, $18,847-853$.

260. F. E. Osterloh Chem. MATER., 2008, 20 , $35-54$.

261.L. XU , J. GUAN , L. GAO AND Z. SUn , CATAL. COMMUN., 2011, 12 , 548 -552.

262.L. XU , J. GUAN , W. SHI AND L. LIU , J. COLLOID INTERFACE SCI., 2012, 377 , 160 -168.

263.J. L. Herek , W. Wohlleben , R. J. Cogdell , D. Zeidler and M. Motzkus, Nature, 2002, 417 , 533 -535.

264.Y. TACHIBANA , L. VAYSSIERES AND J. R. DURRANt, NAT. PHOTONICS, 2012, 6, 511 -518.

265.Y. UMENA , K. KAWAKAMI , J. SHEN AND N. KAMIYA , NATURE, 2011, 473, 55 -60.

266. K. MAedA AND K. Domen , J. Phys. Chem. LeTt., 2010, 1, 2655 -2661.

267. A. KUdO AND Y. MISEKI , CHEM. SOC. REV., 2009, 38 , $253-278$.

268. A. J. BARD J. PHOTOCHEM., 1979, $10,59-75$.

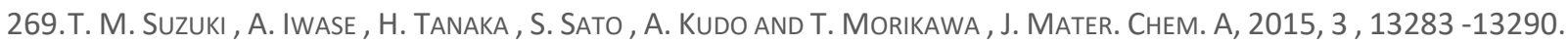

270.K. MAEDA ACS CATAL., 2013, 3 , $1486-1503$.

271. K. QI , B. CHENG , J. YU AND J. W. HO , CHIN. J. CATAL., 2017, 38 , 1936 -1955.

272.J. Low , C. JiAng , B. Cheng , S. WAgeh , A. A. Al-Ghamdi And J. Yu , Small Methods, 2017, 1, 1700080.

273. H. LI , W. TU , Y. ZHOU AND Z. ZOU , AdV. SCI., 2016, 3 , 1500389.

274.K. MAedA , M. HigASHI , D. Lu , R. Abe ANd K. Domen , J. AM. CheM. SoC., 2010, 132 , 5858 -5868.

275. R. ABE , M. HIGASHI AND K. DOMEN , CHEMSUSCHEM, 2011, 4 , 228 -237.

276. R. Abe , K. Sayama And H. Sugihara , J. Phys. Chem. B, 2005, 109 , $16052-16061$. 
277.Y. SASAKI , A. IWASE , H. Kato AND A. KUdO , J. CATAL., 2008, 259 , $133-137$.

278.J. Li , S. K. Cushing , P. Zheng , T. Senty, F. Meng , A. D. Bristow , A. Manivannan And N. Wu , J. Am. Chem. Soc., 2014,136 , $8438-8449$.

279. H. J. YUn , H. LeE , N. D. KIM , D. M. LeE , S. Yu AND J. YI , ACS NANO, 2011, $5,4084-4090$.

280. H. TAdA , T. MitsuI , T. KiyonagA, T. AKITA ANd K. TANAKA, NAT. MATER., 2006, 5 , 782 -786.

281.Z. Cheng , F. BIng , Q. LiU , Z. Zhang And X. FAng , J. MAter. Chem. A, 2015, 3 , 4652 -4658.

282.J. LI , Y. XIE , Y. ZHONG AND Y. Hu , J. MATER. CheM. A, 2015, 3 , 5474 -5481.

283.J. HOU , Z. WANG , C. YANG , W. ZHOU , S. JIAO AND H. ZHU , J. PhYS. CHEM. C, 2013, 117, 5132 -5141.

284. R. Kobayashi, S. TANIGAWA, T. TAKASHIMA , B. OHTANI AND H. IRIE , J. PHYS. CHEM. C, 2014, 118, 22450 -22458.

285. H. Cheng , J. HOU , H. ZHU AND X.-M. GUO, RSC AdV., 2014, 4 , 41622 -41630.

286.S. LIU , J. ChEN , D. Xu , X. Zhang AND M. SHEN , J. MATER. Res., 2018, 33 , 1391 -1400.

287. N. Subha , M. Mahalakshmi , M. Myilsamy , B. Neppolian and V. MurugeSAn , Appl. Catal., A, 2018, 553 , 43 -51.

288. C. XIONG , S. JIANG , S. SONG , X. WU , J. LI AND Z. Le , ACS SuStAINABLE CheM. ENG., 2018, 6, 10905 -10913.

289.J. Yu , S. WANG , J. LoW ANd W. XIAo , Phys. Chem. Chem. Phys., 2013, 15, 16883 -16890.

290.J. LI , M. ZHANG , Q. LI AND J. YANG , APPL. SURF. SCI., 2016, 391 , 184 -193.

291.P. XIA , B. ZHU , B. Cheng , J. YU AND J. XU , ACS SustainABle CheM. ENG., 2018, 6 , 965 -973.

292.Q. XU , B. ZHU , C. JIANG , B. CHENG AND J. YU , SOL. RRL, 2018, 2 , 1800006.

293. M. B. StARR AND X. WANG , NANO ENERGY, 2015, $14,296-311$.

294. M. WANG , B. WANG , F. HuAng And Z. LIN , AngeW. Chem., INT. Ed., 2019, 58 , 7526 -7536.

295.Y. CUI , J. BRISCOE AND S. DUNN , CHEM. MATER., 2013, 25 , $4215-4223$.

296. F. Chen , H. HuAng , L. Guo , Y. Zhang ANd T. MA , ANGEW. Chem., Int. Ed., 2019, 10.1002/Anie.201901361.

297.Z. LIANG , C. F. YAN, S. RTIMI AND J. BANDARA , ApPl. CATAL., B, 2019, 241 , $256-269$.

298.Y. T. WANG AND K. S. ChANG , J. AM. CerAM. SOC., 2016, 99 , $2593-2600$.

299.X. XUE , W. ZANG , P. Deng , Q. WANG , L. XING , Y. ZhANG AND Z. L. WANG , NANO ENERGY, 2015, 13 , 414 -422.

300.S. Singh AND N. KHARE, NANO ENERGY, 2017, 38 , 335 -341.

301.S. LAN , X. Zeng , R. A. RATHer AND I. M. C. Lo , EnVIRON. SCI.: NANO, 2019, 6, 554 -564.

302. H. LI , Y. SANG , S. ChANG , X. HuANG , Y. ZHANG , R. YANG , H. JIANG , H. LIU AND Z. L. WANG , NANo LetT., 2015,15 , 2372 -2379.

303.F. GoMollon-Bel CHeM. INT., 2019, $41,12-17$.

304.J. M. HERRMANN CATAL. TODAY, 1995, $24,157-164$.

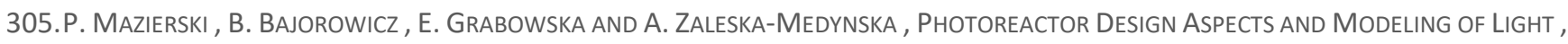

J. Colmenares And Y.-J. Xu, Springer, Berlin, Heidelberg, 2016.

306. M. Bouchy AND O. ZAHRAA , INT. J. PHOtOENERgY, 2003, 5 , 191 -197.

307. A. E. Cassano , C. A. Martin , R. J. Brandi And O. M. Alfano , Ind. Eng. Chem. Res., 1995, $34,2155-2201$.

308. B. Bajorowicz , A. Cybula , M. J. WiniarSki , T. KlimcZUK ANd A. ZaleSKA , MoleCUles, 2014, 19, 15339 -15360.

309.D. Cambie , C. Bottecchia , N. J. W. StraAthof , V. Hessel And T. Noël, Chem. ReV., 2016, 116, 10276 -10341.

310.C. Bottecchia , N. ERdmann, P. M. A. Tijssen , L.-G. Milroy , L. Brunsveld , V. HesSel AND T. NoËl, ChemSusChem, 2016, 9 , $1781-1785$.

311.Y. Boyjoo , H. SUn, J. LIU , V. K. PAREek AND S. WANG , ChEM. ENG. J., 2017, 310, 537 -559.

312. M. Hajaghazadeh, V. Vaiano , D. Sannino , H. Kakooel , R. Sotudeh-Gharebagh And P. Ciambelli , Catal. Today, 2014,230 , 79 84.

313.V. TOMASIC, F. JOVIC AND Z. GOMZI , CATAL. TODAY, 2008, 137, 350 -356.

314.G. E. Imoberdorf , A. E. Cassano , H. A. Irazoqui And O. M. Alfano, Catal. Today, 2007, 129, 118 -126.

315.G. Vincent , P. M. Marquaire and O. ZahraA , J. Рhotochem. Рhotobiol., A, 2008, 197 , 177 -189.

316.T. N. OBEe AND S. O. HAY, ENVIRON. SCI. TECHNOL., 1997, 31 , 2034 -2038.

317.M. MOHSENI AND F. TAGHIPOUR, CHEM. ENG. SCI., 2004, 59 , 1601 -1609.

318. M. A. Behnajady, N. Modirshahla , N. Daneshvar And M. Rabbani , Chem. Eng. J., 2007, 127,167 -176.

319.D. LI , H. Zheng , Q. WANG , X. WANG , W. JIANG , Z. Zhang ANd Y. YANG , Sep. PuRIF. TeChnOL., 2014, $123,130-138$.

320.X.-G. HAO , H.-H. LI , Z.-L. ZhANG , C.-M. FAN , S.-B. LIU AND Y.-P. SUn , ChEM. ENG. ReS. DeS., 2009, 87, 1604 -1611.

321.D. Arney, C. Hardy , B. Greve and P. A. Maggard , J. Photochem. Рhotobiol., A, 2010, 214 , 54 -60.

322.R. PRIYA AND S. KANMANI, SOL. ENERGY, 2009, 83, $1802-1805$.

323. C. McCullagh , P. K. J. Robertson , M. Adams, P. M. Pollard and A. Mohammed , J. Photochem. Photobiol., A, 2010,211 , 42 46.

324.B. Pieber , M. Shalom , M. Antonietti , P. H. Seeberger and K. Gilmore , AngeW. Chem., Int. Ed., 2018, 57 , 9976 -9979.

325. Y. Su , N. J. W. StraAthof , V. Hessel AND T. Nö̈L , Chem. - Eur. J., 2014, $20,10562$.

326.T. Van Gerven , G. Mul, J. Moulijn and A. Stankiewicz, Chem. Eng. Process., 2007, 46,781 -789.

327. K. S. Elvira , X. CaSadevall I Solvas, R. C. R. Wootton and A. J. deMello , Nat. Chem., 2013, 5 , 905 -915.

328.T. NOËL J. FLOW CHEM., 2017, 7, 87 -93.

329.R. Rakhshaee AND J. DarVazeh , J. HAZARD. MATER., 2018, 356,61 -72. 
FOOTNOTE

† THESE TWO AUTHORS EQUALLY CONTRIBUTED TO THIS WORK. 


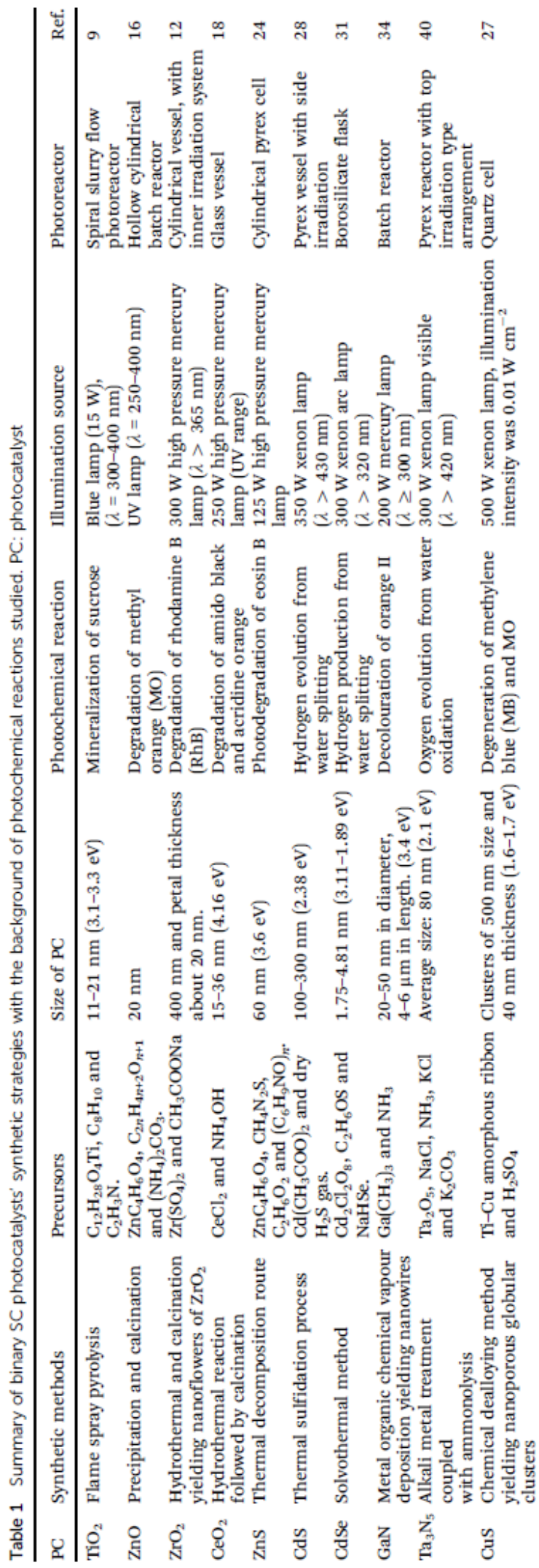




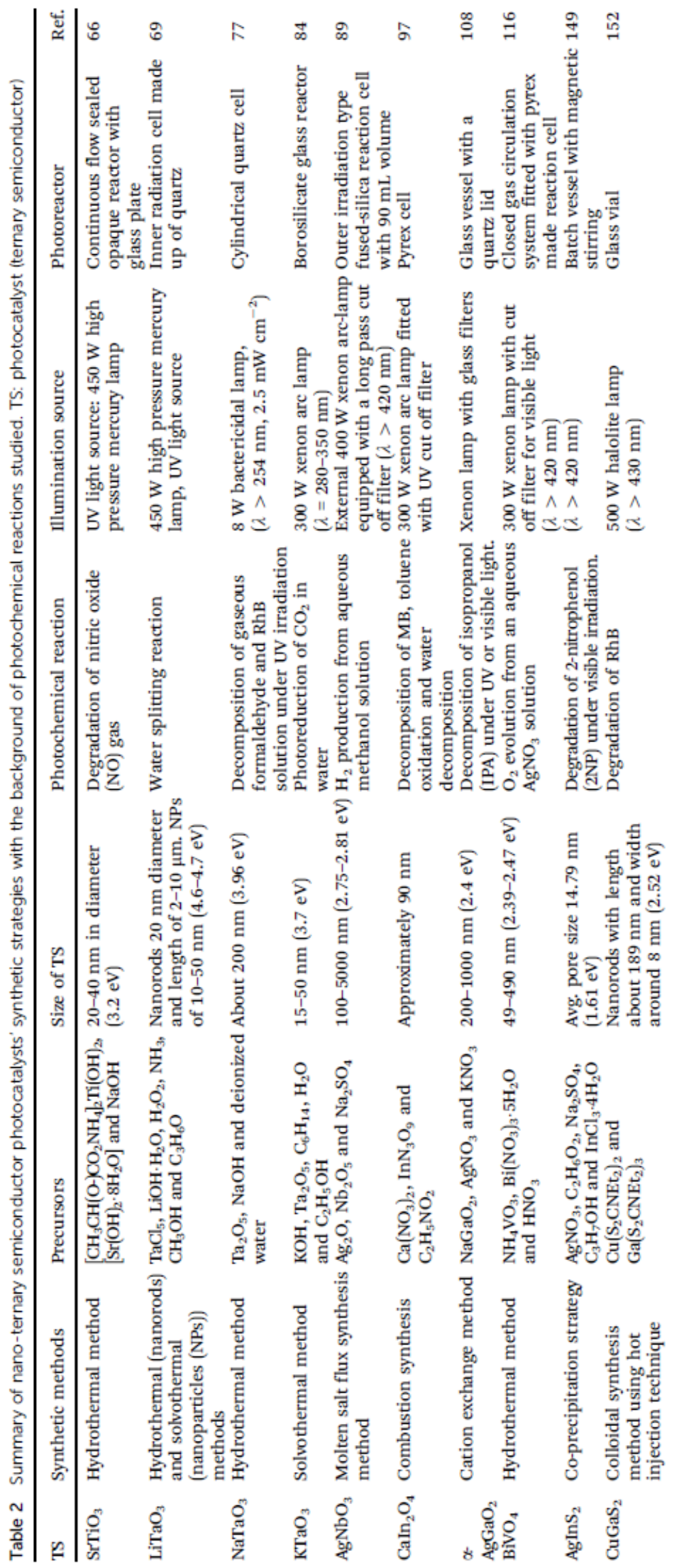




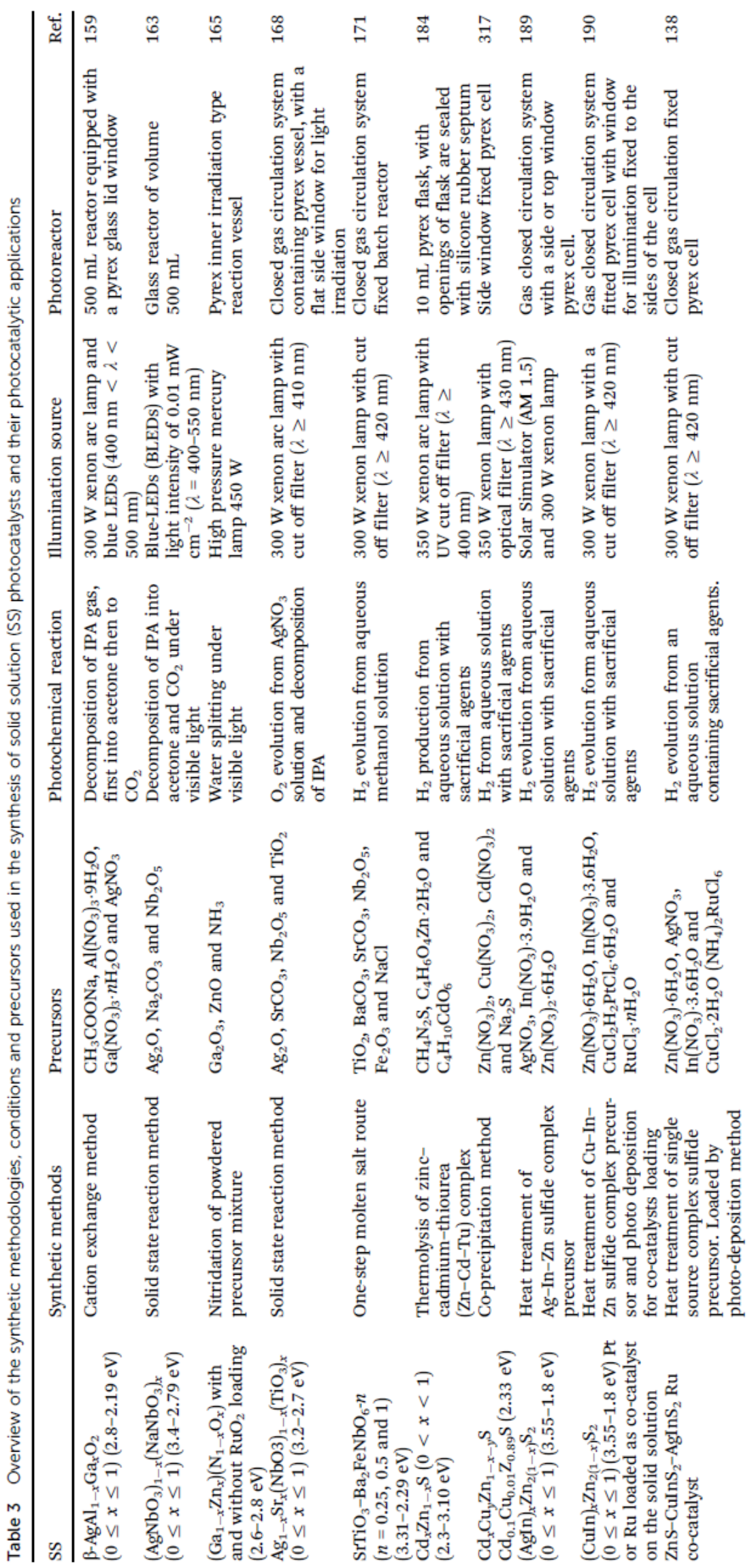




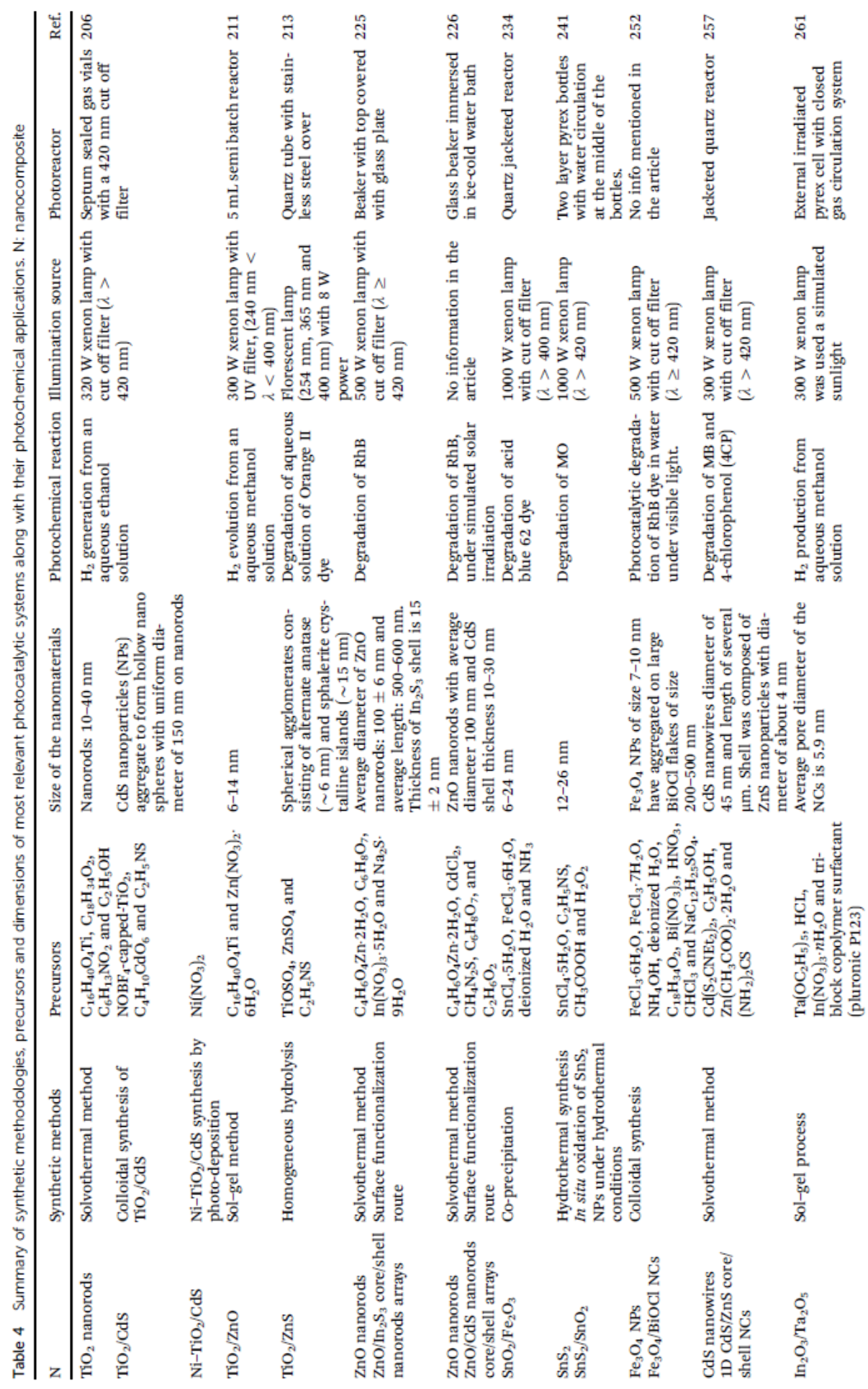

